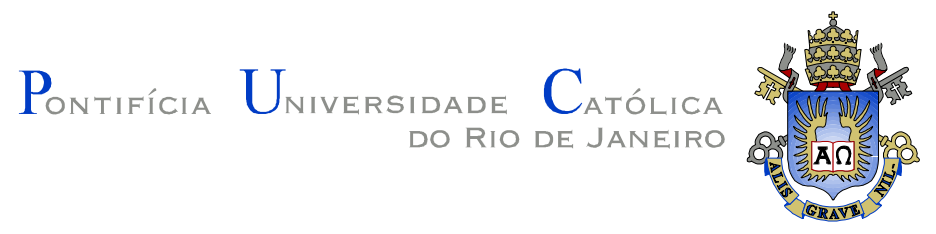

Igor Freitas Fagundes

Previsão da Atenuação por Chuvas a partir de Dados Meteorológicos Globais

Dissertação de Mestrado

Dissertação apresentada como requisito parcial para obtenção do título de Mestre pelo Programa de PósGraduação em Engenharia Elétrica da PUC-Rio.

Orientador: Prof. Luiz Alencar Reis da Silva Mello 


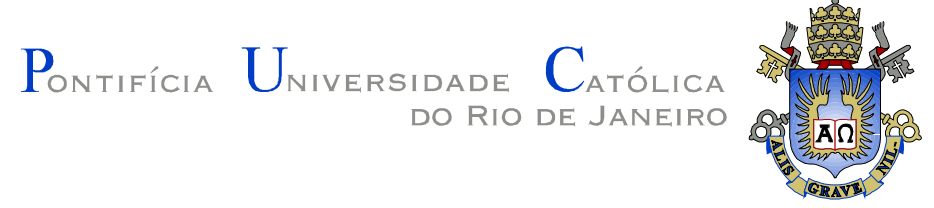

Igor Freitas Fagundes

\title{
Previsão da Atenuação por Chuvas a partir de Dados Meteorológicos Globais
}

\begin{abstract}
Dissertação de Mestrado apresentada como requisito parcial para obtenção do grau de Mestre pelo Programa de Pós-Graduação em Engenharia Elétrica do Departamento de Engenharia Elétrica do Centro Técnico Científico da PUC-Rio. Aprovada pela Comissão Examinadora abaixo assinada.
\end{abstract}

Prof. Luiz Alencar Reis da Silva Mello

Orientador

Centro de Estudos em Telecomunicações - PUC-Rio

Prof. Emanoel Paiva de Oliveira Costa

Centro de Estudos em Telecomunicações - PUC-Rio

Prof. Gláucio Lima Siqueira

Centro de Estudos em Telecomunicações - PUC-Rio

Dr. Rodolfo Saboia Lima de Souza

INMETRO

Dra. Marta Pudwell Chaves de Almeida

INMETRO

Prof. José Eugenio Leal Coordenador Setorial do Centro

Técnico Científico - PUC-Rio

Rio de Janeiro, 04 de Abril de 2014 
Todos os direitos reservados. É proibida a reprodução total ou parcial do trabalho sem autorização da universidade, do autor e do orientador.

\section{Igor Freitas Fagundes}

Graduou-se em Engenharia Elétrica pela Universidade Federal de Santa Maria - UFSM em 2010. Foi bolsista de Iniciação Científica de 2008 a 2010 no Laboratório de Radiofrequência e Comunicações do Centro Regional Sul de Pesquisas Espaciais/INPE. Possui pós-graduação em Engenharia de Redes e Sistemas de Telecomunicações pelo Instituto Nacional de Telecomunicações - INATEL (2013).

Ficha Catalográfica

Fagundes, Igor Freitas
Previsão da atenuação por chuvas a partir de
dados meteorológicos globais / Igor Freitas Fagundes ;
orientador: Luiz Alencar Reis da Silva Mello-2014.
$72 \mathrm{f} . ; 30 \mathrm{~cm}$
Dissertação (mestrado)-Pontifícia Universidade
Católica do Rio de Janeiro, Departamento de Engenharia
Elétrica, 2014.
Inclui bibliografia
1. Engenharia elétrica - Teses. 2. Atenuação por
chuvas. 3. Enlaces terrestres. 4. Radiometeorologia. I.
Mello, Luiz Alencar Reis da Silva. II. Pontifícia
Universidade Católica do Rio de Janeiro. Departamento de
Engenharia Elétrica. III. Título.

CDD: 621.3 


\section{Agradecimentos}

À minha família, em especial à minha esposa Carolina, à minha filha Alice e à minha mãe Elisabete, pelo incentivo, paciência e compreensão durante a realização do trabalho.

Ao meu orientador, professor Dr. Luiz Alencar Reis da Silva Mello, pelo incentivo e apoio para conclusão do trabalho.

Ao CNPq e a PUC-Rio, pelos auxílios e bolsas concedidos sem os quais este trabalho não poderia ter sido realizado.

Aos pesquisadores Dr. Fernando José de Almeida Andrade e Dra. Marta Pudwell Chaves de Almeida, pelo apoio na elaboração e revisão das rotinas para processamento de dados meteorológicos.

A todos os colegas e amigos que de forma direta e indireta participaram desta longa caminhada. 


\section{Resumo}

Fagundes, Igor Freitas; Mello, Luiz Alencar Reis da Silva. Previsão da Atenuação por Chuvas a partir de Dados Meteorológicos Globais. Rio de Janeiro, 2014. 72p. Dissertação de Mestrado - Departamento de Engenharia Elétrica, Pontifícia Universidade Católica do Rio de Janeiro.

A disponibilidade é o parâmetro chave no dimensionamento de sistemas de comunicação. Em sistema via rádio diversos fatores reduzem esta disponibilidade, entre os quais se podem citar o desvanecimento, as atenuações adicionais, as interferências externas e a ocorrência de falhas dos equipamentos. A atenuação por chuvas é o principal fenômeno de atenuação adicional para sistemas que operam em frequências superiores a $10 \mathrm{GHz}$. A chuva é um fenômeno aleatório que apresenta grande variação no espaço e no tempo. Diversos modelos teóricos e semi-empíricos foram propostos na literatura à medida que crescia a utilização de frequências mais elevadas na faixa de micro-ondas. A principal diferença entre os modelos está na maneira de representar a variação espaço-temporal da chuva e o seu efeito na onda eletromagnética em propagação. No trabalho é investigada a influência de parâmetros meteorológicos de direção e velocidade do vento, e testado o conceito de taxa de precipitação efetiva na modelagem. Dois modelos semi-empíricos são desenvolvidos com base em distribuições cumulativas de atenuação e taxas de precipitação pontuais disponíveis no banco de dados da União Internacional de Telecomunicações (UIT-R). Os testes de comparação demonstram que os modelos obtidos apresentam desempenho superior se comparados aos modelos atualmente recomendados para previsão da atenuação por chuvas. Em outra linha de investigação, foi desenvolvido um modelo estatisticamente consistente para previsão da distribuição da atenuação a partir da representação da distribuição cumulativa complementar da taxa de precipitação. A distribuição cumulativa da atenuação foi obtida a partir da suposição de um relacionamento com significado físico entre a taxa de precipitação e atenuação por chuvas. A comparação dos modelos demonstra que o modelo obtido apresenta resultados comparáveis a modelos de Recomendações do UIT-R.

\section{Palavras-chave}

Atenuação por chuvas; Enlaces terrestres; Radiometeorologia. 


\section{Abstract}

Fagundes, Igor Freitas; Mello, Luiz Alencar Reis da Silva (Advisor). Rain Attenuation Prediction from Global Weather Data. Rio de Janeiro, 2014. 72p. MSc. Dissertation - Departamento de Engenharia Elétrica, Pontifícia Universidade Católica do Rio de Janeiro.

Availability is the key parameter in the communication systems design. In radio system many factors impact the availability, including fading, additional loss, external interference and equipment availability. The rain attenuation is the main impairments in systems operating at frequencies above $10 \mathrm{GHz}$. The rain is a random phenomenon that is highly variable in space and time. Several theoretical and semi-empirical models have been proposed in the literature as the growing use of higher frequencies in the microwave range. The main difference between the models is the way to represent the rain variation effect on electromagnetic waves. This work investigates the meteorological parameters direction and speed of wind influence in modeling. Two semi-empirical models are developed based on attenuation and rainfall rates cumulative distributions available at International Telecommunication Union (ITU-R) database. ITU-R testing criteria shows that the obtained models have superior performance compared to currently recommended models for rain attenuation prediction. In another line of investigation, a statistically consistent model to predict attenuation distribution from the complementary cumulative distribution of rainfall rate was developed. The attenuation cumulative distribution was obtained from rainfall rate and rain attenuation physical relationship assumption. ITU-R testing criteria show that the obtained model has results comparable with Recommendations ITU-R models.

\section{Keywords}

Rain attenuation; Terrestrial links; Radiometeorology. 


\section{Sumário}

1 Introdução 13

2 Atenuação por Chuvas em Radioenlaces Terrestres 16

2.1. Atenuação Específica Devida à Chuva ………………………....... 17

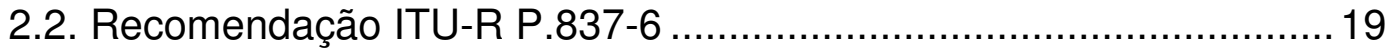

2.3. Modelo ITU-R Recomendação P.530-13 ...................................... 21

2.4. Modelo ITU-R Recomendação P.530-14 ......................................... 24

2.5. Modelo Documento ITU-R 3M/208-E Brasil .................................... 26

3 Bancos de Dados Experimentais 28

3.1. Medidas de Atenuação Realizadas no Brasil ................................... 28

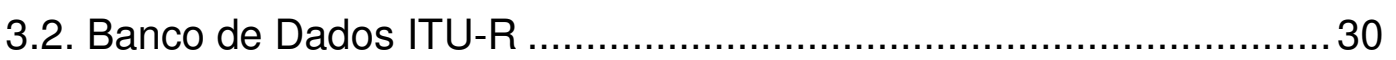

3.3. Banco de Dados Meteorológicos ECMWF ....................................... 33

4 Desenvolvimento de Modelos para Previsão da Atenuação por

Chuvas para Radioenlaces Terrestres $\quad \mathbf{4 1}$

4.1. Modelos Semi-empíricos Empregando a Taxa de Precipitação

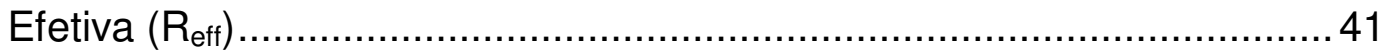

4.1.1. Modelos a partir de Dados Experimentais do Brasil ....................... 42

4.1.2. Modelos a partir de Dados Experimentais do UIT-R ..................... 45

4.1.3. Comparação dos Modelos Semi-empíricos...................................53

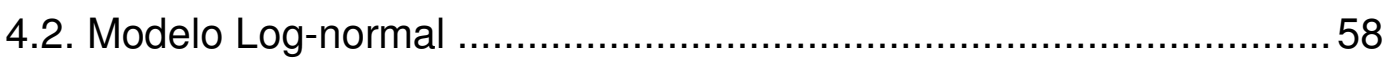

4.2.1. Distribuição da Taxa de Precipitação …………............................ 58

4.2.2. Distribuição da Atenuação por Chuvas ........................................ 59

4.2.3. Ajuste dos parâmetros do Modelo Log-normal...............................61

4.2.4. Comparação Modelo Log-normal ................................................. 65

5 Conclusões $\quad 69$ 
6 Referências Bibliográficas 


\section{Lista de figuras}

Figura 1 - Mapa da taxa de precipitação excedida durante $0,01 \%$ do tempo em um ano.

Figura 2 - Mapa da taxa de precipitação excedida durante $0,001 \%$ do tempo em um ano.

Figura 3 - Modelo para célula de chuva equivalente da Recomendação ITU-R P. 530-13

Figura 4 - Setup experimental das medições de atenuação por chuvas realizadas em enlaces convergentes no Brasil [15]. 28

Figura 5 - Distribuição espacial enlaces convergentes estação RIS São Paulo.

Figura 6 - Distribuição espacial enlaces convergentes estação BSA Brasília.

Figura 7 - Distribuição espacial enlaces convergentes estação PDC -

Rio de Janeiro 30

Figura 8 - Áreas de dados meteorológicos ECMWF. 35

Figura 9 - Chuva média acumulada em um ano $\mathrm{M}_{\mathrm{T}}[\mathrm{mm}]$ - banco de dados Recomendação ITU-R P.837-6.

Figura 10 - Razão entre a chuva convectiva e total, parâmetro $\beta$ banco de dados Recomendação ITU-R P.837-6.

Figura 11 - Chuva acumulada no ano de 1994 - banco de dados

ERA-40 (subárea dados Brasil)

Figura 12 - Razão entre a chuva convectiva e total no ano de 1994 -

banco de dados ERA-40 (subárea dados Brasil).

Figura 13 - Chuva estratiforme acumulada em intervalos de 6 horas ano 1994 estação RIS.

Figura 14 - Chuva convectiva acumulada em intervalos de 6 horas ano 1994 estação RIS.

Figura 15 - Chuva total acumulada em intervalos de 6 horas ano 1994 estação RIS. 39

Figura 16 - Direção média do vento em relação ao Leste em intervalos 
de 6 horas ano 1994 estação RIS.

Figura 17 - Velocidade média do vento em intervalos de 6 horas ano 1994 estação RIS.

Figura 18 - Taxa de precipitação $(R)$ x Taxa de precipitação efetiva $\left(R_{\text {eff }}\right)$ dos enlaces em $15 \mathrm{GHz}$ de São Paulo. 43

Figura 19 - Valores previstos versus observados de $R_{\text {eff }}(\mathrm{p}, \mathrm{d})$.

$R^{2}=0,9283$

Figura 20 - Valores previstos versus observados de $R_{\text {eff }}(\mathrm{p}, \mathrm{d}, \theta)$.

$R^{2}=0,9609$.

Figura 21 - Taxa de precipitação $(R)$ x Taxa de precipitação efetiva $\left(R_{\text {eff }}\right)$ dados UIT-R. 46

Figura 22 - Comprimento do enlace (d) x Taxa de precipitação efetiva $\left(R_{\text {eff }}\right)$ dados UIT-R. 46

Figura 23 - Valores estimados versus medidos de $R_{\text {eff }}\left(R_{p}, d\right)$ Modelo 1 . $R^{2}=0,9387$. 48

Figura 24 - Distribuição dos resíduos do ajuste do $R_{\text {eff }}\left(R_{p}\right.$, d) Modelo 1 . . 48 Figura 25 - Atenuação estimada Modelo $1 \mathrm{x}$ atenuação medida dados UIT-R. $R^{2}=0,7703$. 49

Figura 26 - Distribuição resíduos Modelo 1. 49

Figura 27 - Geometria e variáveis consideradas em um radioenlace entre as estações $A$ e $B$. 50

Figura 28 - Valores estimados versus medidos de $R_{\text {eff }}\left(R_{p}, d, \theta\right)$ Modelo 2 . $R^{2}=0,9427$. 52

Figura 29 - Distribuição dos resíduos do ajuste do $R_{\text {eff }}\left(R_{p}\right.$, d) Modelo 2. . 52

Figura 30 - Atenuação prevista Modelo $2 \times$ atenuação medida dados

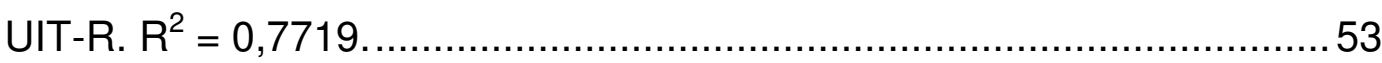

Figura 31 - Distribuição resíduos Modelo 2 ..........................................53

Figura 32 - Comparação valor médio da variável de teste ITU-R P.311-13 56

Figura 33 - Comparação desvio padrão da variável de teste ITU-R P.311-13 56

Figura 34 - Comparação valor r.m.s. da variável de teste ITU-R

P.311-13. 
Figura 35 - Comparação entre valores calculados e previstos de bd.

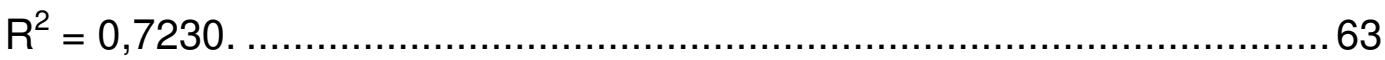

Figura 36 - Histograma dos resíduos da estimativa de bd...................... 63

Figura 37 - Comparação entre valores calculados e estimados de $\chi$.

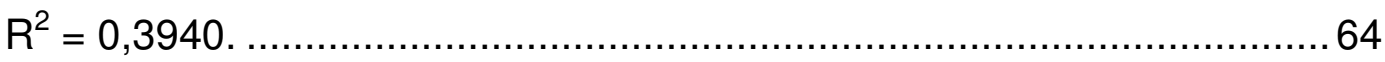

Figura 38 - Histograma dos resíduos da estimativa de $\chi \ldots \ldots \ldots \ldots \ldots \ldots \ldots \ldots . . . . . . . . .65$

Figura 39 - Valor médio da variável de teste ITU-R P.311-13

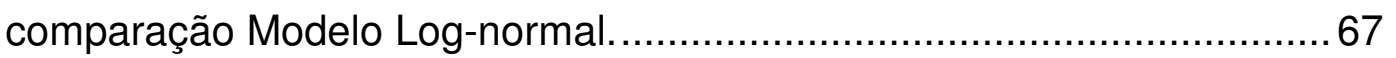

Figura 40 - Desvio padrão da variável de teste ITU-R P.311-13

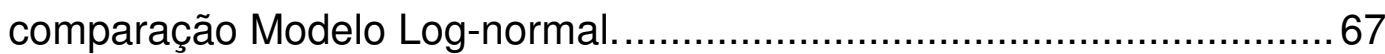

Figura 41 - Valor r.m.s. da variável de teste ITU-R P.311-13 comparação Modelo Log-normal. 68 


\section{Lista de tabelas}

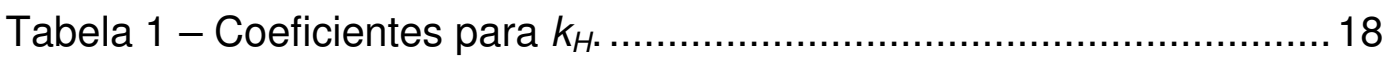

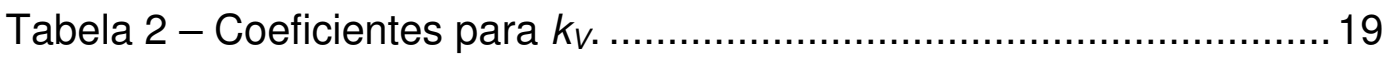

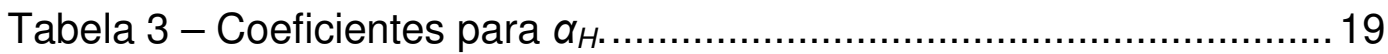

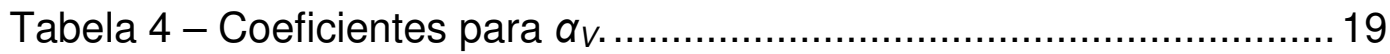

Tabela 5 - Característica dos enlaces Brasil. ......................................... 30

Tabela 6 - Característica dos enlaces DBSG3 ITU-R............................. 32

Tabela 7 - Coeficientes do ajuste Modelo 1....................................... 47

Tabela 8 - Coeficientes do ajuste Modelo 2. ........................................ 51

Tabela 9 - Erro médio variável ITU-R P.311-13 dos modelos semiempíricos para a atenuação por chuvas em enlaces terrestres. ……....... 55 Tabela 10 - Desvio padrão variável ITU-R P.311-13 dos modelos semiempíricos para atenuação por chuvas em enlaces terrestres.

Tabela 11 - Valor RMS da variável ITU-R P.311-13 dos modelos semiempíricos para atenuação por chuvas em enlaces terrestres.

Tabela 12 - Características dos enlaces e parâmetros das distribuições log-normais. 62

Tabela 13 - Média da variável ITU-R P.311-13 comparação modelo Lognormal para atenuação por chuvas em enlaces terrestres 66 Tabela 14 - Desvio padrão da variável ITU-R P.311-13 comparação modelo Log-normal para atenuação por chuvas em enlaces terrestres...66 Tabela 15 - Valor RMS da variável ITU-R P.311-13 comparação modelo Log-normal para atenuação por chuvas em enlaces terrestres. 66 


\section{1 \\ Introdução}

A disponibilidade é o parâmetro chave no dimensionamento de sistemas de comunicação. Este parâmetro pode ser expresso, para sistemas digitais, como a porcentagem de tempo em que um link opera com qualidade igual ou superior a uma determinada taxa de erro de bits. Em sistemas de comunicação via rádio, a ocorrência de uma série de fatores resulta em redução da disponibilidade, incluindo efeitos de propagação (fading, atenuações adicionais, entre outros), interferências externas e indisponibilidade dos equipamentos.

Entre as fontes de atenuação adicional, a atenuação por chuvas é o principal efeito de propagação em sistemas que operam em frequências superiores a 10 GHz. A presença de hidrometeoros, em particular da chuva, no percurso de propagação provoca espalhamento e absorção da onda em propagação. As gotas da chuva comportam-se como um meio dielétrico dissipativo para o campo elétrico incidente, absorvendo energia ou espalhando-a em diversas direções.

A absorção de energia corresponde à dissipação térmica, sendo função da condutividade da água. A dispersão está associada às modificações nas direções de propagação da onda para satisfazer as condições de contorno na superfície das gotas de chuva.

Para caracterizar o efeito da atenuação por chuvas, modelos teóricos e semiempíricos são empregados para estimar a margem de desvanecimento necessária para garantir a operação dos radioenlaces com os níveis de disponibilidade requeridos. A atenuação devida à chuva depende da taxa de precipitação, tamanho e forma das gotas, e densidade volumétrica $\left(\mathrm{n}^{\mathrm{o}}\right.$ de gotas por $\mathrm{m}^{3}$ ) da chuva [1] Destes parâmetros, a taxa de precipitação é o mais facilmente medido e, por esta razão, o mais frequentemente empregado na modelagem da atenuação por chuvas.

A principal diferença entre os vários métodos desenvolvidos para prever as estatísticas de atenuação por chuvas a partir de medições da taxa de precipitação está na modelagem utilizada para descrever a estrutura espaço-temporal da taxa de precipitação [2]. O método da tempestade sintética gera estatísticas de atenuação 
convertendo perfis de taxa de precipitação versus tempo registrada em um ponto em perfis de taxa de precipitação versus distância usando a velocidade de translação da chuva, estimada pela velocidade do vento. Recentemente diversas pesquisas têm sido realizadas visando o desenvolvimento de modelos de sintetizadores de séries temporais para fornecer estatísticas de atenuação por chuvas.

Outras linhas de pesquisas têm explorado o desenvolvimento de métodos que fazem uso de distribuições cumulativas de taxa de precipitação medida em um ponto como dado de entrada para prever a atenuação. Alguns métodos derivam o perfil estatístico da chuva ao longo do percurso supondo uma única célula de forma adequada ou uma distribuição estatística de tamanhos para as células de uma forma específica. Outros métodos caracterizam o perfil estatístico da precipitação simplesmente por um coeficiente de redução, que pode ser derivado da função de correlação espacial da intensidade da chuva a partir de medições usando pluviômetros de resposta rápida espaçados ao longo de uma linha.

Um procedimento alternativo aplica o coeficiente de redução ao comprimento real do percurso, o que resulta um comprimento efetivo ao longo do qual a intensidade de chuva pode ser assumida como sendo constante. Este conceito de coeficiente de redução do percurso foi empregado nos métodos de predição de atenuação por chuvas recomendados pela União Internacional de Telecomunicação (UIT) até a Recomendação ITU-R P.530-13 [3].

$\mathrm{Na}$ última década, diversas propostas de alteração dos modelos de previsão [10][11][12][13] foram submetidas ao grupo de estudo de Radiopropagação da UIT-R. As alterações propostas tinham como objetivo comum aprimorar o desempenho dos modelos com base em novos dados experimentais disponíveis. Os estudos de maneira geral demonstravam que os modelos recomendados subestimavam a atenuação por chuvas, com destaque para as regiões de clima tropical, onde os regimes de precipitação são mais intensos.

No ano de 2012, a partir da publicação da Recomendação ITU-R P.530-14 [4] foi adotado um novo modelo desenvolvido com base na proposta apresentada pela China [12]. Apesar de apresentar melhores resultados numéricos quando comparado ao banco de dados experimentais disponíveis atualmente, o modelo ITU-R P.530-14 tem como principal desvantagem a perda de alguns conceitos físicos empregados até a Recomendação anterior. 
O presente trabalho apresenta os resultados obtidos a partir da investigação da influência de parâmetros meteorológicos de direção e velocidade do vento na modelagem da atenuação por chuvas. O conceito de taxa de precipitação efetiva foi empregado no desenvolvimento dos modelos semi-empíricos, permitindo a aplicação da distribuição cumulativa da taxa de precipitação para todas as porcentagens de tempo disponíveis nos bancos de dados oficiais do UIT-R. Em outra linha de investigação, foi desenvolvido um modelo estatisticamente consistente para obtenção da distribuição cumulativa da atenuação a partir da distribuição cumulativa da taxa de precipitação.

O trabalho está organizado em cinco capítulos. No Capítulo 2, é apresentado um resumo das Recomendações do UIT-R aplicadas à previsão da atenuação por chuvas para radioenlaces terrestres e os modelos utilizados na comparação com modelos desenvolvidos no trabalho. No Capítulo 3, são descritos os bancos de dados experimentais de medições de atenuação por chuvas, bem como os bancos de dados meteorológicos empregados nos ajustes dos modelos. No Capítulo 4, são apresentados os modelos propostos e os resultados das comparações realizadas conforme as Recomendações do UIT-R. Por fim, no Capítulo 5 são apresentadas as conclusões e as sugestões para trabalhos futuros. 


\section{2 Atenuação por Chuvas em Radioenlaces Terrestres}

O procedimento para previsão da atenuação por chuvas atual é baseado na relação entre a atenuação específica $\gamma_{R}(\mathrm{~dB} / \mathrm{km})$ e a taxa de precipitação $R(\mathrm{~mm} / \mathrm{h})$, estabelecida com base na modelagem da estrutura da chuva - forma, tamanho, temperatura e velocidade terminal das gotas de chuva. Se a variação da taxa de precipitação ao longo de determinado percurso é conhecida, a atenuação devida à chuva no enlace pode ser calculada integrando-se a atenuação específica sobre o comprimento do percurso.

A taxa de precipitação não é homogênea no espaço e no tempo. Registros pluviométricos mostram curtos intervalos de maior taxa de chuva incorporada a longos períodos de chuva menos intensa. Estas observações são típicas de ocorrências de chuva em todas as regiões climáticas.

A chuva é um fenômeno meteorológico de estrutura complexa devida a sua variabilidade no espaço, na duração e na frequência de ocorrência, particularmente em regiões tropicais e equatoriais. Os meteorologistas têm classificado as chuvas em duas categorias, estratiformes ou convectivas [5]. As diferenças entre os dois tipos dependem em geral da taxa de precipitação máxima associada ao processo de chuva.

As precipitações estratiformes resultam da formação de pequenas partículas de gelo nas camadas elevadas da troposfera. Ao caírem, estas partículas agregamse umas às outras formando núcleos cada vez maiores. Estes núcleos tornam-se instáveis e, ao passarem por uma faixa de altitude entre 500 a 1000 metros abaixo da isoterma de $0^{\circ} \mathrm{C}$, transformam-se em gotas de chuva que precipitam.

As chuvas convectivas, por outro lado, estão associadas a nuvens formadas geralmente abaixo da isoterma de $0^{\circ} \mathrm{C}$, que são impelidas para cima por fortes movimentos de massas de ar devidos a diferenças de pressão na troposfera. No processo, formam-se gotas de água que crescem de tamanho até que a força da gravidade as precipite em direção ao solo. As chuvas tropicais são 
predominantemente convectivas, caracterizadas por altas taxas de precipitação que ocorrem geralmente em áreas pouco extensas e têm curta duração.

A principal diferença entre os vários métodos desenvolvidos para prever as estatísticas de atenuação por chuvas a partir de medições da taxa de precipitação está nos modelos utilizados para descrever a estrutura espaço-temporal da taxa de precipitação.

Formulações matemáticas rigorosas para o cálculo da atenuação por chuva estão disponíveis na literatura, porém a complexidade para obtenção das variáveis de entrada destes métodos dificulta a sua utilização. Para aplicações práticas, formulações semi-empíricas que expressam a atenuação específica da chuva em função da taxa de precipitação, frequência e polarização da onda são utilizadas.

Os métodos recomendados pelo UIT-R para obtenção da atenuação específica, taxa de precipitação e atenuação por chuvas são descritos na sequência do capítulo. De forma complementar, o modelo proposto pelo Brasil [13] e utilizado nas comparações de desempenho no trabalho é apresentado.

\section{1.}

\section{Atenuação Específica Devida à Chuva}

A atenuação de uma onda que se propaga em um meio com chuva é obtida pela soma das contribuições individuais das gotas que compõem o meio. Considerando as dimensões distintas das gotas de chuva, a atenuação específica $\gamma$ $(\mathrm{dB} / \mathrm{km})$ é calculada pela integração das contribuições de cada gota, conforme equação (2.1) [5].

$$
\gamma=0,4343 \int_{0}^{\infty} Q_{t}(D) \cdot N(D) d D
$$

As variáveis da expressão (2.1) e as suas unidades usuais são, respectivamente, a seção reta de uma gota esférica $Q_{t}(D)\left(\mathrm{cm}^{2}\right)$ de diâmetro $D$ $(\mathrm{mm})$, e o número de gotas de chuva por unidade de volume $N(D)\left(\mathrm{mm}^{-1} \mathrm{~m}^{-3}\right)$ com diâmetro compreendidos entre $D$ e $D+\mathrm{d} D(\mathrm{~mm})$.

Para aplicações práticas, a relação entre a atenuação específica $\gamma_{R}(\mathrm{~dB} / \mathrm{km})$ e a taxa de precipitação $R(\mathrm{~mm} / \mathrm{h})$ pode ser aproximada por uma lei de potência, conforme (2.2). 


$$
\gamma_{R}=k \cdot R^{\alpha}
$$

O trabalho desenvolvido por Gibbins e Walden [6] é a base da Recomendação ITU-R P.838-3, que fornece valores de $k$ e $\alpha$ como funções da frequência $f(\mathrm{GHz})$, no intervalo de 1 a $1000 \mathrm{GHz}$, e da polarização da onda. Estas funções foram obtidas através de ajustes de curvas e coeficientes de leis de potência derivados de cálculos de espalhamento.

Para determinar a atenuação específica para uma dada taxa de precipitação, a frequência de operação é utilizada para selecionar o coeficiente de regressão apropriado. As equações a seguir são utilizadas para obter os valores de $k$ e $\alpha$ para as polarizações horizontal $(H)$ e vertical $(V), k_{H}, k_{V}, \alpha_{H}, \alpha_{V}[8]$.

$$
\begin{gathered}
\log _{10} k=\sum_{j=1}^{4} a_{j} \exp \left[-\left(\frac{\log _{10} f-b_{j}}{c_{j}}\right)^{2}\right]+m_{k} \log _{10} f+c_{k} \\
\alpha=\sum_{j=1}^{5} a_{j} \exp \left[-\left(\frac{\log _{10} f-b_{j}}{c_{j}}\right)^{2}\right]+m_{\alpha} \log _{10} f+c_{\alpha}
\end{gathered}
$$

Nestas equações, $f$ é a frequência em GHz, $k$ é $k_{H}$ ou $k_{V}$ e $\alpha$ é $\alpha_{H}$ ou $\alpha_{V}$.

Os valores dos coeficientes para polarização horizontal $k_{H}$ e $\alpha_{H}$ são apresentados na Tabela 1 e Tabela 3 e os coeficientes para a polarização vertical $k_{V}$ e $\alpha_{V}$ apresentados na Tabela 2 e Tabela 4. Estas Tabelas foram reproduzidas da Recomendação ITU-R P.838-3.

Tabela 1 - Coeficientes para $k_{H}$.

\begin{tabular}{|c|c|c|c|c|c|}
\hline$j$ & $a_{j}$ & $b_{j}$ & $c_{j}$ & $m_{k}$ & $c_{k}$ \\
\hline 1 & $-5,33980$ & $-0,10008$ & 1,13098 & & \\
\cline { 1 - 3 } 2 & $-0,35551$ & 1,26970 & 0,45400 & \multirow{2}{*}{$-0,18961$} & 0,71147 \\
\hline 3 & $-0,23789$ & 0,86036 & 0,15354 & & \\
\hline 4 & $-0,94158$ & 0,64552 & 0,16817 & & \\
\hline
\end{tabular}


Tabela 2 - Coeficientes para $k_{V}$.

\begin{tabular}{|c|c|c|c|c|c|}
\hline$j$ & $a_{j}$ & $b_{j}$ & $c_{j}$ & $m_{k}$ & $c_{k}$ \\
\hline 1 & $-3,80595$ & 0,56934 & 0,81061 & & \\
\cline { 1 - 3 } 2 & $-3,44965$ & $-0,22911$ & 0,51059 & \multirow{2}{*}{$-0,16398$} & \multirow{2}{*}{0,63297} \\
\hline 3 & $-0,39902$ & 0,73042 & 0,11899 & & \\
\hline 4 & 0,50167 & 1,07319 & 0,27195 & & \\
\hline
\end{tabular}

Tabela 3 - Coeficientes para $\alpha_{H}$

\begin{tabular}{|c|c|c|c|c|c|}
\hline$j$ & $a_{j}$ & $b_{j}$ & $c_{j}$ & $m_{\alpha}$ & $c_{\alpha}$ \\
\cline { 1 - 3 } 1 & $-0,14318$ & 1,18442 & $-0,55187$ & & \\
\cline { 1 - 3 } 2 & 0,29591 & 0,77564 & 0,19822 & \multirow{2}{*}{0,67849} & $-1,95537$ \\
\hline 3 & 0,32177 & 0,63773 & 0,13164 & & \\
\hline 5 & $-5,37610$ & $-0,96230$ & 1,47828 & & \\
\hline
\end{tabular}

Tabela 4 - Coeficientes para $\alpha_{V}$.

\begin{tabular}{|c|c|c|c|c|c|}
\hline$j$ & $a_{j}$ & $b_{j}$ & $c_{j}$ & $m_{\alpha}$ & $c_{\alpha}$ \\
\hline 1 & $-0,07771$ & 2,33840 & $-0,76284$ & & \\
\cline { 1 - 3 } 2 & 0,56727 & 0,95545 & 0,54039 & & \multirow{2}{*}{$0,0,053739$} \\
\cline { 1 - 3 } 3 & $-0,20238$ & 1,14520 & 0,26809 & & \\
\hline 4 & $-48,2991$ & 0,791669 & 0,116226 & & \\
\hline 5 & 48,5833 & 0,791459 & 0,116479 & & \\
\hline
\end{tabular}

Para polarização linear e circular, para todas as geometrias de enlaces, os coeficientes $k$ e $\alpha$ podem ser calculados por:

$$
\begin{gathered}
k=\left[k_{H}+k_{V}+\left(k_{H}-k_{V}\right) \cos ^{2} \theta \cos 2 \tau\right] / 2 \\
\alpha=\left[k_{H} \alpha_{H}+k_{V} \alpha_{V}+\left(k_{H} \alpha_{H}-k_{V} \alpha_{V}\right) \cos ^{2} \theta \cos 2 \tau\right] / 2 k
\end{gathered}
$$

onde $\theta$ é o ângulo de elevação do enlace e $\tau$ é o ângulo de inclinação da polarização em relação à horizontal ( $\tau=45^{\circ}$ para polarização circular).

\section{2.}

\section{Recomendação ITU-R P.837-6}

A maioria dos modelos atuais utiliza como um dos dados de entrada a taxa de precipitação em $\mathrm{mm} / \mathrm{h}$ excedida para uma determinada porcentagem de tempo do ano. A distribuição cumulativa da taxa de precipitação deve ser obtida preferencialmente de dados de medidas locais. Quando estes dados não estiverem 
disponíveis, deve-se utilizar a Recomendação ITU-R P.837-6 [9] para obter a distribuição cumulativa da taxa de precipitação.

A Recomendação ITU-R P.837-6 contém mapas de parâmetros meteorológicos obtidos através do banco de dados ERA-40 do European Centre for Medium-Range Weather Forecast (ECMWF). Estes mapas permitem obter estatísticas da taxa de precipitação com tempo de integração de 1 min. A taxa de precipitação excedida em determinada porcentagem do tempo é obtida a partir das coordenadas de latitude e longitude do ponto de interesse.

O método tem como variáveis de entrada os seguintes parâmetros: $P_{r 6}$ probabilidade da ocorrência de chuva em intervalos de 6 horas, $M_{T}$ média de chuva anual em mm (soma das médias de chuva convectiva e estratiforme), e $\beta$ razão entre a média de chuva convectiva anual $M_{C} \mathrm{em} \mathrm{mm}$ e a $M_{T}$. Estes parâmetros estão disponíveis em arquivos de texto no endereço eletrônico do Grupo de Estudos 3 de Radiopropagação da UIT.

A Figura 1 e a Figura 2 apresentam exemplos de mapas globais de taxa de precipitação obtidos a partir da recomendação ITU-R P.837-6, para as porcentagens de tempo de $0,01 \%$ e $0,001 \%$ do ano.

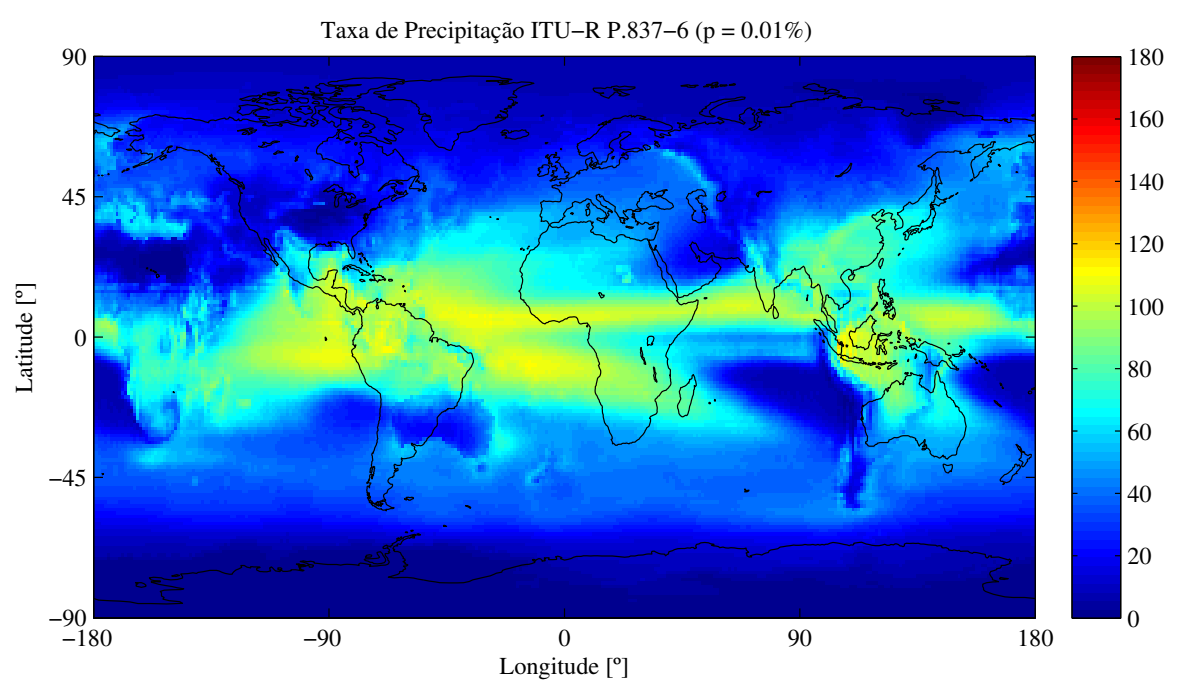

Figura 1 - Mapa da taxa de precipitação excedida durante $0,01 \%$ do tempo em um ano. 


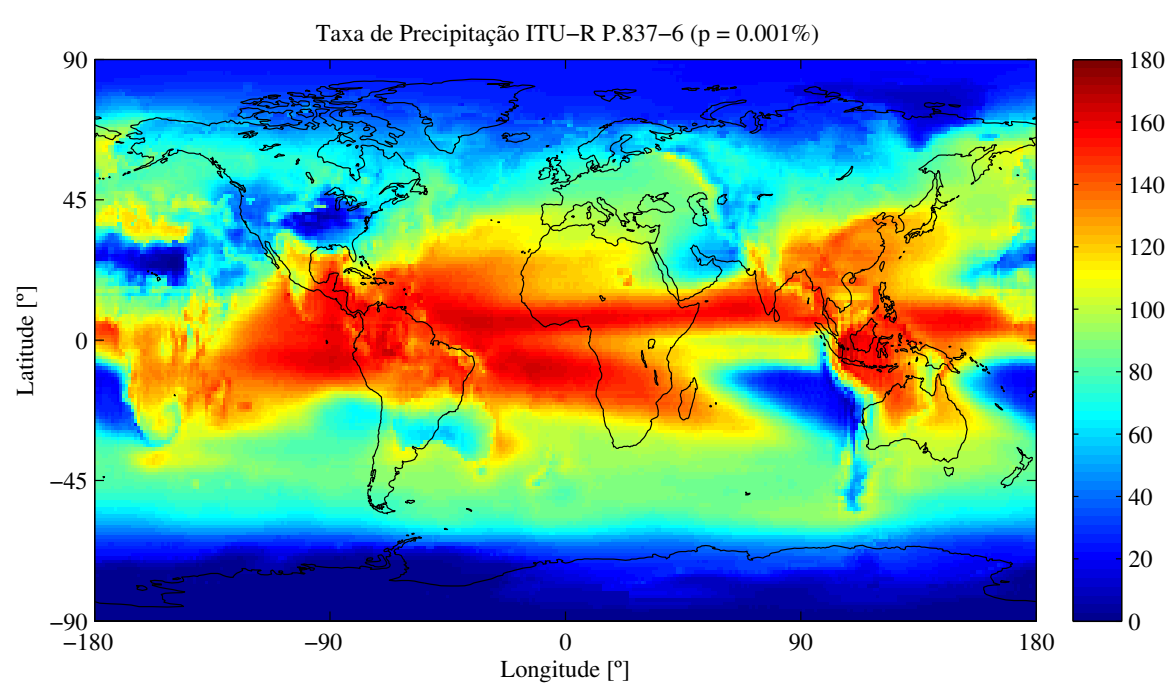

Figura 2 - Mapa da taxa de precipitação excedida durante $0,001 \%$ do tempo em um ano.

É possível observar nos mapas das Figuras 1 e 2 a ocorrência de diferenças significativas entre valor esperado e previsto das taxas de precipitação em locais como o Rio de Janeiro, o qual apresenta elevadas taxas de precipitação. Este tema é apresentado com maior detalhe na referência [22]. Apesar destas correções necessárias ao modelo, a Recomendação atual apresenta resultados com desempenho superior se comparada ao método da divisão do globo em Regiões Radioclimáticas, empregado inicialmente nos modelos de previsão da atenuação por chuvas.

\section{3. \\ Modelo ITU-R Recomendação P.530-13}

O método de previsão da atenuação por chuvas da recomendação ITU-R P.530-13 foi desenvolvido com base no modelo simplificado de uma célula equivalente de chuva com diâmetro $d_{0}$ interceptando o enlace, conforme representado na Figura 3. Os coeficientes das expressões foram obtidos a partir de técnicas de regressão aplicados a dados experimentais, predominantemente de clima temperado. 


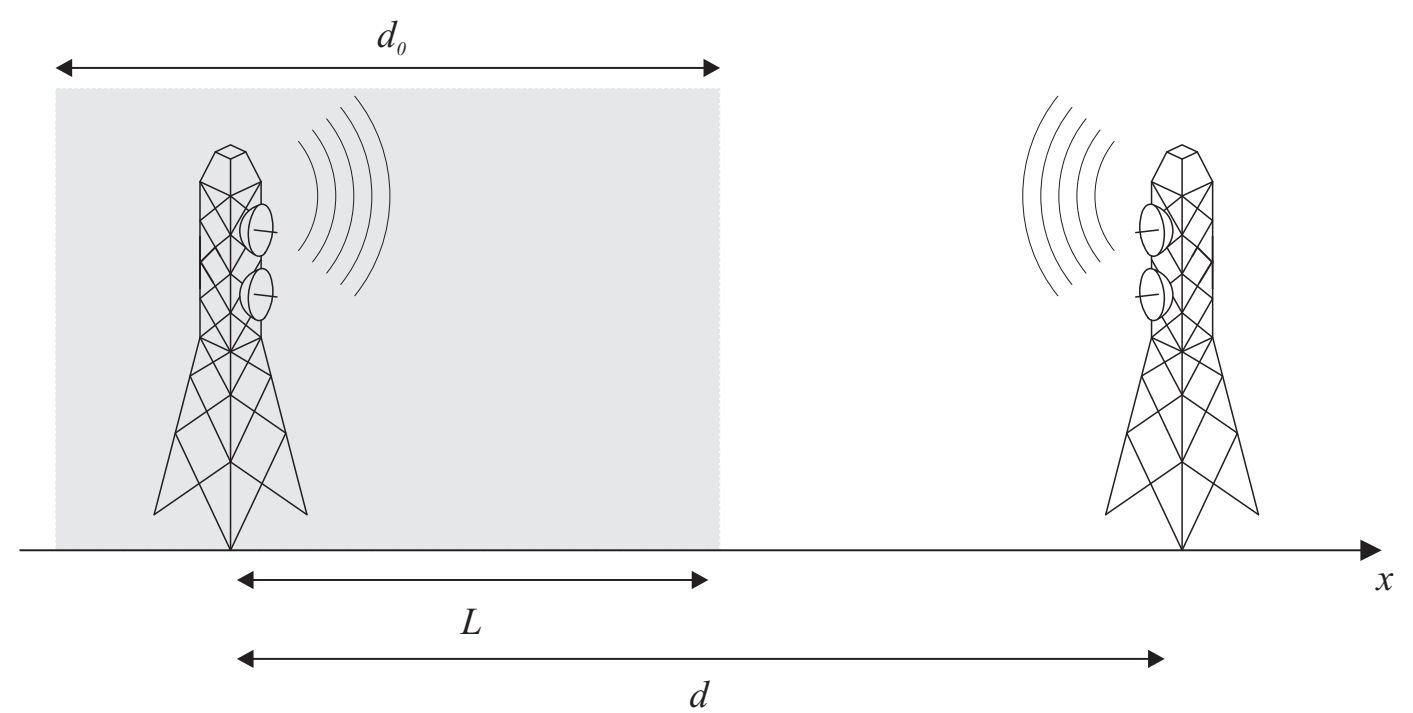

Figura 3 - Modelo para célula de chuva equivalente da Recomendação ITU-R P. 530-13.

A hipótese principal do método é que uma célula equivalente com taxa de precipitação constante e raio igual a $d_{0}$ pode modelar a taxa de precipitação não uniforme ao longo do percurso de propagação. Considerando que esta célula equivalente cilíndrica, com seção reta retangular, pode interceptar o enlace em qualquer posição com igual probabilidade, o comprimento efetivo do enlace $\left(d_{e f f}\right)$ é calculado conforme a expressão (2.7).

$$
d_{\text {eff }}=\frac{1}{d_{0}+d} \int_{-d_{0}}^{d} L(x) d x=r \cdot d=\frac{1}{1+d / d_{0}} \cdot d
$$

Desta forma, tem-se que o comprimento efetivo é o comprimento médio da intersecção entre a célula de chuva e o enlace. Como resultado destas suposições, tem-se que o comprimento efetivo do enlace é sempre menor do que o comprimento real do enlace, levando à definição de um fator de redução $r$. A dedução completa da expressão (2.7) pode ser encontrada na referência [7].

O método de previsão da atenuação por chuvas da recomendação ITU-R P.530-13 é considerado válido para todas as partes do globo terrestre para frequências até $40 \mathrm{GHz}$ e enlaces com comprimento de até $60 \mathrm{~km}$ [3]. O método é descrito na Recomendação em seis passos, e utiliza equações diretas, conforme apresentado a seguir. 
O primeiro passo do método consiste em obter a taxa de precipitação excedida em $0,01 \%$ do tempo $R_{0.01} \mathrm{em} \mathrm{mm} / \mathrm{h}$, com o tempo de integração de 1 minuto. Se informações locais de chuva não estão disponíveis, estimativas podem ser obtidas através da Recomendação ITU-R P.837-6.

No segundo passo, deve ser calculada a atenuação específica $\gamma_{R}[\mathrm{~dB} / \mathrm{km}]$ para a frequência, polarização e taxa de precipitação de interesse, utilizando a Recomendação ITU-R P.838-3.

No terceiro passo, é calculado o comprimento efetivo do enlace $\left(d_{e f f}\right)$, obtido pela multiplicação do comprimento do enlace $d$ pelo fator de distância $r$, estimado conforme as equações (2.8) e (2.9).

$$
r=\frac{1}{1+d / d_{0}}
$$

onde, para $R_{0.01} \leq 100 \mathrm{~mm} / \mathrm{h}$,

$$
d_{0}=35 \cdot \exp \left(-0,015 \cdot R_{0.01}\right)
$$

Para $R_{0.01}>100 \mathrm{~mm} / \mathrm{h}$, o valor da taxa de precipitação deve ser substituído por $100 \mathrm{~mm} / \mathrm{h}$. Uma estimativa da atenuação excedida em $0,01 \%$ do tempo devida à chuva é dada por,

$$
A_{0.01}=\gamma_{R} \cdot d_{e f f}=\gamma_{R} \cdot d \cdot r
$$

Para radioenlaces localizados em latitudes iguais ou maiores do que $30^{\circ}$ (Norte ou Sul), a atenuação excedida para outras porcentagens de tempo $p$ na faixa de $0,001 \%$ a $1 \%$ pode ser obtida a partir da seguinte lei de potência:

$$
\frac{A_{p}}{A_{0.01}}=0,12 p^{-\left(0,546+0,043 \log _{10} p\right)}
$$

A equação (2.11) foi estabelecida para fornecer os fatores $0,12,0,39,1 \mathrm{e}$ 2,14 para $1 \%, 0,1 \%, 0,01 \%$ e $0,001 \%$ respectivamente, e deve ser utilizada apenas 
nesta faixa. Para radioenlaces localizados em latitudes inferiores a $30^{\circ}$ (Norte ou Sul), a atenuação excedida para outras porcentagens de tempo $p$ na faixa de $0,001 \%$ a $1 \%$ pode ser obtida a partir da seguinte lei de potência:

$$
\frac{A_{p}}{A_{0.01}}=0,07 p^{-\left(0,855+0,139 \log _{10} p\right)}
$$

A equação (2.12) foi estabelecida para fornecer os fatores $0,07,0,36,1 \mathrm{e}$ 1,44 para $1 \%, 0,1 \%, 0,01 \%$ e $0,001 \%$, respectivamente, e deve ser utilizada apenas nesta faixa.

Observa-se que as equações (2.11) e (2.12) impõem uma descontinuidade em latitude em torno de $30^{\circ}$ ( $\mathrm{N}$ ou $\mathrm{S}$ ). Esta condição de ajuste foi imposta para obter melhores resultados nos ajustes dos dados experimentais, e não representa nenhum significado físico.

\section{4 . \\ Modelo ITU-R Recomendação P.530-14}

Um novo método para previsão da atenuação por chuvas para enlaces terrestres foi proposto pela China no documento ITU-R 3M/107-E [12] apresentado ao UIT-R em 2005. O modelo proposto era similar ao da Recomendação ITU-R P.530-10, e tinha como principal mudança a utilização de uma nova formulação para o cálculo do fator de distância $r$.

Conforme análise apresentada na proposta, o fator de distância era independente do coeficiente $k$, porém apresentava dependência com relação à frequência e ao coeficiente $\alpha$ da atenuação específica. Esta dependência foi observada através de análise teórica realizada para dados experimentais de enlaces terrestres e via satélite que integravam o banco de dados na época da realização do trabalho.

O método de previsão da atenuação por chuvas da Recomendação ITU-R P.530-14 é considerado válido para todas as partes do globo para frequências até $100 \mathrm{GHz}$ e enlaces com comprimento de até $60 \mathrm{~km}$ [4]. Os dois primeiros passos da Recomendação ITU-R P.530-14 são idênticos aos da Recomendação ITU-R 
P.530-13. As modificações constam a partir da obtenção do comprimento efetivo do enlace. O novo fator de distância $r$ é determinado por

$$
r=\frac{1}{0,477 d^{0,633} R_{0,01}^{0,073 \alpha} f^{0,123}-10,579(1-\exp (-0,024 \cdot d))}
$$

onde $f$ é a frequência em $\mathrm{GHz}$ e $\alpha$ é o coeficiente da atenuação específica obtida no segundo passo do método. O máximo valor para $r$ recomendado é 2,5, tal que a equação (2.13) não é utilizada para pequenos valores do denominador. Uma estimativa da atenuação excedida em $0,01 \%$ do tempo devido à chuva é calculada conforme a expressão (2.10).

A atenuação excedida para outras porcentagens de tempo $p$ na faixa de $0,001 \%$ a $1 \%$ pode ser obtida a partir da seguinte lei de potência:

$$
\frac{A_{p}}{A_{0.01}}=C_{1} p^{-\left(C 2+C 3 \log _{10} p\right)}
$$

Onde,

$$
\begin{gathered}
C_{1}=0,07^{C_{0}}\left(0,12^{\left(1-C_{0}\right)}\right) \\
C_{2}=0,855 C_{0}+0,546\left(1-C_{0}\right) \\
C_{3}=0,139 C_{0}+0,043\left(1-C_{0}\right) \\
C_{0}=\left\{\begin{array}{l}
0,12+0,4\left[\log _{10}(f / 10)^{0,8}\right] f \geq 10 G H z \\
0,12 \\
f<10 G H z
\end{array}\right.
\end{gathered}
$$




\section{5. Modelo Documento ITU-R 3M/208-E Brasil}

Um modelo semi-empírico alternativo foi apresentado pelo Brasil no documento ITU-R 3M/2008-E [13]. O método mantinha o conceito de célula equivalente de chuva, porém considerava a distribuição completa da taxa de precipitação. Desta forma, evitava o uso de funções de extrapolação para obter a atenuação por chuvas para porcentagens de tempo diferentes de $0,01 \%$.

$\mathrm{O}$ conceito de taxa de precipitação efetiva foi empregado no modelo, a fim de permitir a obtenção de comprimentos efetivos do enlace maiores que o comprimento real do enlace. Assim, o primeiro passo do método é obter a distribuição cumulativa da taxa de precipitação.

Para cada porcentagem de tempo $p$, calcula-se o comprimento efetivo do enlace, $d_{e f f}(p)$, multiplicando o comprimento do enlace $d$ pelo fator de distância $r_{p}$. Uma estimativa do fator $r_{p}$ é dada por:

$$
r_{p}=\frac{1}{1+d / d_{0}(p)}
$$

onde,

$$
d_{0}(p)=191 \cdot R_{p}^{-0,244}
$$

e $R_{p}$ é a taxa de precipitação excedida para $p \%$ do tempo.

Para cada porcentagem de tempo $p$, deve-se computar a taxa de precipitação efetiva $R_{\text {eff }}(p)$ dada por,

$$
R_{\text {eff }}(p)=1,763 R_{p}^{0,753++^{0,197} / d}
$$

A estimativa da atenuação excedida em $p \%$ do tempo é calculada por,

$$
A_{p}=k \cdot R_{e f f}^{\alpha}(p) \cdot d_{e f f}(p)=k \cdot R_{e f f}^{\alpha}(p) \cdot d \cdot r_{p}
$$


O método apresentado acima é considerado válido para todos os pontos do globo terrestre para frequências até $60 \mathrm{GHz}$ e enlaces com comprimento de até 60 $\mathrm{km}$. 


\section{3 \\ Bancos de Dados Experimentais}

\section{1. Medidas de Atenuação Realizadas no Brasil}

Os dados experimentais inicialmente empregados na investigação da influência da direção do vento na atenuação por chuvas foram obtidos no Brasil entre os anos 1990 e 2000. Os dados são referentes a campanhas de medição realizadas em enlaces convergentes nas cidades de São Paulo, Brasília e Rio de Janeiro.

O setup experimental utilizado nas medições consiste de dois rádios, um pluviômetro basculante de resposta rápida com tempo de integração de 1 minuto e uma unidade de aquisição. A unidade de aquisição registrava simultaneamente os dados do pluviômetro e do controle automático de ganho (AGC) dos equipamentos de rádio, os quais eram posteriormente processados para obter as curvas de distribuição cumulativa de taxa de precipitação e atenuação.

O pluviômetro e a unidade de aquisição de dados foram instalados nas estações centrais dos enlaces convergentes. Uma representação do setup experimental é ilustrada na Figura 4.

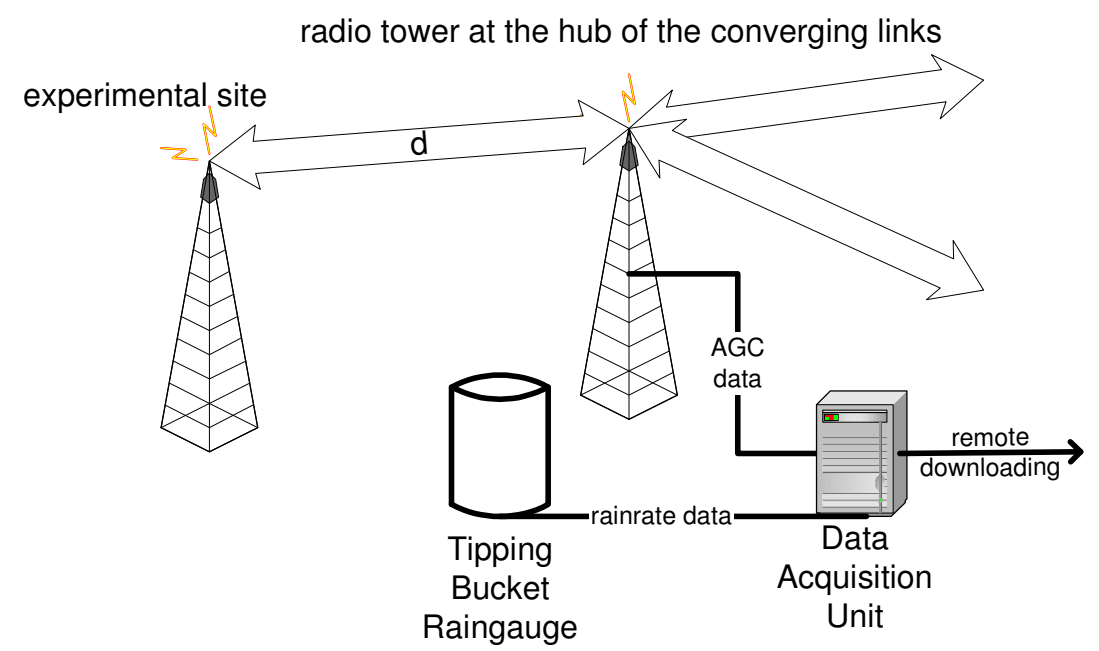

Figura 4 - Setup experimental das medições de atenuação por chuvas realizadas em enlaces convergentes no Brasil [15]. 
$\mathrm{Na}$ estação Rua dos Ingleses (RIS) em São Paulo as medições foram realizadas em cinco enlaces operando em frequências na faixa de $15 \mathrm{GHz}$ e dois enlaces operando em $18 \mathrm{GHz}$. As medições foram realizadas entre os anos de 1994 e 1996. Relatórios de pré-campanhas de medição [16] realizadas em São Paulo já citavam uma possível influência da orientação do enlace em relação à direção predominante do vento na região.

Na estação Brasília (BSA) em Brasília os dados considerados são referentes a três enlaces operando em $23 \mathrm{GHz}$ e quatro enlaces operando em $38 \mathrm{GHz}$. No Rio de Janeiro os dados foram registrados na estação Palácio Duque de Caxias (PDC) para dois enlaces operando em $15 \mathrm{GHz}$, um enlace operando em $18 \mathrm{GHz}$ e um enlace operando em 23 GHz. Estas medições ocorreram entre os anos de 2003 e 2006.

Parte dos dados obtidos no Brasil compõe o banco de dados oficial do UITR. As figuras a seguir apresentam a distribuição geográfica dos enlaces convergentes. A Tabela 5 apresenta as características dos enlaces do Brasil.

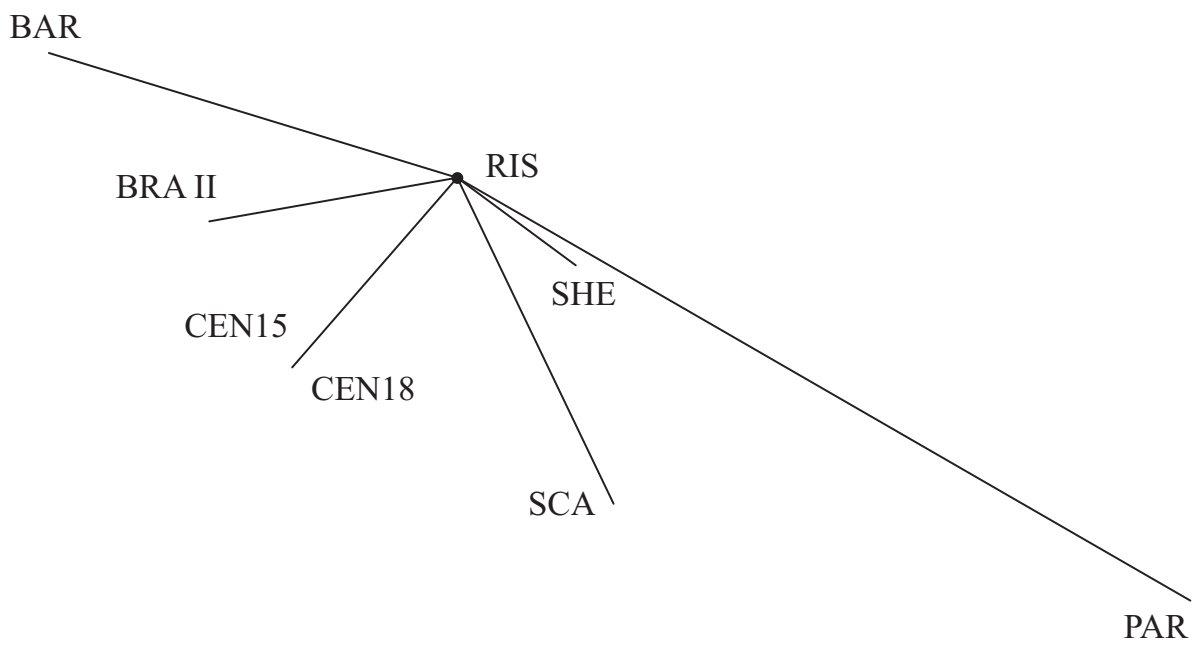

Figura 5 - Distribuição espacial enlaces convergentes estação RIS - São Paulo.

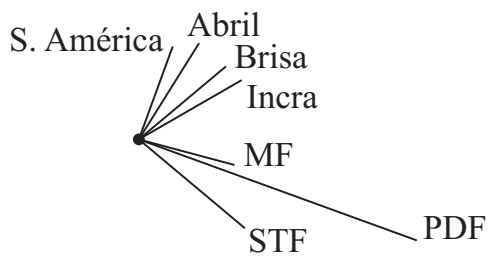

Figura 6 - Distribuição espacial enlaces convergentes estação BSA - Brasília. 


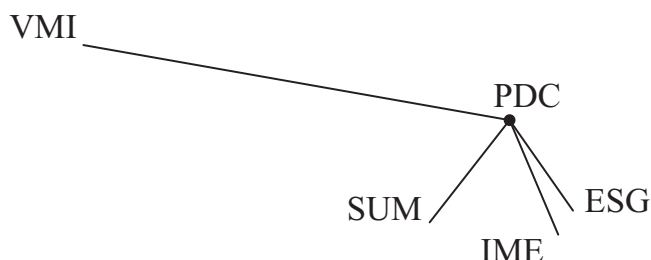

Figura 7 - Distribuição espacial enlaces convergentes estação PDC - Rio de Janeiro.

Tabela 5 - Característica dos enlaces Brasil.

\begin{tabular}{|c|c|c|c|c|c|c|c|}
\hline Local & Estação Tx & Estação Rx & $\mathbf{d}[\mathbf{k m}]$ & Azimute $\left[{ }^{\circ}\right]$ & $\mathbf{f}[\mathbf{G H z}]$ & Polarização & Período \\
\hline SP & BRADESCO II & RIS & 12,79 & 259,98 & 15,0 & $\mathrm{~V}$ & 2 anos \\
\hline SP & CENESP15 & RIS & 12,78 & 221,10 & 15,0 & $\mathrm{H}$ & 2 anos \\
\hline SP & CENESP18 & RIS & 12,78 & 221,10 & 18,0 & $\mathrm{~V}$ & 1 ano \\
\hline SP & SCANIA & RIS & 18,38 & 154,40 & 15,0 & $\mathrm{~V}$ & 2 anos \\
\hline SP & BARUERI & RIS & 21,69 & 287,07 & 15,0 & $\mathrm{~V}$ & 1 ano \\
\hline SP & SHELL & RIS & 7,48 & 126,48 & 18,0 & V & 1 ano \\
\hline SP & PARANAPIACABA & RIS & 42,99 & 124,27 & 15,0 & $\mathrm{H}$ & 2 anos \\
\hline DF & ABRIL & BSA & 1,12 & 34,58 & 38,0 & $\mathrm{H}$ & 1,5 anos \\
\hline DF & MF38 & BSA & 1,00 & 141,00 & 38,0 & V & 1,5 anos \\
\hline DF & DPF & BSA & 6,73 & 235,50 & 23,0 & V & 1,5 anos \\
\hline DF & INCRA & BSA & 1,20 & 58,00 & 23,0 & H & 1,5 anos \\
\hline DF & AMÉRICA & BSA & 0,93 & 20,50 & 38,0 & V & 1,5 anos \\
\hline DF & STF & BSA & 4,48 & 103,86 & 23,0 & V & 1,5 anos \\
\hline DF & BRISA & BSA & 1,09 & 52,65 & 38,0 & H & 1,5 anos \\
\hline RJ & IME & PDC & 5,60 & 157,00 & 15,0 & V & 2 anos \\
\hline RJ & ESG & PDC & 5,20 & 144,30 & 18,0 & H & 2 anos \\
\hline RJ & SUMARÉ & PDC & 5,10 & 216,91 & 23,0 & V & 2 anos \\
\hline RJ & VMI & PDC & 22,00 & 280,40 & 8,0 & H & 2 anos \\
\hline
\end{tabular}

\section{2.}

\section{Banco de Dados ITU-R}

A Tabela C1_1 do banco de dados do Grupo de Estudos 3 de Radiopropagação (DBSG3) do UIT-R é um conjunto de dados de atenuação por chuvas de enlaces terrestres obtidos de medições de mais de 30 anos. Atualmente medições de várias regiões radioclimáticas do globo terrestre estão disponíveis, permitindo a obtenção e avaliação de modelos com aplicação global. Porém, se comparado ao número de enlaces e diversidade de regimes de precipitação, os dados atuais ainda representam uma pequena amostra de dados experimentais.

Os dados têm sido revisados constantemente por Grupos de Estudos e sinalizadores são utilizados para indicar a adequação dos mesmos para comparação com métodos de previsão da atenuação por chuvas. Atualmente há 
oito sinalizadores indicando a faixa de validade dos dados, conforme definidos a seguir:

- FLAG 1 - Porcentagem $p$ inicial válida para função distribuição cumulativa da taxa de precipitação.

- FLAG 2 - Porcentagem $p$ final válida para função distribuição cumulativa da taxa de precipitação.

- FLAG 3 - Porcentagem $p$ inicial válida para função distribuição cumulativa da atenuação medida.

- FLAG 4 - Porcentagem $p$ final válida para função distribuição cumulativa da atenuação medida.

- FLAG 5 - Utilizada para identificar estatísticas de um ano (S), múltiplos anos (M) ou dados duplicados (T).

- FLAGS 6 a 8 - Não utilizadas nas tabelas atuais.

O banco de dados completo atual é composto 89 estatísticas, provenientes de enlaces localizados em 16 países. As faixas frequências das medidas variam de 7 a $137 \mathrm{GHz}$, para enlaces com comprimento entre $500 \mathrm{~m}$ e $58 \mathrm{~km}$.

Entre as 89 estatísticas da Tabela C1_1 do banco de dados experimentais da UIT-R, 36 com as informações de latitude e longitude das estações transmissora e receptora foram utilizados para o ajuste dos modelos semi-empíricos. A partir das coordenadas das estações foi possível calcular o azimute do enlace para o lado da estação receptora, na qual as medições de taxa de precipitação foram efetuadas.

As 36 estatísticas de atenuação por chuvas e taxa de precipitação do DBSG3 representam aproximadamente 76 ano-estações, correspondente a 25 radioenlaces entre 34 estações, localizadas em 7 países. As características das estatísticas selecionadas são apresentadas na Tabela 6 . 
Tabela 6 - Característica dos enlaces DBSG3 ITU-R.

\begin{tabular}{|c|c|c|c|c|c|c|c|c|}
\hline $\begin{array}{c}\text { Local } \\
\mathbf{N}^{\circ}\end{array}$ & Estação Tx & Estação Rx & \begin{tabular}{c|}
$\mathbf{d}$ \\
{$[\mathrm{km}]$}
\end{tabular} & \begin{tabular}{|c|} 
Azimute \\
{$\left[{ }^{\circ}\right]$}
\end{tabular} & $\begin{array}{c}\mathbf{f} \\
{[\mathrm{GHz}]}\end{array}$ & Pol. & $\begin{array}{l}\text { Data } \\
\text { Início }\end{array}$ & $\begin{array}{l}\text { Data } \\
\text { Fim }\end{array}$ \\
\hline 8001 & Y & IESTCUVI & 15,30 & 75,04 & 14,92 & $\mathrm{H}$ & 01/01/1988 & 31/12/1992 \\
\hline 8002 & MOs & $\begin{array}{c}\text { KAMZIK - } \\
\text { BRATISLAVA }\end{array}$ & 43,80 & 98,28 & 13,14 & V & 01/04/1988 & 30/11/1992 \\
\hline 8003 & SEK & $\mathrm{E}$ & 39,40 & 205,03 & 13,03 & V & 01/01/1989 & 31/12/1993 \\
\hline 8004 & STRAHOV & CHLOUMEK & 34,00 & 198,14 & 13,19 & $\mathrm{H}$ & 01/01/1983 & $31 / 12 / 1987$ \\
\hline 8004 & STR & $\mathrm{K}$ & 34,00 & 198,14 & 13,10 & V & $01 / 01 / 1983$ & $31 / 12 / 1987$ \\
\hline 8005 & PIASECZNO & MIEDZESZYN & 15,40 & 224,55 & 11,50 & $\mathrm{H}$ & 01/01/1989 & $31 / 12 / 1993$ \\
\hline 8006 & PIASECZNO & MIEDZ & 15,40 & 224,55 & 18,60 & $\mathrm{H}$ & 01/01/1989 & $31 / 12 / 1993$ \\
\hline 8007 & DUBNA 3 & DUF & 12,65 & 237,00 & 29,30 & $\mathrm{~V}$ & 01/01/1986 & $31 / 12 / 1990$ \\
\hline 8008 & DUBNA 3 & DUB] & 12,65 & 237,00 & 19,30 & $\mathrm{~V}$ & 01/04/1983 & $31 / 12 / 1990$ \\
\hline 8009 & DU & DUI & 12,65 & 237,00 & 11,50 & V & $01 / 04 / 1983$ & $31 / 12 / 1990$ \\
\hline 8013 & BRA & R. DO & 12,79 & 259,98 & 14,55 & $\mathrm{~V}$ & 07/04/1994 & $31 / 0$ \\
\hline 8014 & BRADESCO II & R. DOS INGLESES & 12,79 & 259,98 & 14,55 & V & $04 / 09 / 1995$ & $31 / 08 / 1996$ \\
\hline 8015 & CENESP 15 & R. DOS INGLESES & 12,78 & 221,10 & 14,55 & $\mathrm{H}$ & 07/04/1994 & $31 / 03 / 1995$ \\
\hline 8016 & CENI & R. DOS INGL & 12,78 & 221,10 & 14,55 & $\mathrm{H}$ & $04 / c$ & 1996 \\
\hline 8017 & CENESP 18 & R. DOS INGLESES & 12,78 & 221,10 & 18,61 & $\mathrm{~V}$ & $07 / 04 / 1994$ & $31 / 03 / 1995$ \\
\hline 8018 & $x^{x}$ & R. DOS & 18,38 & 154,40 & 14,50 & V & $07 / 04 / 1994$ & $31 / 03 / 1995$ \\
\hline 8019 & S & SES & 18,38 & 154,40 & 14,50 & V & $04 / 09$ & 31/08/1996 \\
\hline 8020 & BARUERI & R. DOS INGLESES & 21,69 & 287,07 & 14,53 & $\mathrm{~V}$ & 07/04/1994 & $31 / 03 / 1995$ \\
\hline 8021 & SHELL & 萡 & 7,48 & 126,48 & 18,59 & $\mathrm{~V}$ & 04/09/1995 & $31 / 08 / 1996$ \\
\hline 8022 & PARANAPIACABA & R. DOS II & 42,99 & 124,27 & 14,52 & $\mathrm{H}$ & $07 / 04 / 1994$ & $31 / 03 / 1995$ \\
\hline 8023 & PARANAPIACABA & R. DOS INGLESES & 42,99 & 124,27 & 14,52 & $\mathrm{H}$ & 04/09/1995 & $31 / 08 / 1996$ \\
\hline 8024 & BRAS & $\mathrm{T}$ & 4,48 & 103,86 & 23,00 & V & $01 / 11 / 2003$ & $31 / 10 / 2004$ \\
\hline 8025 & $\begin{array}{c}\text { RIO DE JAN. - } \\
\text { SUMARE }\end{array}$ & RIO DE JAN.-PDC & 6,55 & 216,91 & 23,00 & V & 01/07/2003 & $30 / 06 / 2005$ \\
\hline 8026 & FUJITSU & & 1,40 & 107,04 & 32,60 & $\mathrm{H}$ & $01 / 01 / 2006$ & $31 / 12 / 2006$ \\
\hline 8027 & YOTSUYA & AA & 2,30 & 347,37 & 33,40 & V & 01/01/2003 & $31 / 12 / 2006$ \\
\hline 8028 & YOTSUYA & AOYAMA & 2,30 & 347,37 & 33,40 & $\mathrm{~V}$ & $01 / 01 / 2004$ & $31 / 12 / 2004$ \\
\hline 8029 & $\mathrm{Y}$ & 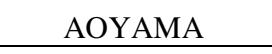 & 2,30 & 347,37 & 33,40 & V & $01 / 01 / 2005$ & $31 / 12 / 2005$ \\
\hline 8030 & AKASAKA & AOYAMA & 2,10 & 180,04 & 32,60 & $\mathrm{~V}$ & $01 / 01 / 2003$ & $31 / 12 / 2003$ \\
\hline 8031 & ANASARA & AOYAMA & 2,10 & 180,04 & 32,60 & V & 01/01/2004 & $31 / 12 / 2004$ \\
\hline 8032 & KASAKA & A & 2,10 & 180,04 & 32,60 & V & $01 / 01 / 2005$ & $31 / 12 / 2005$ \\
\hline 8033 & KOENJI & NAKANO & 1,20 & 219,13 & 23,20 & V & $01 / 04 / 2000$ & $31 / 03 / 2001$ \\
\hline 8034 & KOENJI & NAKANO & 1,20 & 219,13 & 23,20 & V & $01 / 04 / 2000$ & $31 / 03 / 2001$ \\
\hline 8035 & KARA & 0 & 9,10 & 163,59 & 15,25 & $\mathrm{~V}$ & $01 / 04 / 2000$ & $31 / 03 / 2001$ \\
\hline 8036 & KARAGASAKI & NAKANO & 9,10 & 59 & 15,25 & V & $01 / 04 / 2000$ & $31 / 03 / 2002$ \\
\hline 8037 & KARAGASAKI & NAK & 9,10 & 163,59 & 15,25 & V & $01 / 04 / 2001$ & $31 / 03 / 2003$ \\
\hline 8038 & SHIYAKUSYO & YRP & 6,37 & 355,49 & 18,58 & V & $01 / 04 / 2004$ & $31 / 12 / 2004$ \\
\hline
\end{tabular}




\section{3.}

\section{Banco de Dados Meteorológicos ECMWF}

Os dados meteorológicos da reanalise ERA-40 cobrem o período de setembro de 1957 a agosto de 2002, sobrepondo os dados da reanalise ERA-15 (1979 a 1993). Os dados da reanalise ERA-Interim cobrem o período de 1979 até os dias atuais, e são disponibilizados em tempo quase real nos servidores da ECMWF.

Os arquivos são mantidos usando o formato de grade binária de representação (FM 92-IX Ext. GRIB). Todos os campos de dados são globais, exceto para os dados do modelo de ondas no Mediterrâneo. Os dados são arquivados utilizando um número suficiente de bits para permitir que os valores pontuais tenham precisão consistente com os métodos de análise utilizados.

A codificação em grade binária (GRIB) é uma padronização adotada pela Organização Mundial de Meteorologia (OMM) para o arquivamento e transmissão de dados meteorológicos. Um arquivo GRIB é formado por uma sequência de bits agrupados em octetos e organizados em seis seções. As seis seções são divididas em:

(0) Seção de Indicação (IS);

(1) Seção de Definição do Produto (PDS);

(2) Seção de Descrição da Grade (GDS);

(3) Seção de Mapeamento dos Bits (BMS);

(4) Seção de Dados Binários (BDS);

(5) '7777' (caracteres ASCII).

A Seção de Indicação (IS) serve para sinalizar o inicio da mensagem GRIB, indicar o comprimento total da mensagem e o número da edição utilizada para codificar os dados (GRIB 2 para os dados ECMWF). A Seção de Indicação tem comprimento fixo de 8 octetos.

A Seção de Definição do Produto (PDS) contém indicadores da versão da tabela de parâmetros, do centro de origem, do modelo numérico utilizado para gerar os dados, a área geográfica dos dados, o fator de escala decimal e informações de data e hora. Os três primeiros octetos desta seção indicam o seu comprimento, que para os dados ECMWF é de 52 octetos. 
A Seção de Descrição da Grade (GDS) serve para definir a organização da grade de dados. Os 3 primeiros octetos desta seção indicam o seu comprimento, que para os dados em questão é de 32 octetos. Entre as informações estão o número de pontos ao longo de um círculo de latitude e o número de pontos ao longo de um meridiano (longitude), as latitudes e longitudes iniciais e finais, além da direção de incremento dos dados.

A Seção de Mapeamento dos Bits (BDS) é opcional e não é utilizada nos dados da ECMWF.

A Seção de Dados Binários (BDS) contém os dados em si e as informações necessárias para decodificá-los em 11 octetos, localizados no início da seção. A Seção é ajustada para conter um número par de octetos, sendo adicionados 8 bits iguais a zero no final da seção, quando necessário. Os dados são codificados em 2 octetos para cada ponto da grade (16 bits). Para uma subgrade de $90^{\circ}$ x $90^{\circ}$, com resolução de $1,125^{\circ}$, cada seção de dados é formada por 13.134 octetos.

A sequência binária codificada em ASCII '7777' indica o fim da mensagem GRIB. Esta marca serve ainda para identificar se o download do arquivo foi completo.

Somados os octetos de cada seção, cada mensagem GRIB é composta por 13.230 octetos. Mais detalhes sobre a obtenção dos dados meteorológicos podem ser encontrados na referência [17].

O novo servidor de distribuição das análises do ECMWF permite obter subáreas de dados com várias resoluções em grades regulares de latitude e longitude. Apesar de algumas ferramentas serem disponibilizadas para a leitura dos dados, rotinas foram desenvolvidas e aperfeiçoadas para permitir maior flexibilidade na obtenção e tratamento dos dados meteorológicos.

Para obter os parâmetros de direção e velocidade do vento arquivos binários de dados meteorológicos da ECWMF foram obtidos conforme os períodos de inicio e fim dos dados experimentais do DBSG3. O globo terrestre foi subdividido em oito áreas, conforme indica a Figura 8, para facilitar o processamento em função do grande volume de dados. 


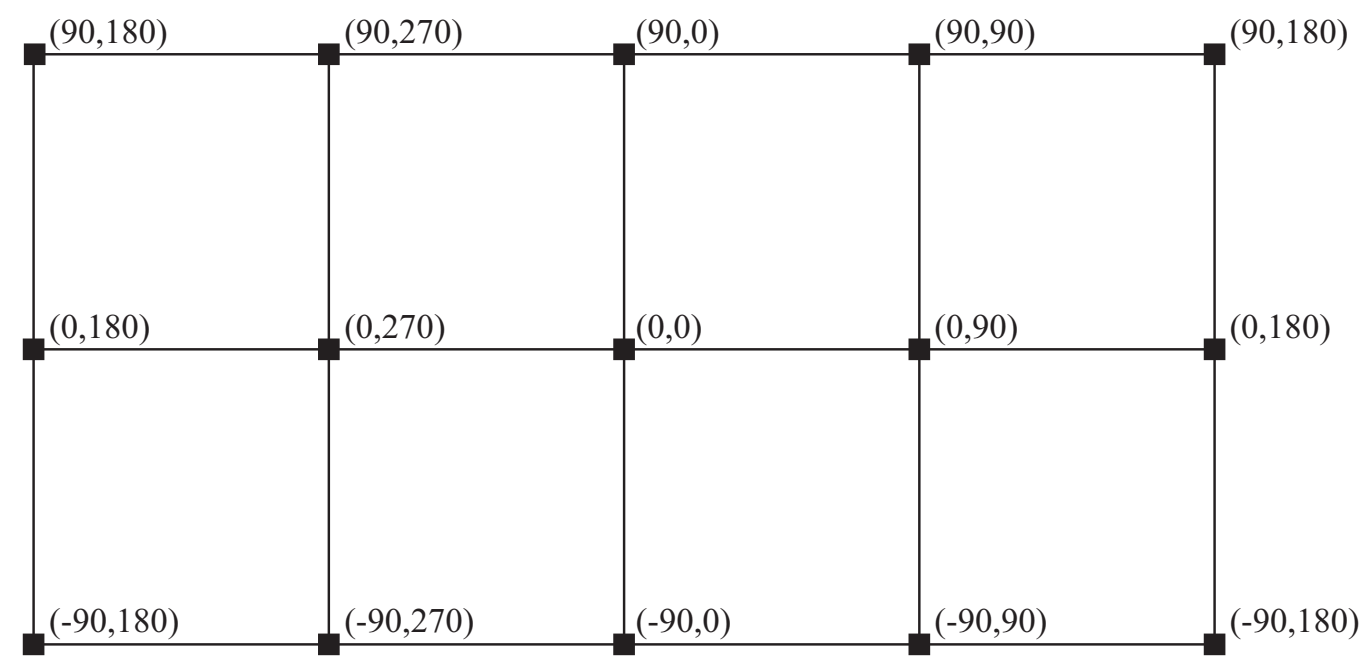

Figura 8 - Áreas de dados meteorológicos ECMWF.

Para cada área de interesse foram obtidos dois arquivos. Estes arquivos continham a componente $u$ (direção Leste) e a componente $v$ (direção Norte) da direção do vento a $10 \mathrm{~m}$ da superfície e o acumulado em intervalos de 6 (ERA-40) ou 12 (ERA-Interim) horas da precipitação estratiforme e convectiva. Os arquivos consistem em matrizes de dados com resolução espacial de $1,125^{\circ}$ x $1,125^{\circ}$, resultando em uma grade de 81 x 81 pontos.

Os parâmetros meteorológicos foram obtidos através de interpolação bilinear dos quatro pontos mais próximos às coordenadas de latitude e longitude de interesse. A velocidade e direção do vento foram calculadas através das relações trigonométricas das componentes $u$ e $v$. A avaliação dos sinais das componentes $u$ e $v$ permite identificar a direção do vento em relação à direção Leste.

$$
\begin{gathered}
\text { vel. }[\mathrm{m} / \mathrm{s}]=\sqrt{u^{2}+v^{2}} \\
\theta=\tan ^{-1}\left(\frac{v}{u}\right)
\end{gathered}
$$

A validação da rotina desenvolvida foi realizada por meio de comparação gráfica com os parâmetros $M_{T}$ e $\beta$ do banco de dados da Recomendação ITU-R P.837-6. O objetivo do teste era avaliar a ordem de grandeza das variáveis meteorológicas obtidas, quando comparadas aos dados da Recomendação. 


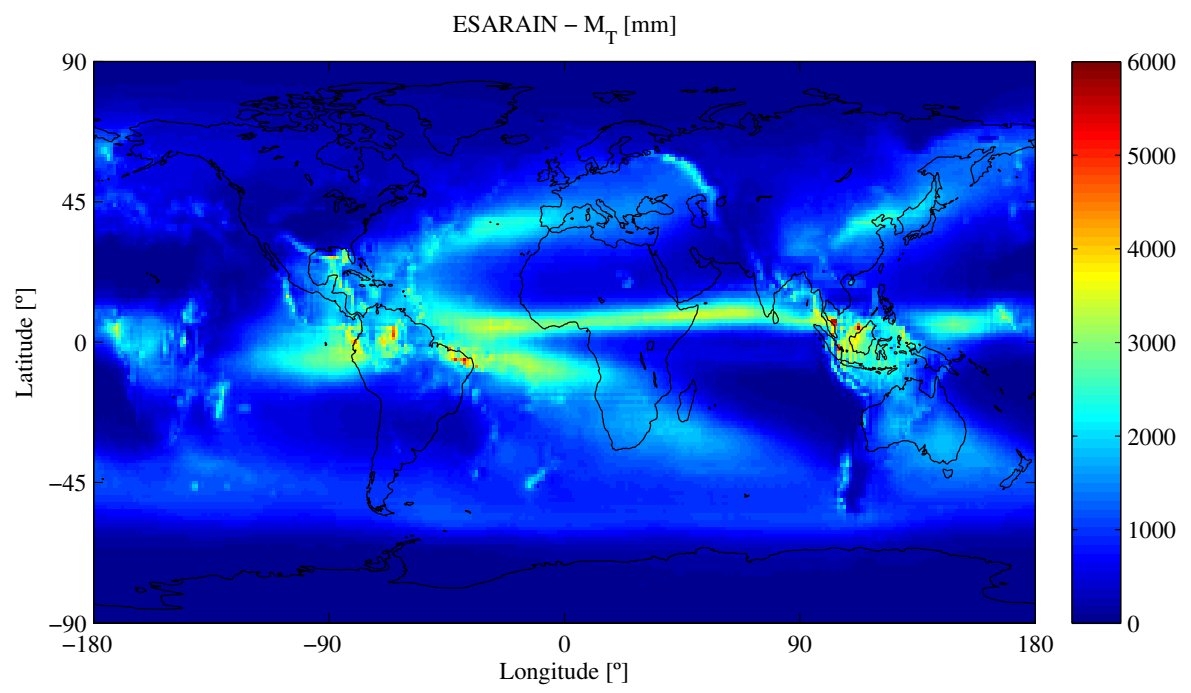

Figura 9 - Chuva média acumulada em um ano $\mathrm{M}_{\mathrm{T}}[\mathrm{mm}]$ - banco de dados Recomendação ITU-R P.837-6.

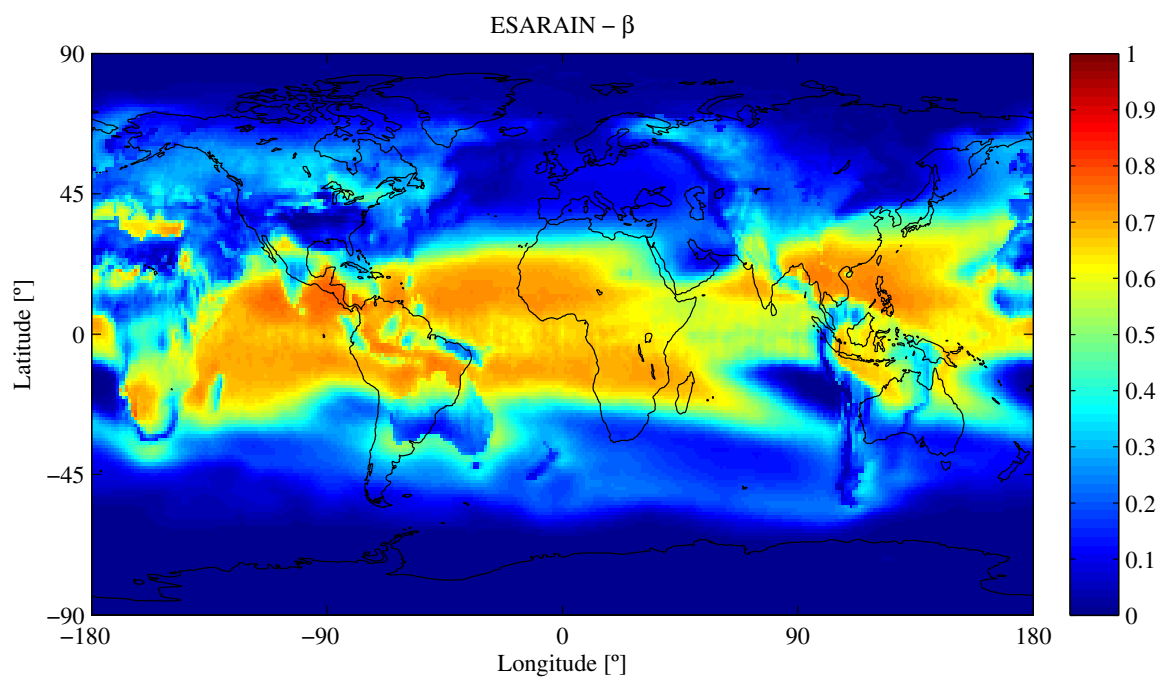

Figura 10 - Razão entre a chuva convectiva e total, parâmetro $\beta$ - banco de dados Recomendação ITU-R P.837-6. 


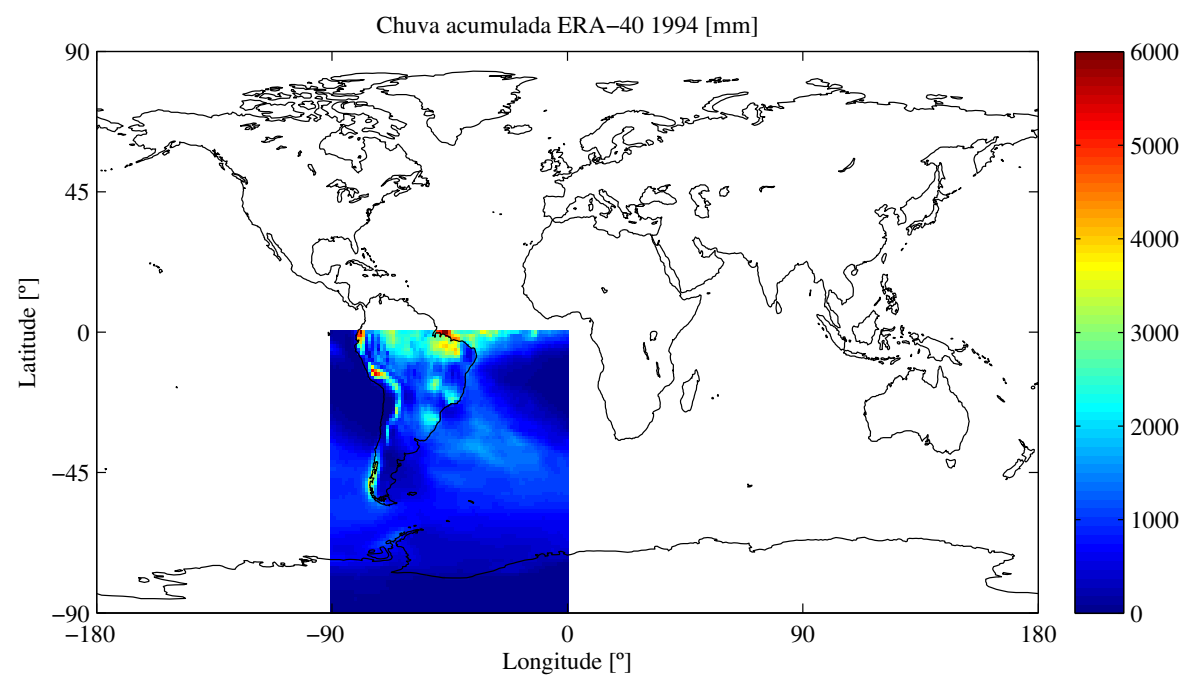

Figura 11 - Chuva acumulada no ano de 1994 - banco de dados ERA-40 (subárea dados Brasil).

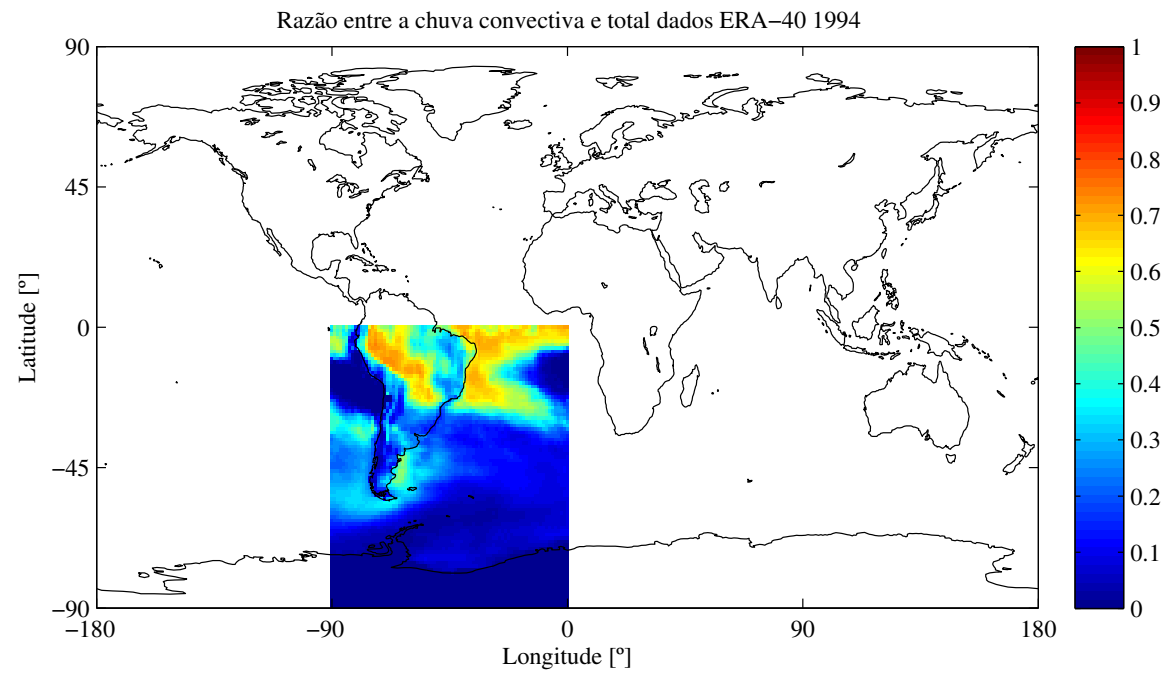

Figura 12 - Razão entre a chuva convectiva e total no ano de 1994 - banco de dados ERA-40 (subárea dados Brasil).

Para ilustrar os parâmetros meteorológicos obtidos, as figuras a seguir apresentam os dados para as coordenadas da estação RIS, em São Paulo, para o ano de 1994. As figuras mostram o acumulado de precipitação estratiforme, convectiva e total (estratiforme + convectiva), a direção e velocidade do vento, com resolução de 6 horas referentes ao banco de dados ERA-40 (1460 valores para um período de 1 ano). 


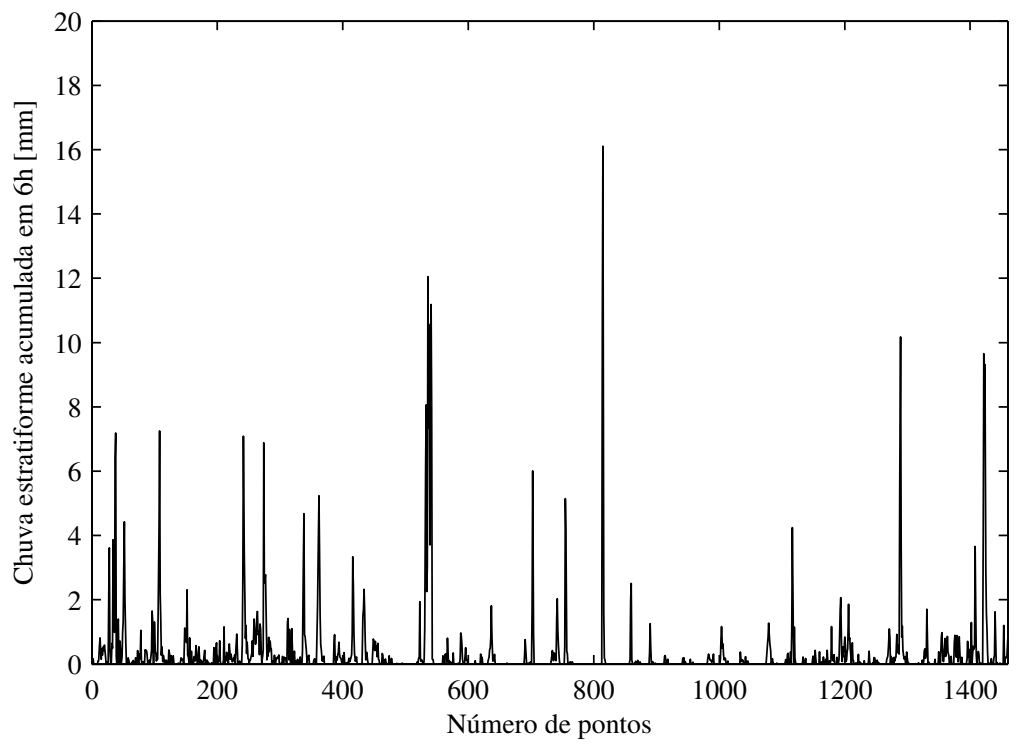

Figura 13 - Chuva estratiforme acumulada em intervalos de 6 horas ano 1994 estação RIS.

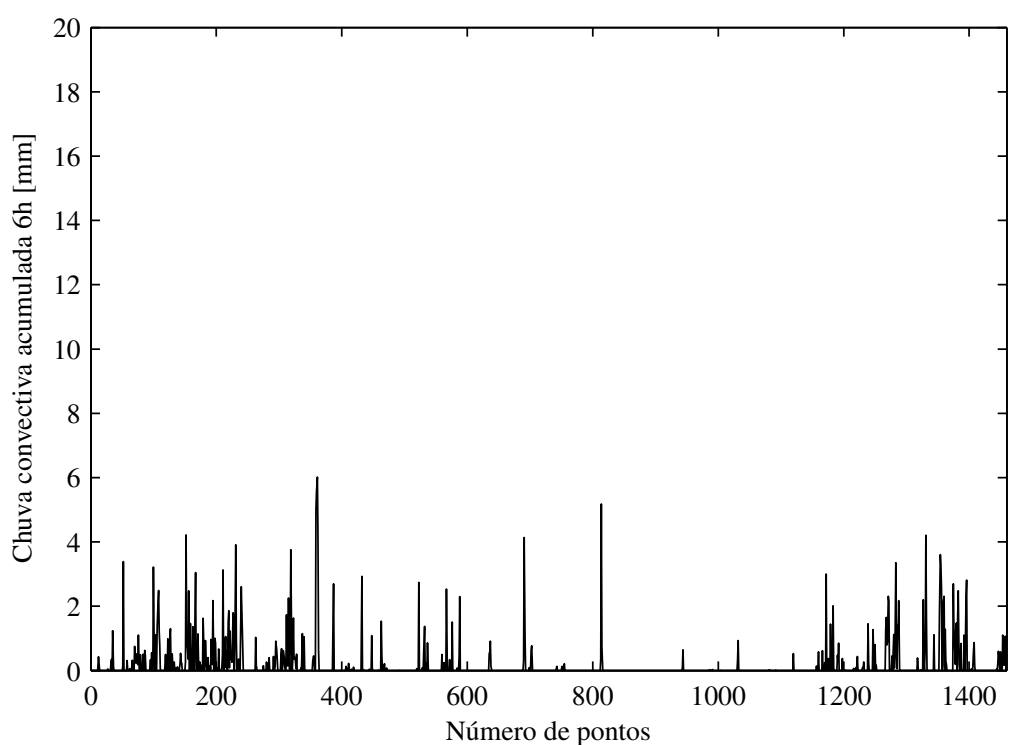

Figura 14 - Chuva convectiva acumulada em intervalos de 6 horas ano 1994 estação RIS. 


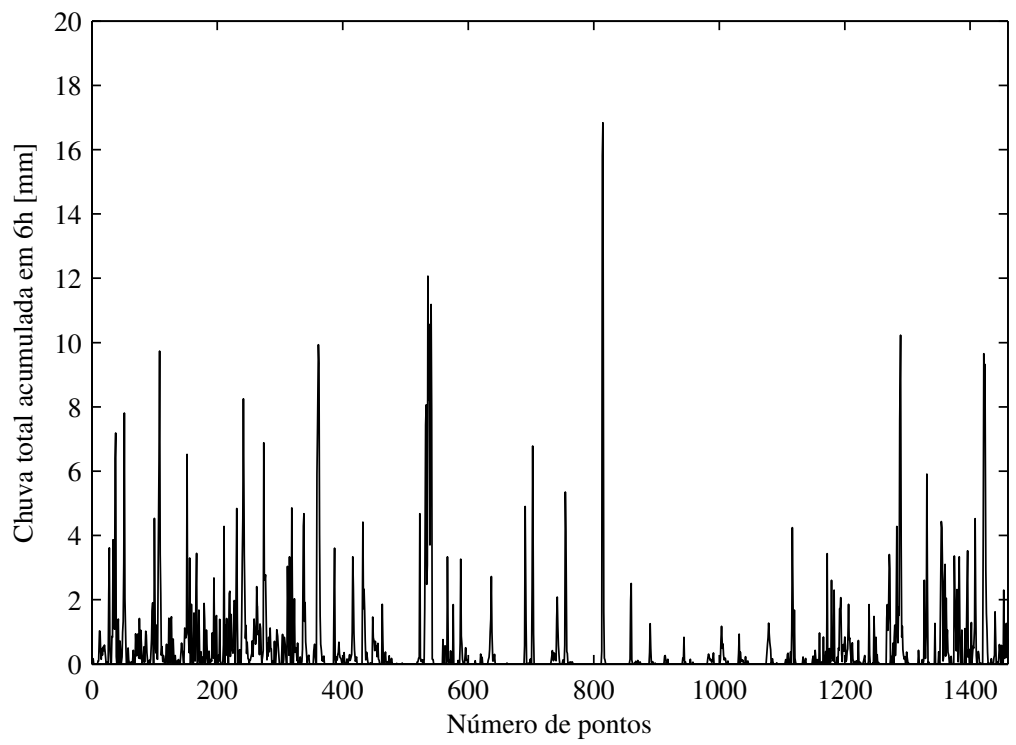

Figura 15 - Chuva total acumulada em intervalos de 6 horas ano 1994 estação RIS.

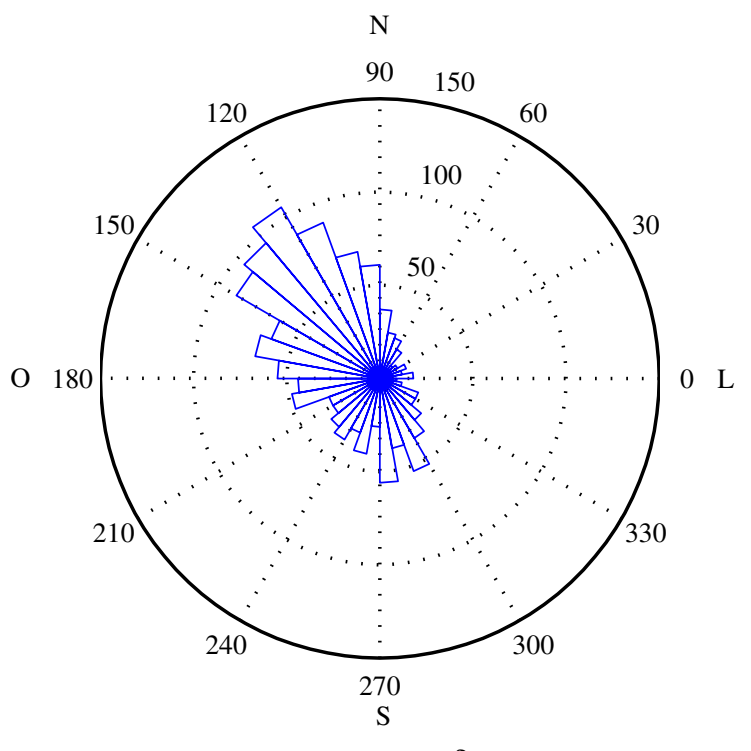

Direção do vento $\delta\left[^{\circ}\right]$

Figura 16 - Direção média do vento em relação ao Leste em intervalos de 6 horas ano 1994 estação RIS. 


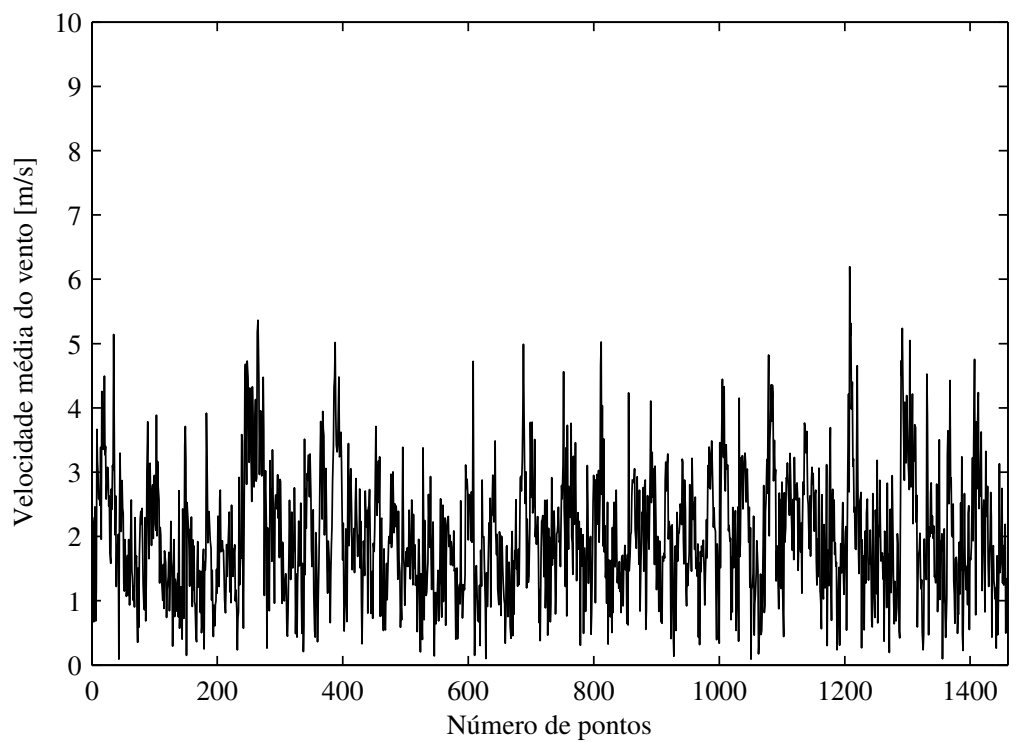

Figura 17 - Velocidade média do vento em intervalos de 6 horas ano 1994 estação RIS.

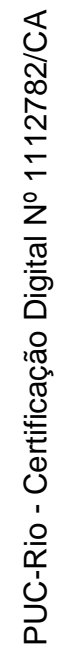




\section{4 \\ Desenvolvimento de Modelos para Previsão da Atenuação por Chuvas para Radioenlaces Terrestres}

Algumas publicações na literatura [14][15] têm discutido uma nova abordagem para a previsão da atenuação por chuvas, incluindo novos parâmetros meteorológicos na modelagem. Testes foram realizados utilizando a taxa efetiva de precipitação calculada a partir de dados de atenuação e taxa de precipitação pontual obtidas de medidas realizadas em radioenlaces convergentes no Brasil. Os resultados e expressões semi-empíricas obtidos demonstram que a direção principal do vento em relação ao enlace é um parâmetro de modelagem promissor.

Para ampliar o estudo sobre a influência da direção principal e velocidade do vento, dados do banco de dados do UIT-R são considerados na modelagem. Desta forma, os modelos obtidos no trabalho permitem aplicação global.

No capítulo, são apresentados os modelos desenvolvidos, nos quais os parâmetros de direção são adicionados ao equacionamento dos modelos em conjunto aos parâmetros de taxa de precipitação e comprimento dos enlaces já considerados nos modelos atuais. Tentativas de modelagem foram efetuadas com o parâmetro velocidade do vento. Como não foram observadas melhorias significativas na precisão dos modelos, foi descartada a utilização deste parâmetro. Na seção 4.1 são apresentadas as expressões semi-empíricas obtidas para radioenlaces convergentes do Brasil e para o banco de dados da UIT-R. Na seção 4.2 são apresentadas as expressões do modelo estatisticamente consistente desenvolvido.

\section{1.} Modelos Semi-empíricos Empregando a Taxa de Precipitação Efetiva $\left(\mathbf{R}_{\text {eff }}\right)$

A taxa de precipitação efetiva $\left(R_{e f f}\right)$ é relacionada de forma simples com a atenuação por chuvas $(A)$. Esta relação também é dependente do comprimento $(d)$, frequência e polarização (parâmetros $k \mathrm{e} \alpha$ ) do enlace. 


$$
A=k\left(R_{e f f}\right)^{\alpha} d
$$

Empregando o parâmetro $R_{e f f}$, as contribuições da não homogeneidade espacial da chuva para a atenuação são representadas por uma extensão de precipitação homogênea com comprimento $d$ igual ao do enlace. A taxa de precipitação efetiva é um parâmetro de difícil obtenção a partir de medidas diretas, havendo a necessidade de utilização de pluviômetros espacialmente distribuídos. Radares meteorológicos são frequentemente utilizados para observar a distribuição espacial da precipitação em uma determinada área, mas os custos elevados limitam o emprego deste tipo de equipamento.

A $R_{\text {eff }}$ é obtida de forma indireta por meio dos valores da distribuição de atenuação e taxa de precipitação medidas para uma porcentagem $p$ do tempo, e dos parâmetros $k$ e $\alpha$ calculados conforme a Recomendação ITU-R P.838-3. A partir da equação (4.1), tem-se,

$$
R_{e f f}=\left(\frac{A_{p}}{k \cdot d}\right)^{1 / \alpha}
$$

\subsection{1. Modelos a partir de Dados Experimentais do Brasil}

Os dados experimentais de três estações localizadas em São Paulo, Brasília e Rio de Janeiro, apresentados no Capítulo 3, foram empregados na modelagem. Da primeira estação (São Paulo), foram utilizados dados de cinco enlaces em 15 GHz e dois enlaces em $18 \mathrm{GHz}$. Da segunda estação (Brasília), foram utilizados dados de três enlaces em $23 \mathrm{GHz}$ e quatro enlaces em $38 \mathrm{GHz}$. Da terceira estação (Rio de Janeiro), foram utilizados dados de dois enlaces em $15 \mathrm{GHz}$, um enlace em $18 \mathrm{GHz}$ e um enlace em $23 \mathrm{GHz}$.

A Figura 18 mostra a $R_{\text {eff }}$ calculada versus a $R$ medida para os cinco radioenlaces em $15 \mathrm{GHz}$ da região de São Paulo. Para este conjunto de dados, observa-se que, para valores elevados de $R$, a taxa de precipitação efetiva tende a saturar em valores que diminuem com o aumento do comprimento do enlace [15]. 


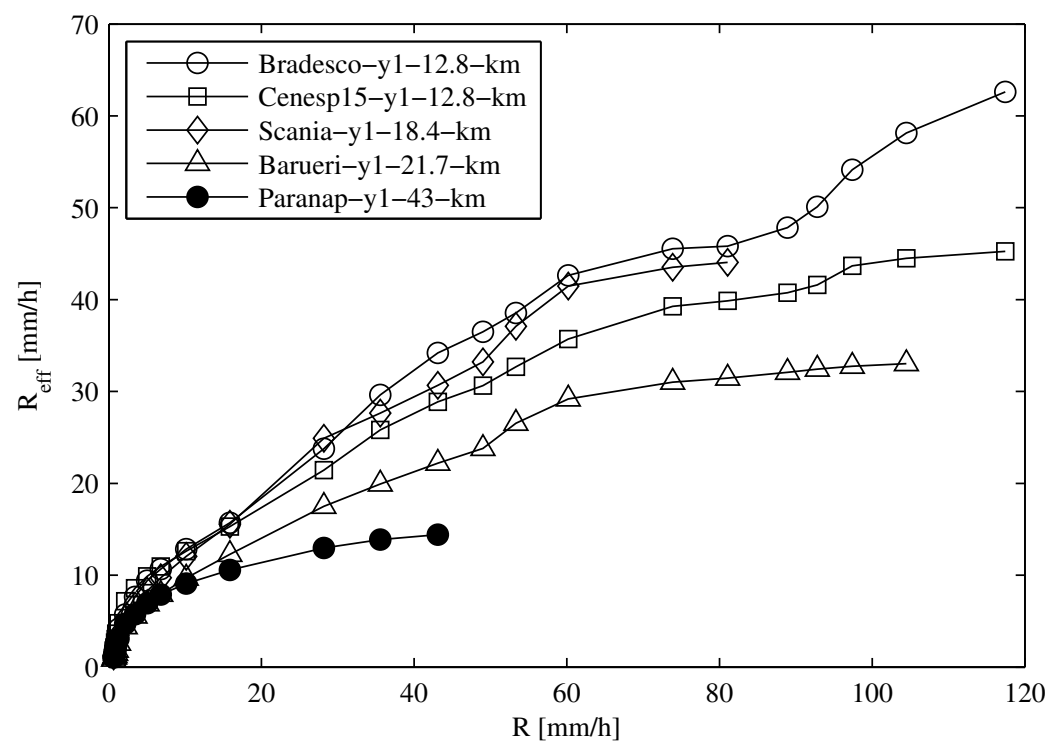

Figura 18 - Taxa de precipitação $(R)$ x Taxa de precipitação efetiva $\left(R_{\text {eff }}\right)$ dos enlaces em $15 \mathrm{GHz}$ de São Paulo.

Considerando esta característica, a expressão (4.3) foi utilizada para ajustar o modelo. Para pequenos valores de taxa de precipitação pontual, associadas a chuvas estratiformes, a taxa efetiva de precipitação e a taxa de precipitação pontual terão aproximadamente o mesmo valor. Para valores elevados de $R$, a expressão tende para o valor $R_{0}$ dependente do comprimento do enlace.

$$
R_{e f f}(p, d)=\frac{R(p) \cdot R_{0}(d)}{R(p)+R_{0}(d)}
$$

O melhor ajuste obtido para $R_{0}$, minimizando o erro médio quadrático, para dados experimentais do Brasil foi,

$$
R_{0}(d)=272 \exp (-0,069 d)
$$

O gráfico de dispersão dos valores de $R_{\text {eff }}$ medidos e calculados utilizando as expressões (4.3) e (4.4) é mostrado na Figura 19. Embora os valores apresentem bom ajuste em geral, para grandes valores de $R_{\text {eff }}$ há grande dispersão entre os valores previstos e calculados. 


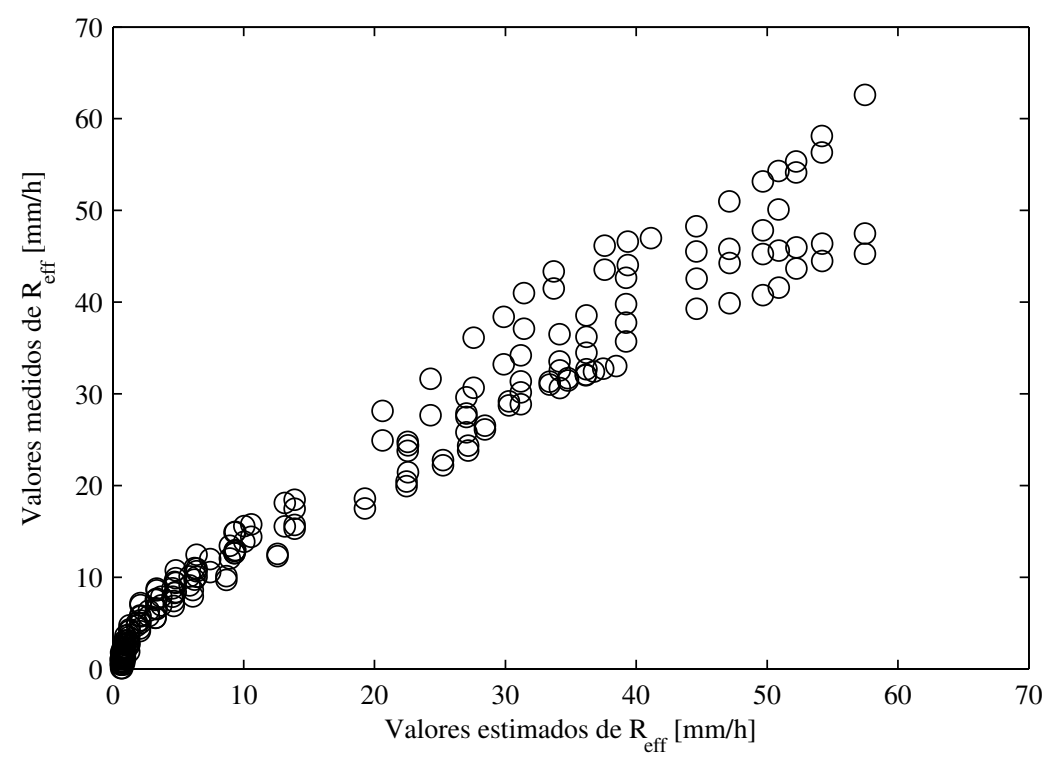

Figura 19 - Valores previstos versus observados de $R_{\text {eff }}(\mathrm{p}, \mathrm{d}) . \mathrm{R}^{2}=0,9283$.

Melhores resultados foram obtidos quando o ângulo $\theta$ entre a direção do enlace e a direção predominante do vento foi incluído no ajuste. A expressão (4.5) utilizada para o novo ajuste considera uma relação linear entre a direção principal do vento, expresso em radianos, e a taxa de precipitação efetiva.

$$
R_{\text {eff }}(p, d, \theta)=\frac{R(p) \cdot R_{0}(d)}{R(p)+R_{0}(d)} \cdot f(\theta)
$$

O melhor ajuste obtido minimizando o erro médio quadrático foi,

$$
\begin{gathered}
R_{0}(d)=210 \exp (-0,08 d) \\
f(\theta)=(1+0,29 \theta)
\end{gathered}
$$

O gráfico de dispersão dos valores de $R_{\text {eff }}$ derivado de medidas e calculados utilizando as expressões (4.5), (4.6) e (4.7) é mostrado na Figura 20. É possível observar a redução da dispersão dos valores estimados, indicado também através do coeficiente de determinação $\left(\mathrm{R}^{2}\right)$. Os resultados observados em trabalhos 
desenvolvidos com dados experimentais obtidos no Brasil motivaram a investigação da aplicabilidade destes parâmetros para um modelo global.

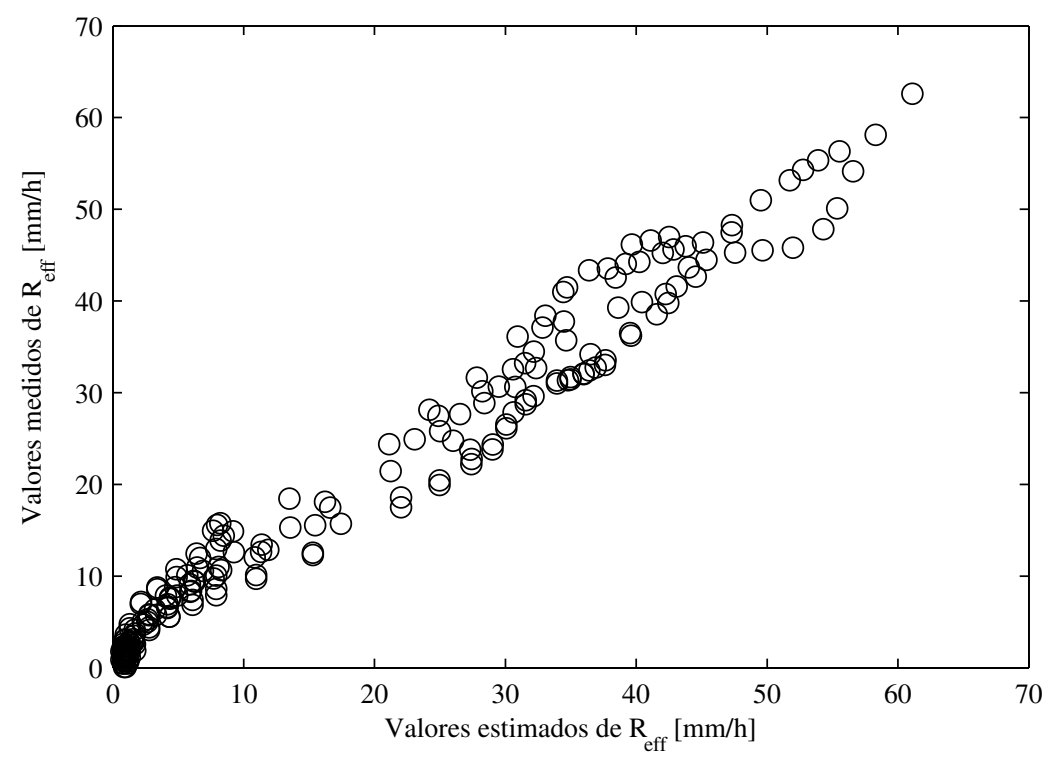

Figura 20 - Valores previstos versus observados de $R_{\text {eff }}(p, d, \theta) \cdot R^{2}=0,9609$

\subsection{2. Modelos a partir de Dados Experimentais do UIT-R}

As 36 estatísticas do banco de dados experimentais do UIT-R utilizados para o ajuste dos modelos foram apresentadas na Tabela 6. Os gráficos da taxa de precipitação efetiva em função da taxa de precipitação pontual e do comprimento do enlace para estes dados são apresentados na Figura 21 e na Figura 22. 


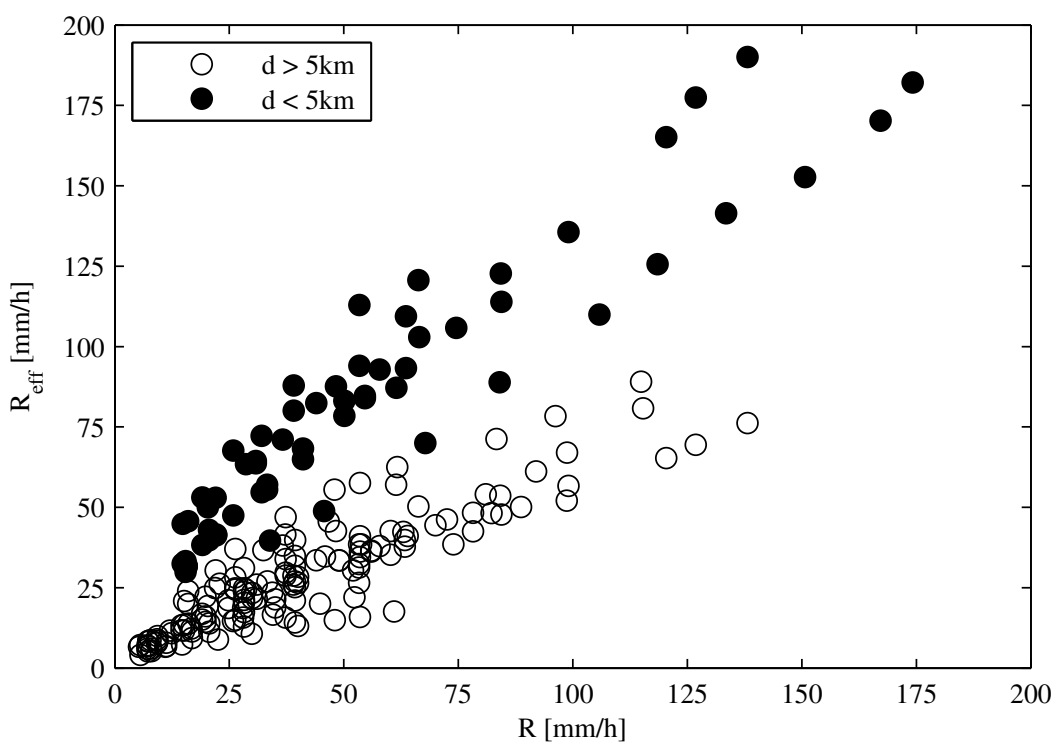

Figura 21 - Taxa de precipitação $(R)$ x Taxa de precipitação efetiva $\left(R_{\text {eff }}\right)$ dados UIT-R.

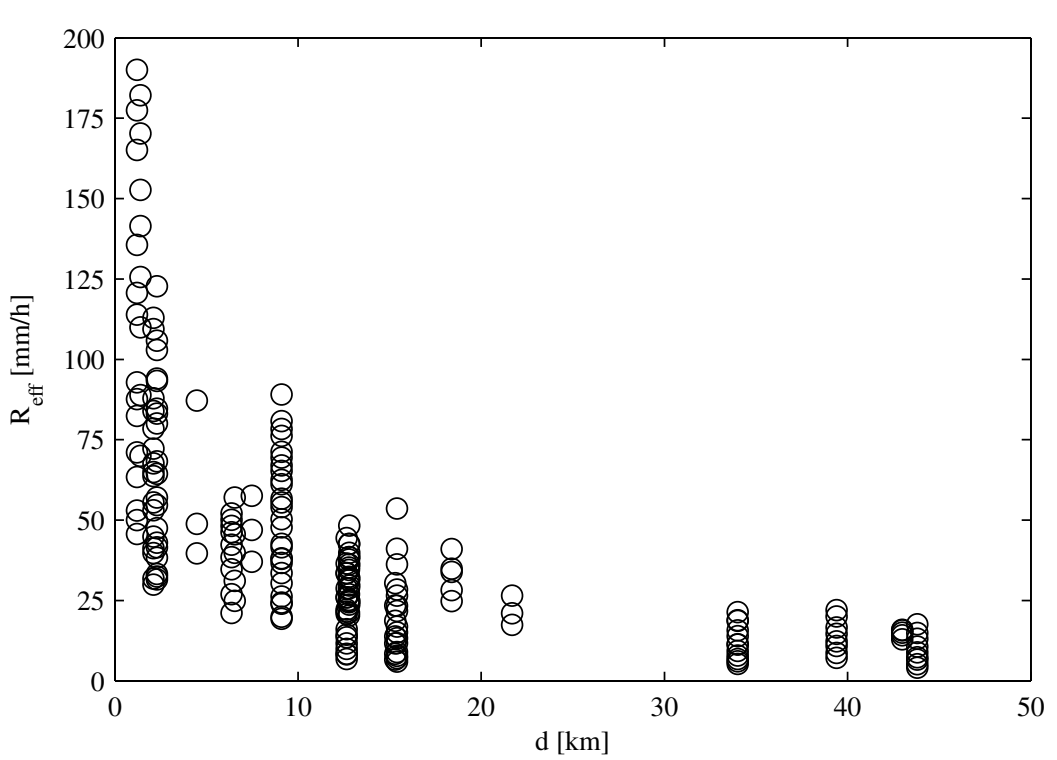

Figura 22 - Comprimento do enlace $(d)$ x Taxa de precipitação efetiva $\left(R_{\text {eff }}\right)$ dados UIT-R.

Na Figura 21, é possível observar que, para parte dos dados do UIT-R, não ocorre a saturação do valor da taxa efetiva como foi observado para os dados dos enlaces do Brasil. A distinção entre os dados de enlaces com distância inferiores a $5 \mathrm{~km}$ mostra que para enlaces curtos a taxa de precipitação efetiva calculada é maior do que a taxa de precipitação pontual medida. Esta característica é semelhante à observada em outras publicações na obtenção do fator de redução do comprimento do enlace, quando a distância efetiva é empregada nos modelos. 
Desta forma, a equação (4.3) não deve ser utilizada, pois a partir dela tem-se que o valor da taxa de precipitação efetiva será sempre menor ou igual a taxa de precipitação pontual.

O Modelo 1 foi obtido considerando $R_{\text {eff }}$ dependente da taxa de precipitação pontual para uma porcentagem $p$ do tempo $R_{p}$ e do comprimento do enlace $d$. Diversas expressões foram testadas, sendo a expressão (4.8) empregada para o ajuste.

$$
R_{e f f}\left(R_{p}, d\right)=a_{1} \cdot R_{p}^{a_{2}} \cdot d^{a_{3}}
$$

Os valores dos coeficientes foram obtidos através de métodos de regressão. Os métodos de Quase-Newton e Hooke-Jeeves implementados no software STATISTICA[23] foram utilizados no ajuste. A função a ser minimizada, em todos os ajustes efetuados no trabalho, foi o erro médio quadrático entre os valores medidos e previstos. Os valores dos coeficientes obtidos no ajuste são apresentados na Tabela 7.

Tabela 7 - Coeficientes do ajuste Modelo 1.

\begin{tabular}{|c|c|}
\hline Coeficientes & Valores \\
\hline $\mathrm{a}_{1}$ & 10,476 \\
\hline $\mathrm{a}_{2}$ & 0,579 \\
\hline $\mathrm{a}_{3}$ & $-0,405$ \\
\hline
\end{tabular}

Os gráficos de dispersão e histograma dos resíduos do ajuste da taxa de precipitação efetiva são apresentados na Figura 23 e na Figura 24. Os gráficos de dispersão e histograma dos resíduos da atenuação estimada e medida são apresentados na Figura 25 e na Figura 26, respectivamente. Observa-se que os erros máximos de previsão da atenuação são da ordem de 25 dB. 
4 Desenvolvimento de Modelos para Previsão da Atenuação por Chuvas para Radioenlaces Terrestres

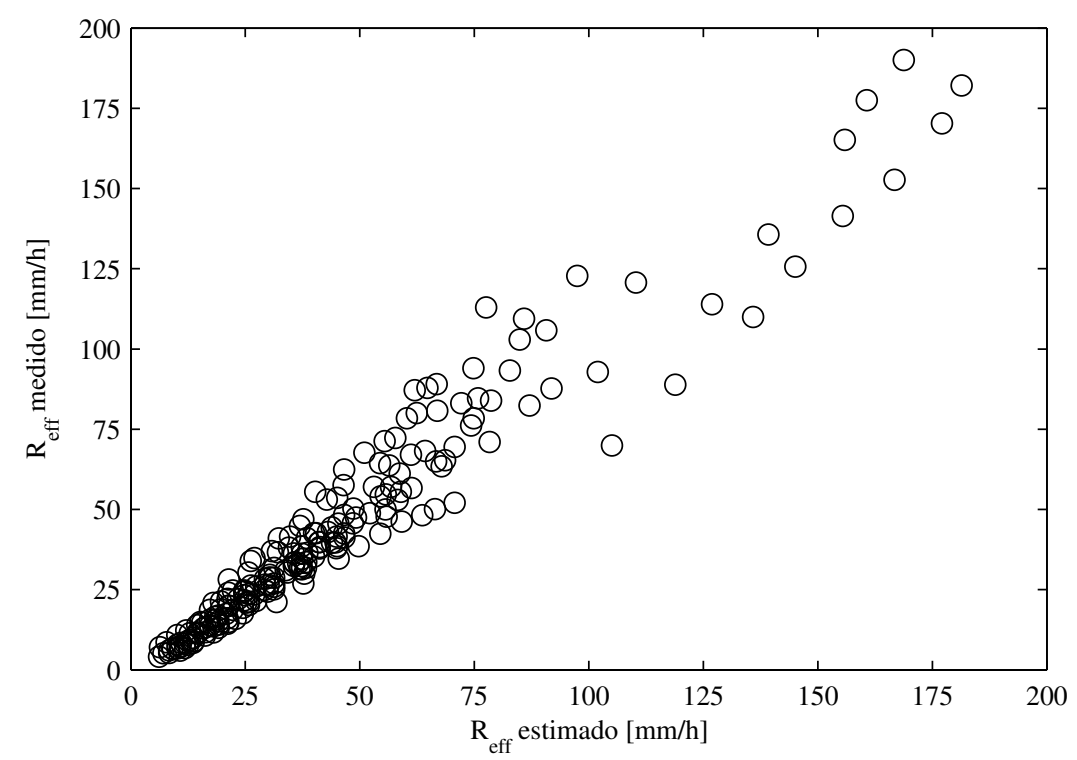

Figura 23 - Valores estimados versus medidos de $R_{\text {eff }}\left(R_{p}\right.$, d) Modelo $1 . \mathrm{R}^{2}=0,9387$

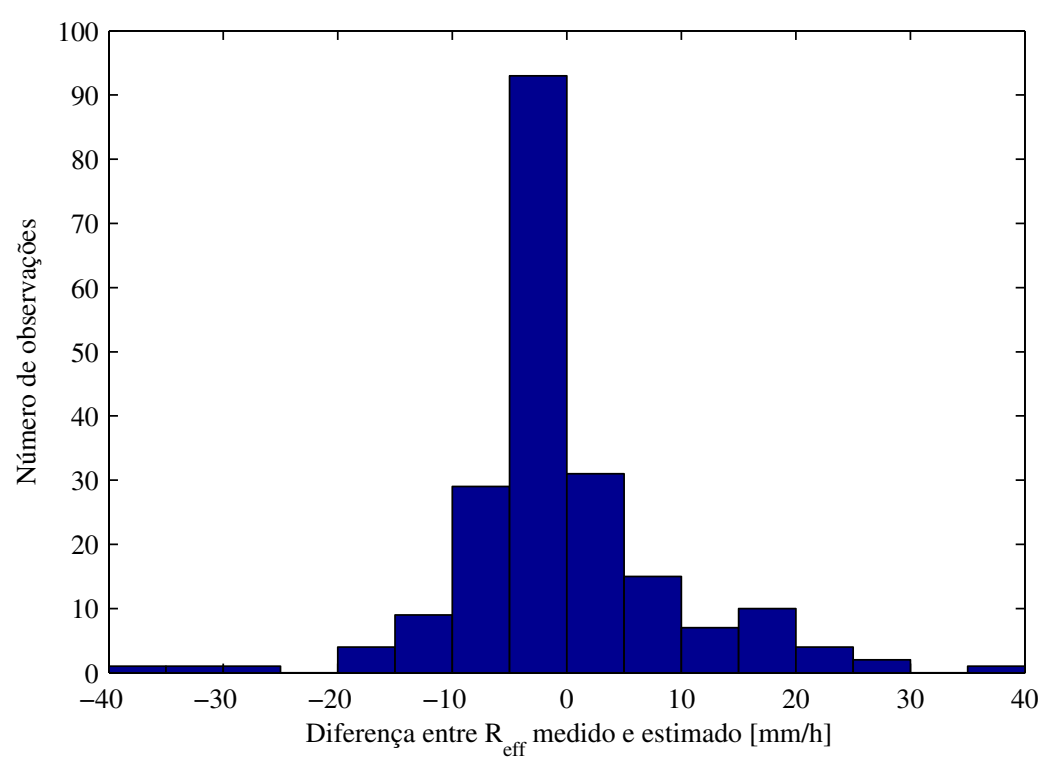

Figura 24 - Distribuição dos resíduos do ajuste do $R_{\text {eff }}\left(R_{p}, d\right)$ Modelo 1. 


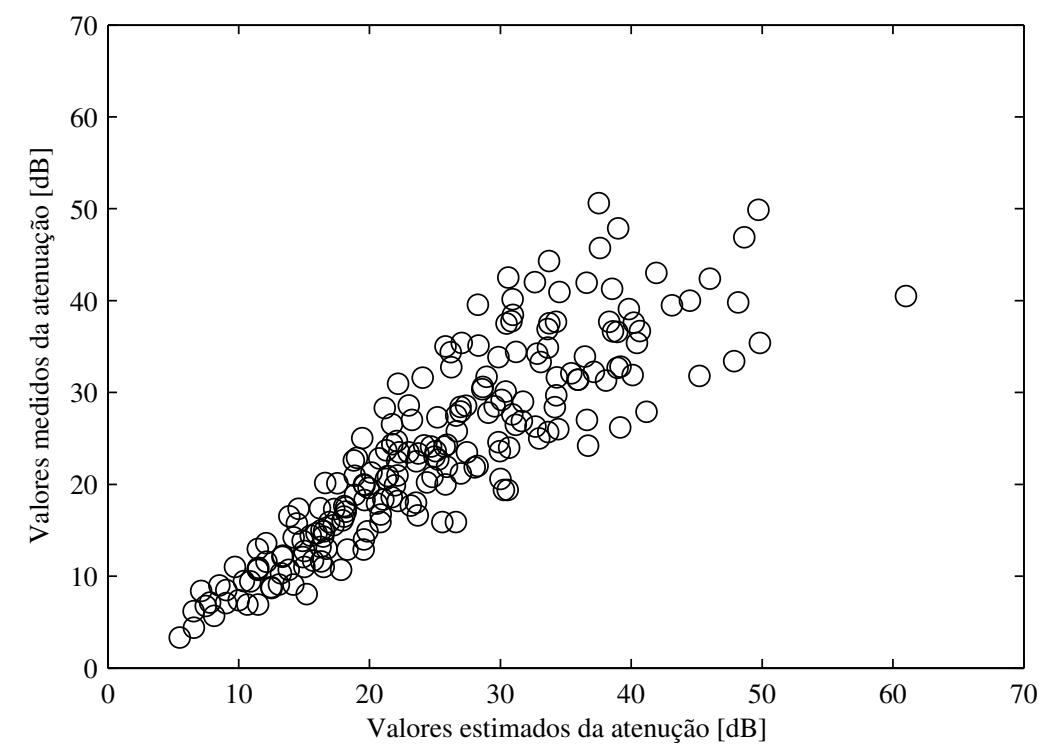

Figura 25 - Atenuação estimada Modelo 1 x atenuação medida dados UIT-R. $R^{2}=$ 0,7703 .

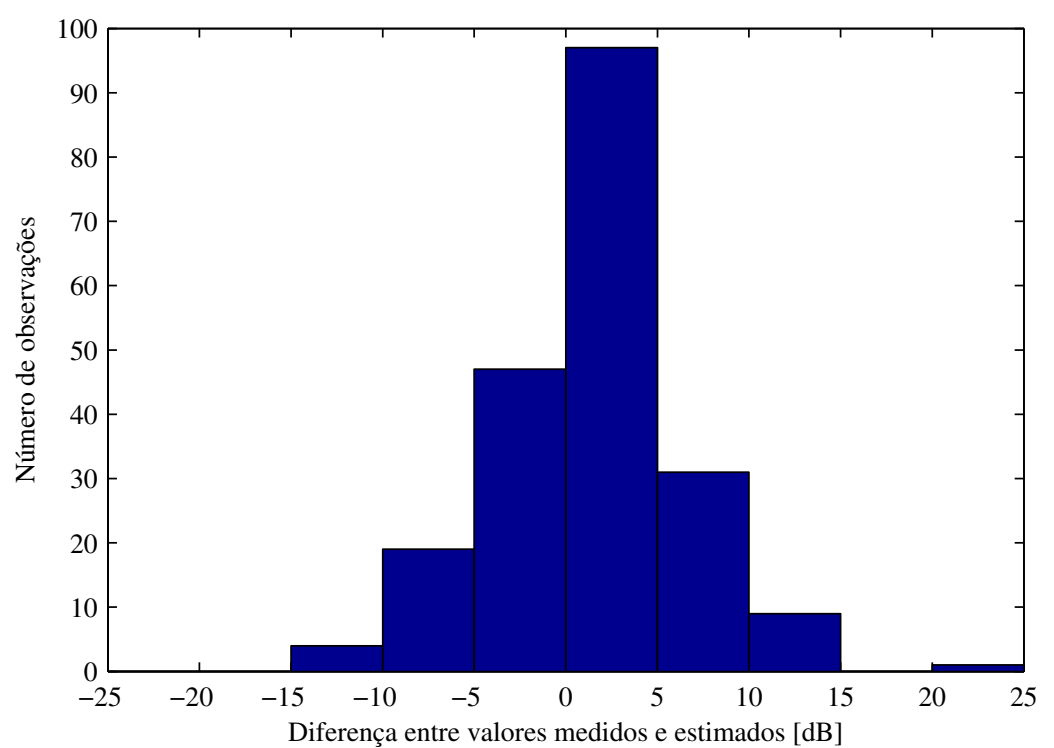

Figura 26 - Distribuição resíduos Modelo 1.

O Modelo 2 foi obtido considerando as variáveis ilustradas na Figura 27 para um radioenlace entre duas estações A e B. Os dados meteorológicos de direção e velocidade do vento foram processados para obter os parâmetros no período da execução dos experimentos do UIT-R. A média e a média ponderada dos parâmetros foram calculadas, sendo o valor da média ponderada da direção 
considerado nos ajustes, pois permite atribuir maior peso para as direções do vento que possuem maiores acumulados de precipitação.

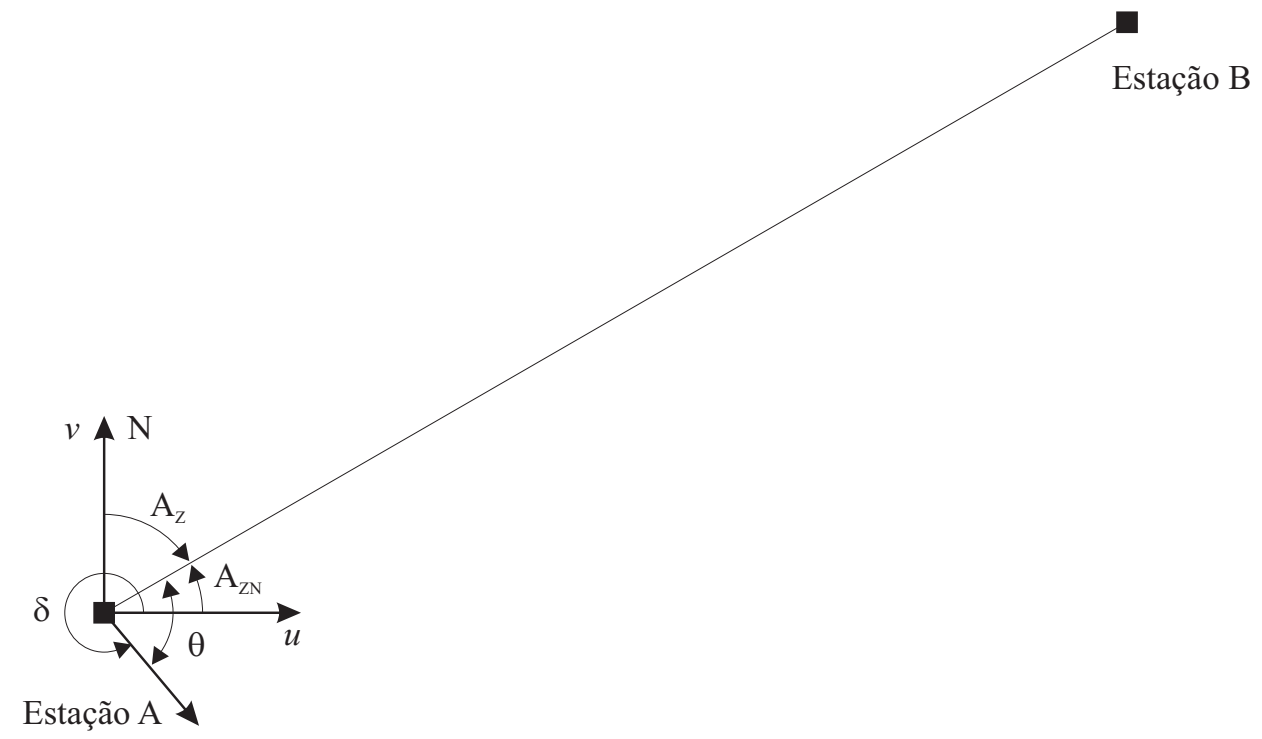

Figura 27 - Geometria e variáveis consideradas em um radioenlace entre as estações $A$ e B.

O ângulo $\theta$ representa a diferença em graus entre a direção do enlace representada pelo azimute $\left(A_{Z}\right)$ e a direção principal do vento em relação ao Leste $(\delta)$. O ângulo $\theta$ varia entre $\left[0^{\circ}, 90^{\circ}\right]$, uma vez que objetiva-se estimar o efeito da chuva deslocando-se ao longo do enlace, de forma perpendicular ou paralela ao mesmo, não havendo interesse no sentido do deslocamento da chuva.

A primeira etapa para obter $\theta$ consiste em calcular o azimute normalizado $A_{Z N}$ que representa o azimute referenciado ao eixo horizontal $u$ (direção Leste e rotação no sentido anti-horário). Este parâmetro assume valores entre $\left[0,360^{\circ}\right]$ sendo adicionados $360^{\circ}$ quando valores negativos são calculados.

$$
A_{\mathrm{ZN}}=90-A_{\mathrm{Z}}
$$

Na segunda etapa, a diferença absoluta entre $A_{Z N}$ e $\delta$ é calculada, para cada intervalo de tempo dos dados (6 ou 12 horas). Este parâmetro assume valores entre $\left[0,360^{\circ}\right]$. Os dados são então referenciados ao primeiro quadrante, e a média ponderada da direção do vento é determinada. O peso é atribuído através da chuva 
acumulada no intervalo de tempo, conforme resolução temporal dos dados meteorológicos.

$$
\theta=a b s\left(A_{Z N}-\delta\right)
$$

Foi observado que a direção do vento apresenta grande variação, mesmo nas ocorrências de maiores acumulados de precipitação. Apesar desta característica comum para os dados experimentais do UIT-R, a utilização do ângulo $\theta$ em radianos na modelagem de $R_{\text {eff }}$ resulta em redução da dispersão dos valores estimados em relação aos medidos.

Diversas expressões foram avaliadas, sendo a expressão (4.11) empregada para o ajuste. Os valores dos coeficientes obtidos no ajuste são apresentados na Tabela 8 .

$$
R_{\text {eff }}\left(R_{p}, d, \theta\right)=a_{1} \cdot R_{p}^{a 2} \cdot d^{\left(a_{3}+a_{4} / d\right)} \cdot\left(1+a_{5} \cdot \theta\right)
$$

Tabela 8 - Coeficientes do ajuste Modelo 2.

\begin{tabular}{|c|c|}
\hline Coeficientes & Valores \\
\hline $\mathrm{a}_{1}$ & 12,344 \\
\hline $\mathrm{a}_{2}$ & 0,642 \\
\hline $\mathrm{a}_{3}$ & $-0,369$ \\
\hline $\mathrm{a}_{4}$ & 0,870 \\
\hline $\mathrm{a}_{5}$ & $-0,637$ \\
\hline
\end{tabular}

Os gráficos de dispersão e histograma dos resíduos do ajuste da taxa de precipitação efetiva são apresentados na Figura 28 e na Figura 29. Os gráficos de dispersão e histograma dos resíduos da atenuação estimada e medida são apresentados na Figura 30 e na Figura 31, respectivamente. Observa-se que os erros máximos de previsão da atenuação também são da ordem de 25 dB. 
4 Desenvolvimento de Modelos para Previsão da Atenuação por Chuvas para Radioenlaces Terrestres

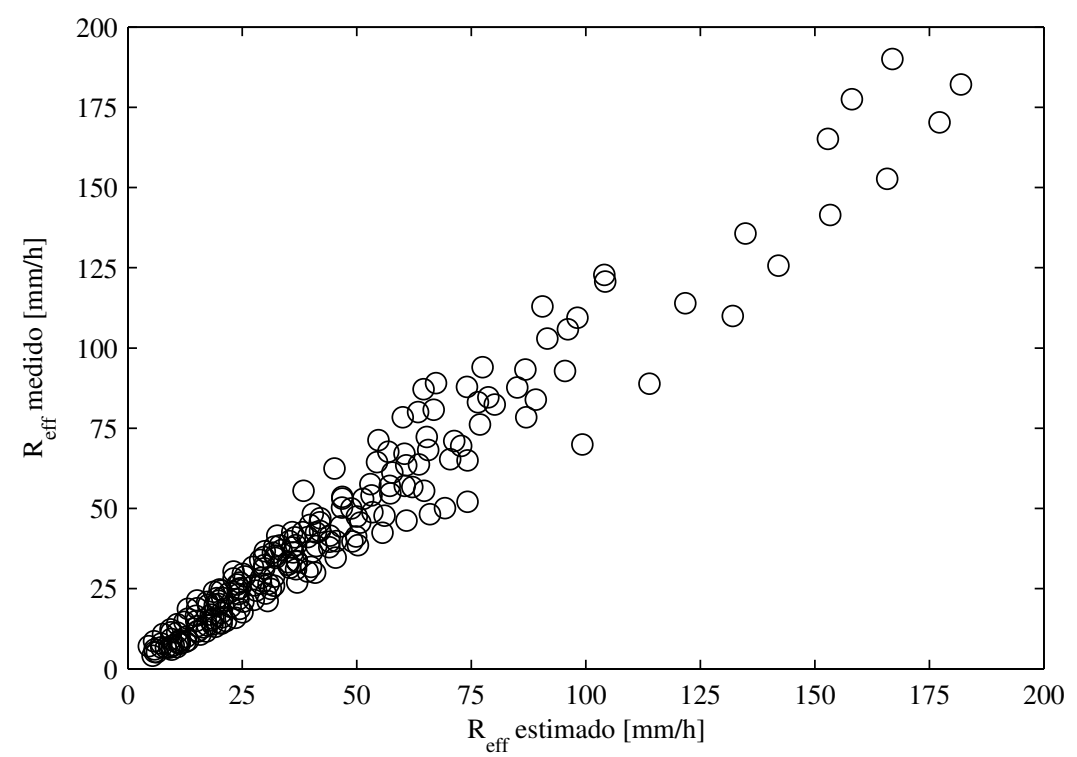

Figura 28 - Valores estimados versus medidos de $R_{\text {eff }}\left(R_{p}, d, \theta\right)$ Modelo $2 . \mathrm{R}^{2}=0,9427$.

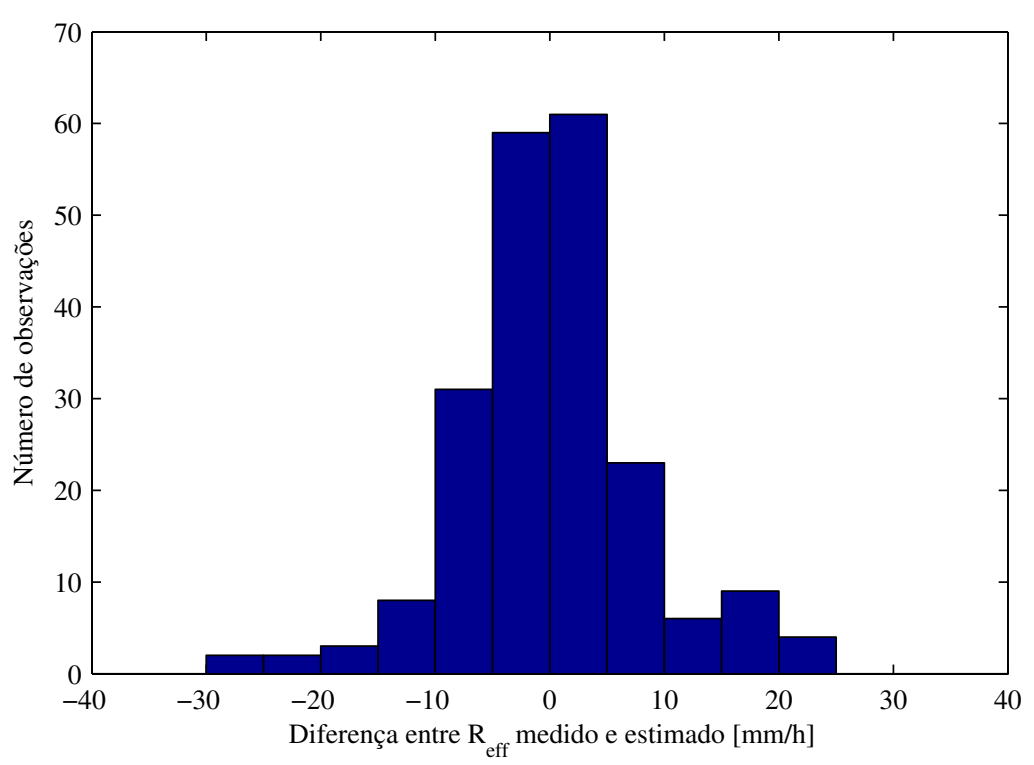

Figura 29 - Distribuição dos resíduos do ajuste do $R_{\text {eff }}\left(R_{p}, d\right)$ Modelo 2 . 


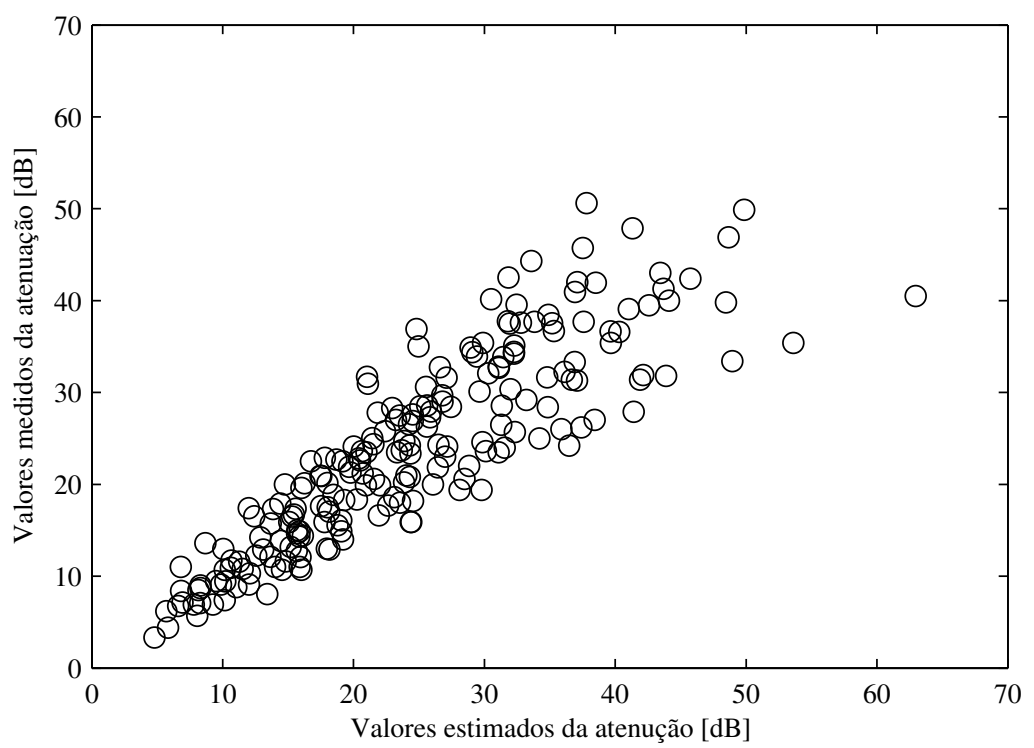

Figura 30 - Atenuação prevista Modelo 2 x atenuação medida dados UIT-R. $R^{2}=0,7719$.

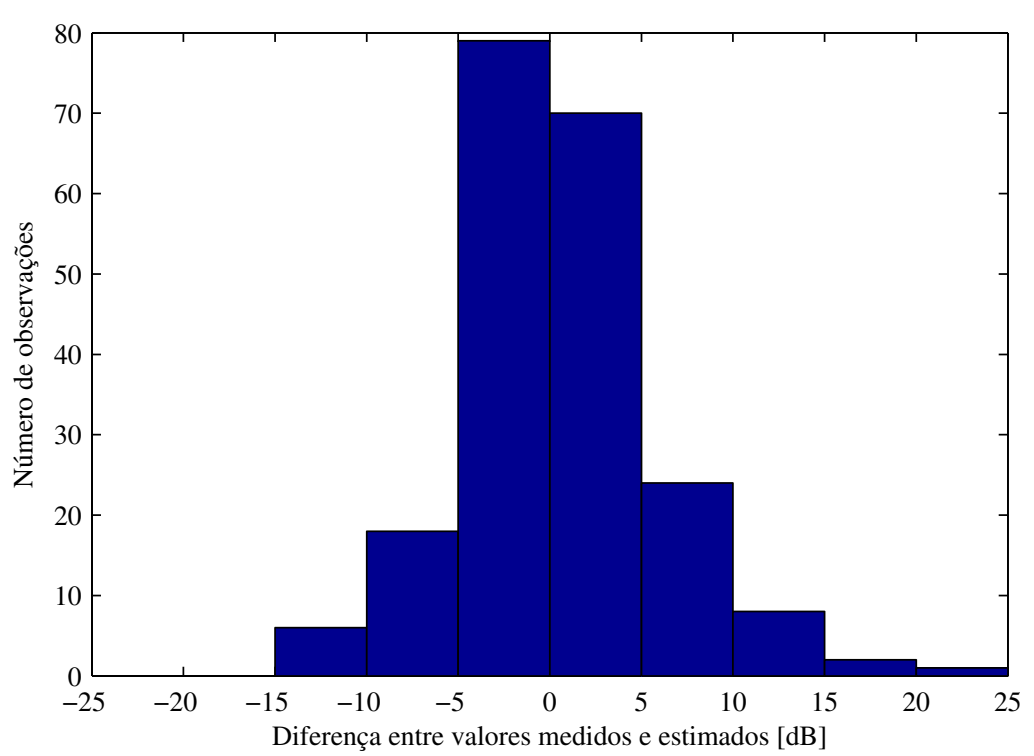

Figura 31 - Distribuição resíduos Modelo 2.

\subsection{3.}

\section{Comparação dos Modelos Semi-empíricos}

O procedimento de teste para comparação dos modelos de atenuação por chuvas está descrito na Recomendação ITU-R P.311-13 [18]. Os requisitos gerais 
para os modelos são, em ordem decrescente de importância, o melhor desempenho em relação à variável de teste, a base física do modelo e a sua simplicidade.

Para obter a variável de teste, deve-se inicialmente calcular para cada porcentagem de tempo $p$, a razão entre a atenuação prevista $\left(A_{p}\right)$ e medida $\left(A_{m}\right)$ em dB para cada enlace.

$$
S_{i}=\frac{A_{p, i}}{A_{m, i}}
$$

Em que $S_{i}$ é a razão calculada para o i-ésimo enlace.

A variável de teste é então calculada como o logaritmo natural da razão $S_{i}$. Para compensar os efeitos das contribuições de outras fontes de atenuação bem como imprecisões das medidas, que predominantemente afetam as pequenas atenuações, a variável de teste deve ser multiplicada por um fator de escala para atenuações medidas menores do que $10 \mathrm{~dB}$.

$$
\begin{array}{ll}
V_{i}=\ln S_{i} \cdot\left(\frac{A_{m, i}}{10}\right)^{0,2} & A_{m, i}<10 \mathrm{~dB} \\
V_{i}=\ln S_{i} & A_{m, i} \geq 10 \mathrm{~dB}
\end{array}
$$

Em seguida, são calculados a média $\left(\mu_{v}\right)$, o desvio padrão $\left(\sigma_{v}\right)$ e o valor r.m.s. $\left(\rho_{v}\right)$ da variável $V_{i}$ para cada porcentagem de tempo $p$. Os métodos que apresentarem os menores valores das variáveis estatísticas do erro de previsão indicam os modelos com melhor desempenho.

$$
\rho_{v}=\left(\mu_{v}^{2}+\sigma_{v}^{2}\right)
$$

Para comparação foram calculados os valores de atenuação dos três modelos apresentados no Capítulo 2 (ITU-R P.530-13, ITU-R P.530-14 e Documento 3M/208-E) e dos Modelos 1 e 2. Conforme recomendado pelo Grupo de Estudos 3 , só foram utilizados na comparação os valores de atenuação em que todos os dados de entrada dos modelos são válidos. 
As tabelas a seguir mostram a comparação entre os modelos. São apresentados o valor médio, o desvio padrão e o valor r.m.s. definidos pela variável de teste da Recomendação ITU-R P.311-13.

Tabela 9 - Erro médio variável ITU-R P.311-13 dos modelos semi-empíricos para a atenuação por chuvas em enlaces terrestres.

\begin{tabular}{|c|c|c|c|c|c|}
\hline $\mathbf{p}$ & Ap_530-13 & Ap_530-14 & Ap_3M/208-E & Modelo 1 & Modelo 2 \\
\hline 0,001 & $-0,0243$ & 0,0041 & $-0,1014$ & $-0,0241$ & 0,0025 \\
\hline 0,002 & $-0,1185$ & $-0,0215$ & $-0,1008$ & 0,0059 & 0,0038 \\
\hline 0,003 & $-0,1546$ & $-0,0713$ & $-0,0818$ & 0,0466 & 0,0534 \\
\hline 0,006 & $-0,2645$ & $-0,1711$ & $-0,1329$ & 0,0414 & 0,0124 \\
\hline 0,01 & $-0,3081$ & $-0,2044$ & $-0,1920$ & 0,0359 & 0,0024 \\
\hline 0,02 & $-0,3472$ & $-0,2458$ & $-0,2184$ & 0,0672 & 0,0088 \\
\hline 0,03 & $-0,3839$ & $-0,2728$ & $-0,2239$ & 0,0709 & 0,0150 \\
\hline 0,06 & $-0,4214$ & $-0,2957$ & $-0,2191$ & 0,1245 & 0,0539 \\
\hline 0,1 & $-0,4463$ & $-0,3124$ & $-0,2356$ & 0,1602 & 0,0716 \\
\hline
\end{tabular}

Tabela 10 - Desvio padrão variável ITU-R P.311-13 dos modelos semi-empíricos para atenuação por chuvas em enlaces terrestres.

\begin{tabular}{|c|c|c|c|c|c|}
\hline $\mathbf{p}$ & Ap_530-13 & Ap_530-14 & Ap_3M/208-E & Modelo 1 & Modelo 2 \\
\hline 0,001 & 0,3165 & 0,3221 & 0,2527 & 0,2398 & 0,2505 \\
\hline 0,002 & 0,2335 & 0,2544 & 0,2445 & 0,1949 & 0,2047 \\
\hline 0,003 & 0,2008 & 0,2274 & 0,2185 & 0,1708 & 0,1944 \\
\hline 0,006 & 0,1933 & 0,2091 & 0,2471 & 0,1773 & 0,2148 \\
\hline 0,01 & 0,2259 & 0,2209 & 0,2653 & 0,1804 & 0,2007 \\
\hline 0,02 & 0,2338 & 0,2121 & 0,2652 & 0,1754 & 0,1889 \\
\hline 0,03 & 0,2451 & 0,2389 & 0,2941 & 0,2020 & 0,2000 \\
\hline 0,06 & 0,2807 & 0,2535 & 0,2903 & 0,2051 & 0,2069 \\
\hline 0,1 & 0,3060 & 0,2622 & 0,2927 & 0,2141 & 0,2188 \\
\hline
\end{tabular}

Tabela 11 - Valor RMS da variável ITU-R P.311-13 dos modelos semi-empíricos para atenuação por chuvas em enlaces terrestres.

\begin{tabular}{|c|c|c|c|c|c|}
\hline $\mathbf{p}$ & Ap_530-13 & Ap_530-14 & Ap_3M/208-E & Modelo 1 & Modelo 2 \\
\hline 0,001 & 0,3174 & 0,3221 & 0,2723 & 0,2410 & 0,2505 \\
\hline 0,002 & 0,2619 & 0,2553 & 0,2645 & 0,1950 & 0,2047 \\
\hline 0,003 & 0,2534 & 0,2383 & 0,2333 & 0,1771 & 0,2016 \\
\hline 0,006 & 0,3275 & 0,2702 & 0,2806 & 0,1821 & 0,2152 \\
\hline 0,01 & 0,3820 & 0,3009 & 0,3275 & 0,1840 & 0,2007 \\
\hline 0,02 & 0,4186 & 0,3246 & 0,3436 & 0,1878 & 0,1891 \\
\hline 0,03 & 0,4554 & 0,3626 & 0,3696 & 0,2141 & 0,2006 \\
\hline 0,06 & 0,5063 & 0,3895 & 0,3637 & 0,2399 & 0,2138 \\
\hline 0,1 & 0,5411 & 0,4079 & 0,3758 & 0,2674 & 0,2302 \\
\hline
\end{tabular}




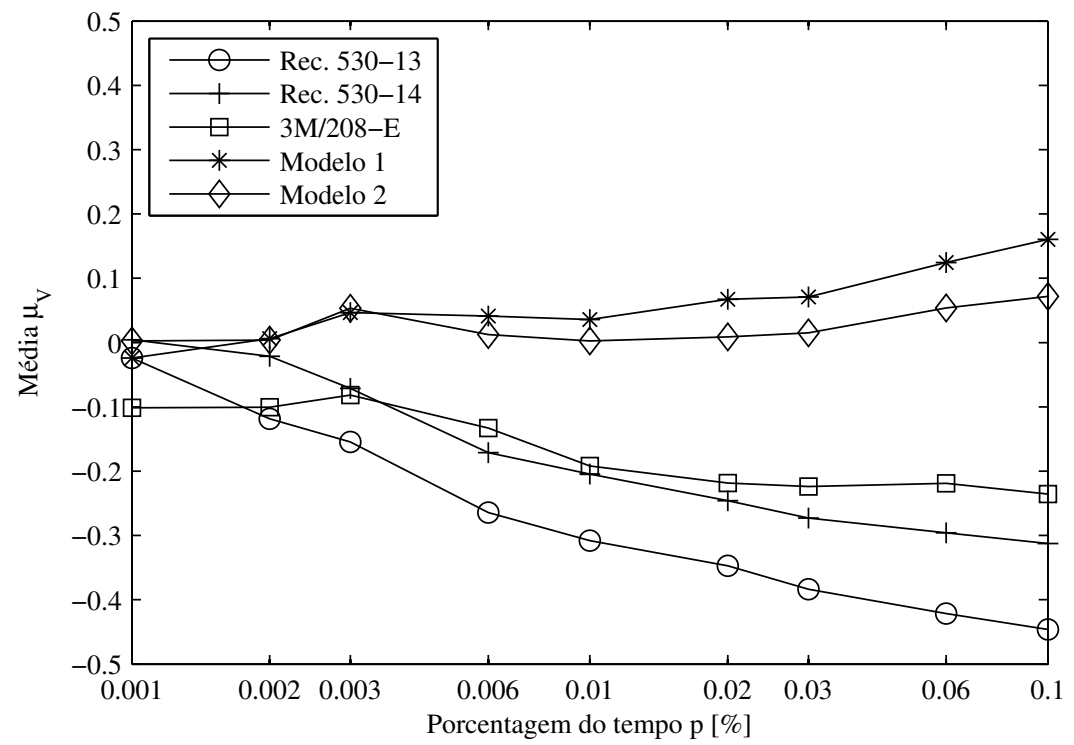

Figura 32 - Comparação valor médio da variável de teste ITU-R P.311-13.

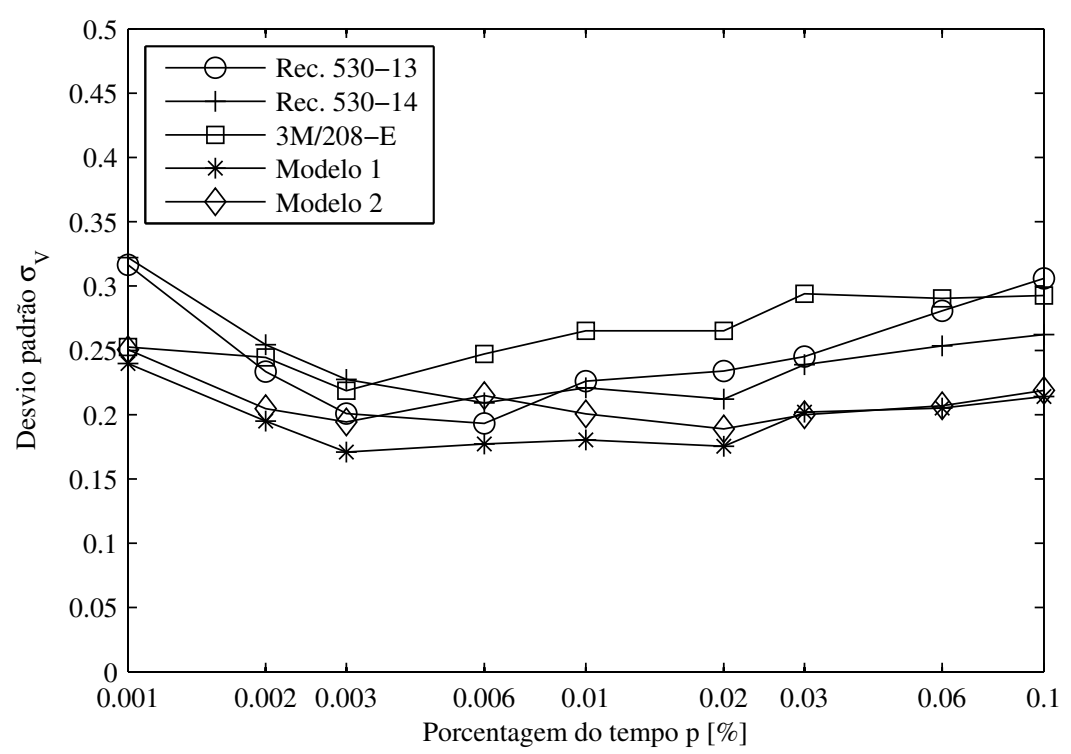

Figura 33 - Comparação desvio padrão da variável de teste ITU-R P.311-13. 


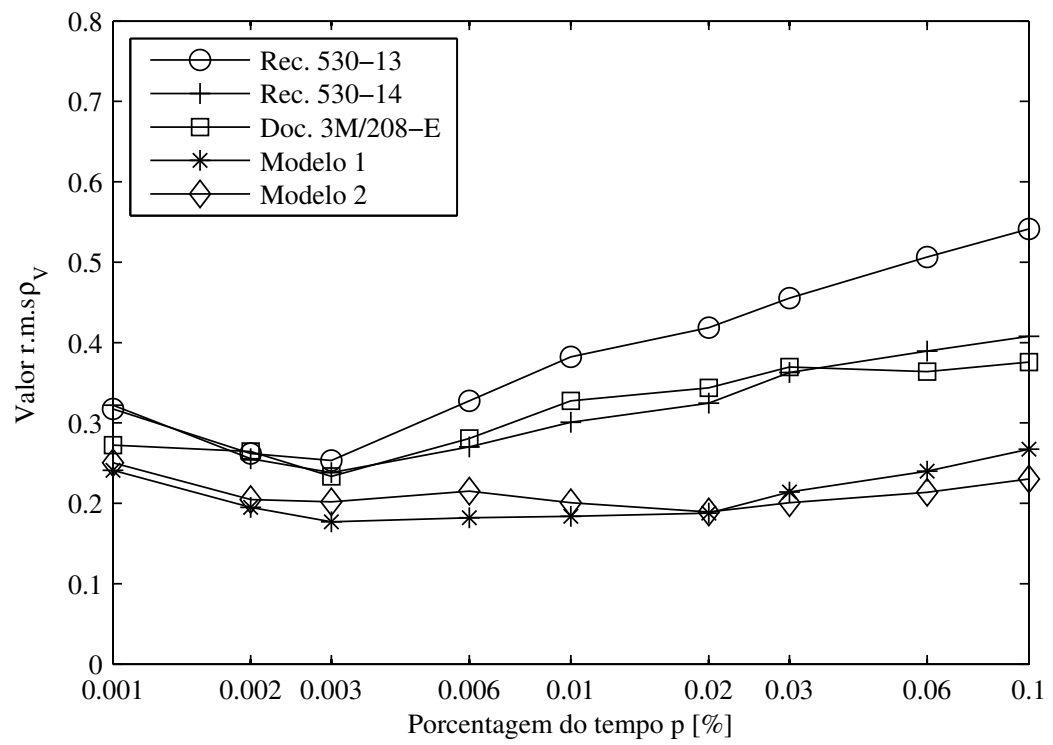

Figura 34 - Comparação valor r.m.s. da variável de teste ITU-R P.311-13.

Os testes demonstram que os modelos das recomendações ITU-R P.530-13, ITU-R P.530-14 e Doc. 3M/208-E na média subestimam as perdas por chuva, enquanto os Modelos 1 e 2 superestimam as perdas. Apesar de apresentar menor erro médio, o Modelo 2 apresenta maior desvio em relação a média se comparado ao Modelo 1. De maneira geral os modelos apresentam desempenho semelhante, sendo que os modelos desenvolvidos apresentam desempenho superior aos modelos atualmente recomendados.

Além disso, os modelos desenvolvidos utilizam o conceito da chuva efetiva equivalente para modelar variação espaço temporal da chuva. A influência da frequência na atenuação por chuvas esta representada através dos parâmetros $k \mathrm{e}$ $\alpha$, diferentemente da recomendação atual, que considera estes parâmetros no cálculo do fator de redução.

Por fim, os modelos apresentam equações mais simples, e utilizam a distribuição cumulativa da taxa de precipitação completa, evitando o emprego de extrapolação para o cálculo da atenuação para porcentagens de tempo diferentes de $0,01 \%$. 


\section{2.}

\section{Modelo Log-normal}

Os modelos semi-empíricos, como os apresentados na seção 4.1, se baseiam na determinação da distribuição cumulativa da atenuação a partir dos valores medidos da distribuição da taxa de precipitação pontual. Embora sejam os mais usados na prática, por permitir uma maior precisão em relação a dados medidos experimentalmente, não têm, a rigor, consistência do ponto de vista estatístico. As funções ajustadas empiricamente aos valores medidos de atenuação representam apenas uma aproximação da distribuição cumulativa complementar na faixa de valores considerados, e não possuem necessariamente as propriedades estatísticas de uma função distribuição. Entre elas, encontram-se os valores zero e um quando o argumento tende a menos e mais infinito, respectivamente. Adicionalmente devem ser necessariamente não decrescentes para quaisquer valores do argumento.

Nesta seção, é desenvolvido um modelo estatisticamente consistente para a previsão da distribuição da atenuação a partir da representação da distribuição cumulativa complementar da taxa de precipitação. Foi suposto um relacionamento com significado físico entre taxa de precipitação e atenuação, e realizado o cálculo analítico da distribuição cumulativa complementar da atenuação. A partir destas representações é possível determinar relações estatisticamente consistentes entre o valor mediano e a variância de cada distribuição, e obter os parâmetros da distribuição de atenuação a partir dos parâmetros das distribuições de taxa de precipitação ajustadas aos dados medidos.

\subsection{1.}

\section{Distribuição da Taxa de Precipitação}

A distribuição da taxa de precipitação medida é, em geral, bem modelada por uma distribuição cumulativa log-normal. Esta será a modelagem utilizada no trabalho.

A função densidade de probabilidade log-normal (fdp log-normal) é dada por:

$$
f_{R}(r)=\frac{1}{r \sigma_{R} \sqrt{2 \pi}} \exp \left(-\left[\ln \left(r / m_{R}\right)\right]^{2} /\left(2 \sigma_{R}^{2}\right)\right)
$$


onde $r$ é um valor da variável aleatória taxa de precipitação $R, m_{R} \mathrm{O}$ valor mediano e $\sigma_{R}$ o desvio padrão da distribuição de $\ln (R)$.

A função distribuição cumulativa log-normal (FDP log-normal) correspondente é dada por:

$$
P(R \leq r)=F_{R}(r)=\frac{1}{2}\left\{1+\operatorname{erf}\left[\ln \left(r / m_{R}\right) /\left(\sigma_{R} \sqrt{2}\right)\right]\right\}
$$

e a função distribuição cumulativa complementar log-normal (FDP lognormal) por

$$
P(R>r)=1-F_{R}(r)=\frac{1}{2}\left\{1-\operatorname{erf}\left[\ln \left(r / m_{R}\right) /\left(\sigma_{R} \sqrt{2}\right)\right]\right\}
$$

\subsection{2. \\ Distribuição da Atenuação por Chuvas}

Será assumido que a atenuação devida à chuva em um enlace é uma variável aleatória (v.a.) função da v.a. taxa de precipitação. Devido aos bons resultados observados na modelagem semi-empírica, supõe-se que a função $g(R)$ que relaciona as duas variáveis é da forma

$$
A=g(R)=k \cdot R^{\alpha} \cdot d_{\text {eff }}
$$

onde $A(d B)$ é a atenuação devida à chuva, $R(\mathrm{~mm} / \mathrm{h})$ a taxa de precipitação pontual e que o comprimento efetivo do enlace $\left(d_{e f f}\right)$ pode ser expresso por

$$
d_{\text {eff }}=b \cdot R^{\chi} \cdot d
$$

de tal forma que,

$$
A=g(R)=k \cdot b \cdot R^{\alpha+\chi} \cdot d
$$

Se $R$ é uma v.a. e $A=g(R)$ então 


$$
f_{A}(a)=\frac{f_{R}\left[g^{-1}(a)\right]}{g\left[g^{-1}(a)\right]}
$$

onde $g^{\curlyvee}(R)=\left.\frac{d g(R)}{d r}\right|_{R=r}$.

Desenvolvendo,

$$
\begin{gathered}
g^{\prime}(r)=(\alpha+\chi) k b d \cdot r^{(\alpha+\chi-1)}=(\alpha+\chi) a\left(\frac{k b d}{a}\right)^{1 /(\alpha+\chi)} \\
f_{A}(a)=\frac{1}{(\alpha+\chi) a\left(\frac{k b d}{a}\right)^{1 /(\alpha+\chi)}} \frac{1}{\left(\frac{a}{k b d}\right)^{1 /(\alpha+\chi)} \sigma_{R} \sqrt{2 \pi}} \exp \left\{-\ln \left[\frac{\left(\frac{a}{k d b}\right)^{1 /(\alpha+\chi)}}{m_{R}}\right]^{2} /\left(2 \sigma_{R}^{2}\right)\right\} \\
f_{A}(a)=\frac{(4.23)}{a(\alpha+\chi) \sigma_{R} \sqrt{2 \pi}} \exp \left\{-\ln \left[\frac{a}{k d b m_{R}^{(\alpha+\chi)}}\right]^{2} /\left[2(\alpha+\chi)^{2} \sigma_{R}^{2}\right]\right\}
\end{gathered}
$$

De (4.24) é possível concluir que $A$ tem fdp log-normal com valor mediano e desvio padrão dados, respectivamente, por

$$
\begin{gathered}
m_{A}=k \cdot d \cdot b \cdot m_{R}^{(\alpha+\chi)} \\
\sigma_{A}=(\alpha+\chi) \cdot \sigma_{R}
\end{gathered}
$$

Nas expressões acima $k, \alpha$ e $d$ são conhecidos para cada enlace, enquanto que $b$ e $\chi$ são parâmetros a determinar em função das características do enlace e parâmetros meteorológicos da região. 


\subsection{3.}

\section{Ajuste dos parâmetros do Modelo Log-normal}

Para obter expressões empíricas para $b$ e $\chi$ valores de $m_{R}, \sigma_{R}, m_{A}$ e $\sigma_{A}$ foram determinados pelo ajuste de distribuições log-normais a um subconjunto das distribuições medidas disponíveis no banco de dados de taxa de precipitação e atenuação por chuvas do ITU-R. Este subconjunto corresponde a 45 estatísticas, para as quais as distribuições medidas contêm um número de pontos suficiente, pelo menos três pontos, para permitir o ajuste tanto da distribuição de taxa de precipitação como da distribuição de atenuação. A Tabela 12 mostra as características dos enlaces cujos dados foram utilizados e os resultados obtidos.

A partir destes resultados, os valores de $b$ e $\chi$ foram obtidos utilizando as expressões (4.25) e (4.26). A seguir foram identificadas as características dos enlaces e variáveis meteorológicas com os quais $b$ e $\chi$ apresentam maior dependência e ajustadas expressões empíricas para sua determinação.

No caso do parâmetro $b$ obteve-se uma dependência com o comprimento do enlace $d(\mathrm{~km})$ e o parâmetro meteorológico $P_{0}$, que corresponde à probabilidade percentual de ocorrência de chuva na região do enlace em um ano. Este parâmetro é obtido dos mapas de parâmetros meteorológicos associados à Recomendação ITU-R P.837-6, derivados do banco de dados ERA-40. 
Tabela 12 - Características dos enlaces e parâmetros das distribuições log-normais

\begin{tabular}{|c|c|c|c|c|c|c|c|c|c|c|}
\hline ESTAÇÃO & d & $\mathbf{f}$ & $\mathbf{P}_{0}$ & $\beta$ & $\mathbf{m}_{\mathrm{A}}$ & $\sigma_{\mathrm{A}}$ & $m_{R}$ & $\sigma_{R}$ & $\chi$ & b \\
\hline STOCKHOLM & 15,00 & 36,00 & 3,069 & 0,171 & 1,862 & 0,852 & 0,063 & 1,347 & $-0,264$ & 2,000 \\
\hline DARMSTADT & 20,00 & 15,00 & 4,490 & 0,200 & 0,248 & 1,012 & 0,187 & 1,236 & $-0,305$ & 1,092 \\
\hline PARIS & 15,40 & 13,00 & 4,219 & 0,186 & 0,103 & 1,104 & 0,295 & 1,366 & $-0,351$ & 0,589 \\
\hline DIJON & 23,00 & 19,30 & 6,208 & 0,159 & 1,255 & 1,087 & 0,774 & 1,236 & $-0,186$ & 0,813 \\
\hline FUCINO & 9,50 & 17,80 & 3,889 & 0,352 & 0,731 & 0,871 & 0,524 & 1,319 & $-0,344$ & 1,566 \\
\hline TURIN & 22,50 & 11,40 & 5,449 & 0,228 & 0,481 & 1,138 & 0,668 & 1,346 & $-0,299$ & 1,496 \\
\hline PALMETTO & 5,10 & 17,70 & 5,548 & 0,373 & 0,231 & 1,257 & 1,968 & 1,022 & 0,145 & 0,291 \\
\hline HOLMDEL & 6,40 & 18,50 & 6,278 & 0,141 & 0,203 & 1,304 & 1,184 & 1,256 & 0,041 & 0,325 \\
\hline TOKYO & 1,30 & 34,50 & 10,743 & 0,191 & 0,165 & 1,118 & 0,999 & 1,357 & $-0,071$ & 0,397 \\
\hline TOKYO & 1,30 & 81,80 & 10,743 & 0,191 & 1,796 & 0,683 & 0,999 & 1,357 & $-0,200$ & 1,161 \\
\hline RIO DE JANEIRO & 8,60 & 10,90 & 6,736 & 0,302 & 0,584 & 0,888 & 2,151 & 1,031 & $-0,357$ & 2,049 \\
\hline CHILBOLTON & 0,50 & 57,00 & 4,344 & 0,214 & 0,872 & 0,754 & 0,737 & 1,152 & $-0,104$ & 2,685 \\
\hline CHILBOLTON & 0,50 & 57,00 & 4,344 & 0,214 & 0,547 & 0,727 & 0,563 & 1,075 & $-0,082$ & 2,036 \\
\hline CHILBOLTON & 0,50 & 57,00 & 4,344 & 0,214 & 0,454 & 0,808 & 0,508 & 1,133 & $-0,046$ & 1,855 \\
\hline CHILBOLTON & 0,50 & 97,00 & 4,344 & 0,214 & 1,186 & 0,680 & 0,732 & 1,157 & $-0,092$ & 2,121 \\
\hline CHILBOLTON & 0,50 & 97,00 & 4,344 & 0,214 & 1,154 & 0,569 & 0,468 & 1,126 & $-0,174$ & 2,521 \\
\hline CHILBOLTON & 0,50 & 97,00 & 4,344 & 0,214 & 1,108 & 0,620 & 0,514 & 1,120 & $-0,126$ & 2,383 \\
\hline CHILBOLTON & 0,50 & 137,00 & 4,344 & 0,214 & 1,477 & 0,530 & 0,521 & 1,125 & $-0,181$ & 2,581 \\
\hline STRAHOV & 34,00 & 13,19 & 3,615 & 0,233 & 0,611 & 1,208 & 0,549 & 1,200 & $-0,148$ & 1,037 \\
\hline STRAHOV & 34,00 & 13,10 & 3,615 & 0,233 & 0,406 & 1,160 & 0,549 & 1,200 & $-0,121$ & 0,636 \\
\hline PIASECZNO & 15,40 & 11,50 & 2,919 & 0,267 & 1,567 & 0,913 & 0,322 & 1,295 & $-0,492$ & 10,931 \\
\hline DUBNA 3 & 12,65 & 19,30 & 2,746 & 0,261 & 0,880 & 0,983 & 0,322 & 1,295 & $-0,231$ & 1,844 \\
\hline DUBNA 3 & 12,65 & 11,50 & 2,746 & 0,261 & 0,690 & 0,731 & 0,322 & 1,295 & $-0,576$ & 4,975 \\
\hline BRADESCO II & 12,79 & 14,55 & 6,744 & 0,396 & 1,848 & 0,778 & 2,537 & 0,740 & $-0,002$ & 1,178 \\
\hline BRADESCO II & 12,79 & 14,55 & 6,744 & 0,396 & 1,998 & 0,665 & 2,412 & 0,804 & $-0,225$ & 1,635 \\
\hline CENESP 15 & 12,78 & 14,55 & 6,744 & 0,396 & 2,061 & 0,635 & 2,537 & 0,740 & $-0,272$ & 1,752 \\
\hline CENESP 15 & 12,78 & 14,55 & 6,744 & 0,396 & 2,228 & 0,598 & 2,412 & 0,804 & $-0,386$ & 2,187 \\
\hline CENESP 18 & 12,78 & 18,61 & 6,744 & 0,396 & 2,141 & 0,718 & 2,537 & 0,740 & $-0,026$ & 0,820 \\
\hline SCANIA & 18,38 & 14,50 & 6,744 & 0,396 & 2,511 & 0,654 & 2,412 & 0,804 & $-0,240$ & 1,462 \\
\hline BARUERI & 21,69 & 14,53 & 6,744 & 0,396 & 2,058 & 0,738 & 2,537 & 0,740 & $-0,056$ & 0,817 \\
\hline SHELL & 7,48 & 18,59 & 6,744 & 0,396 & 2,200 & 0,727 & 2,412 & 0,804 & $-0,092$ & 1,606 \\
\hline $\begin{array}{l}\text { RIO DE JAN. } \\
\text { SUMARE }\end{array}$ & 6,55 & 23,00 & 6,690 & 0,297 & 1,948 & 0,761 & 1,892 & 0,953 & $-0,165$ & 1,393 \\
\hline FUIITSU & 1,40 & 32,60 & 6,509 & 0,596 & 2,448 & 0,517 & 3,558 & 0,570 & $-0,019$ & 1,914 \\
\hline YOTSUYA & 2,30 & 33,40 & 9,506 & 0,129 & 1,386 & 0,912 & 0,923 & 1,285 & $-0,178$ & 2,194 \\
\hline YOTSUYA & 2,30 & 33,40 & 9,506 & 0,129 & 1,523 & 0,929 & 1,246 & 1,166 & $-0,091$ & 1,910 \\
\hline YOTSUYA & 2,30 & 33,40 & 9,506 & 0,129 & 1,816 & 0,718 & 1,603 & 0,996 & $-0,167$ & 1,931 \\
\hline AKASAKA & 2,10 & 32,60 & 9,506 & 0,129 & 2,238 & 0,497 & 0,923 & 1,285 & $-0,507$ & 3,987 \\
\hline AKASAKA & 2,10 & 32,60 & 9,506 & 0,129 & 0,928 & 1,197 & 1,246 & 1,166 & 0,133 & 1,278 \\
\hline AKASAKA & 2,10 & 32,60 & 9,506 & 0,129 & 1,375 & 0,892 & 1,603 & 0,996 & 0,002 & 1,556 \\
\hline KOENJI & 1,20 & 23,20 & 9,424 & 0,127 & 0,519 & 0,949 & 1,049 & 1,348 & $-0,257$ & 3,199 \\
\hline KOENJI & 1,20 & 23,20 & 9,424 & 0,127 & 1,011 & 0,728 & 1,754 & 1,086 & $-0,291$ & 4,422 \\
\hline KARAGASAKI & 9,10 & 15,25 & 9,424 & 0,127 & 1,784 & 0,651 & 1,540 & 1,083 & $-0,438$ & 2,891 \\
\hline KARAGASAKI & 9,10 & 15,25 & 9,424 & 0,127 & 1,395 & 0,792 & 1,754 & 1,086 & $-0,310$ & 1,945 \\
\hline KARAGASAKI & 9,10 & 15,25 & 9,424 & 0,127 & 1,396 & 0,838 & 1,388 & 1,093 & $-0,273$ & 2,281 \\
\hline SHIYAKUSYO & 6,37 & 18,58 & 10,207 & 0,155 & 1,966 & 0,459 & 2,430 & 0,720 & $-0,359$ & 2,124 \\
\hline
\end{tabular}

O ajuste obtido para $b$ minimizando o erro médio quadrático é dado por: 
4 Desenvolvimento de Modelos para Previsão da Atenuação por Chuvas para Radioenlaces Terrestres

$$
b=1,30 \cdot d^{0,54-0,44 \ln (d)} P_{0}^{0,02}
$$

A Figura 35 e a Figura 36 mostram uma comparação entre os valores calculados e estimados, e um histograma dos resíduos. O artifício de utilizar o produto dos parâmetros $b$ e $d$ permite melhor desempenho do método de ajuste empregado, relacionado à ordem de grandeza dos parâmetros.

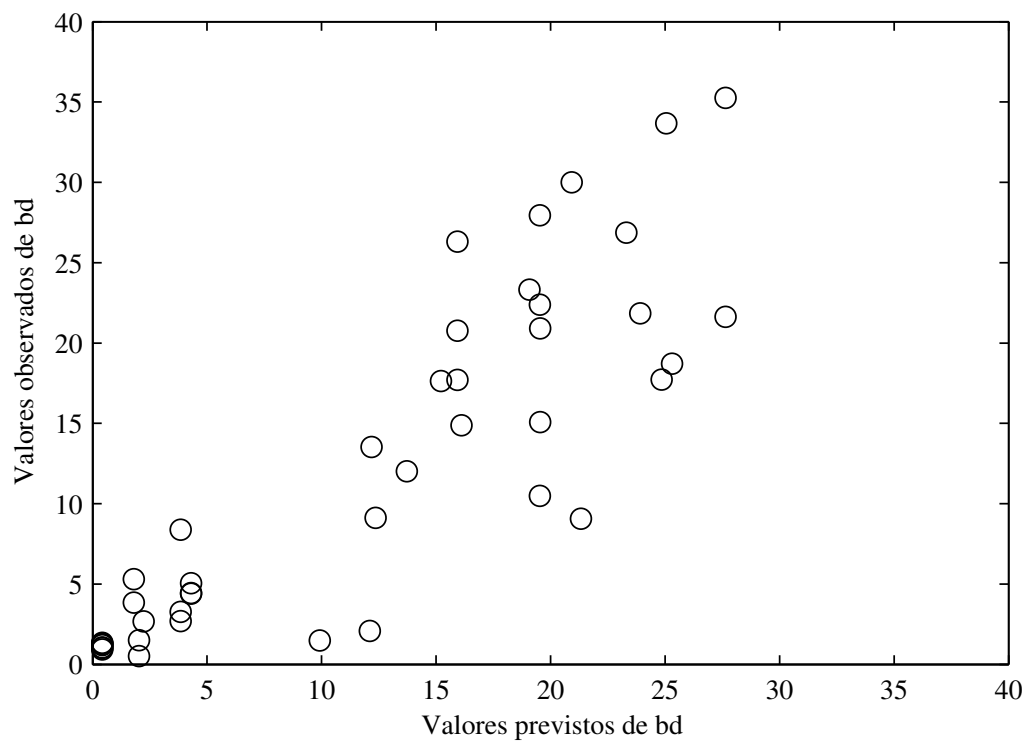

Figura 35 - Comparação entre valores calculados e previstos de $b d . R^{2}=$ 0,7230 .

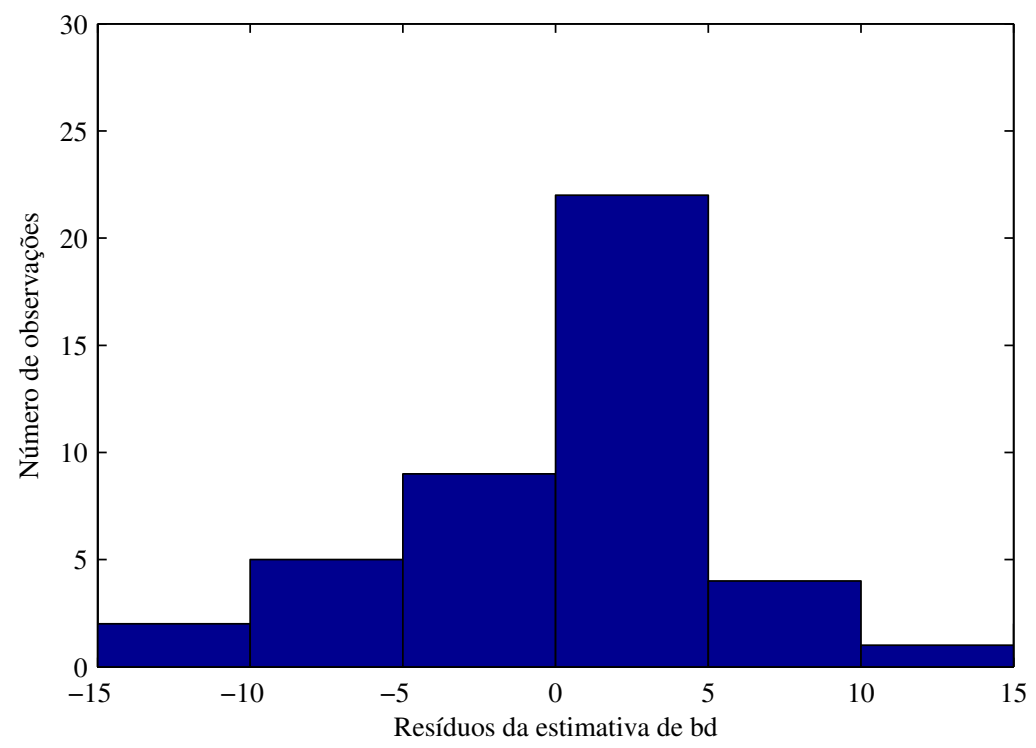

Figura 36 - Histograma dos resíduos da estimativa de bd. 
Já para o parâmetro $\chi$, obteve-se uma dependência com o comprimento do enlace $d(\mathrm{~km})$, a frequência de operação $f(\mathrm{GHz})$ e o parâmetro meteorológico $\beta$, que corresponde à razão entre a precipitação acumulada convectiva e a precipitação acumulada total (estratiforme mais convectiva) na região do enlace, também obtido dos mapas da Recomendação ITU-R P.837-6, derivados do ERA40. O ajuste obtido para $\chi$, que minimiza o erro médio quadrático é dado por:

$$
\chi=-0,41 \exp (-0,014 \cdot d)(1-\beta)^{-13,09+12,09 \log _{10}(f)}
$$

As figuras 35 e 36 mostram uma comparação entre os valores calculados e estimados e um histograma dos resíduos.

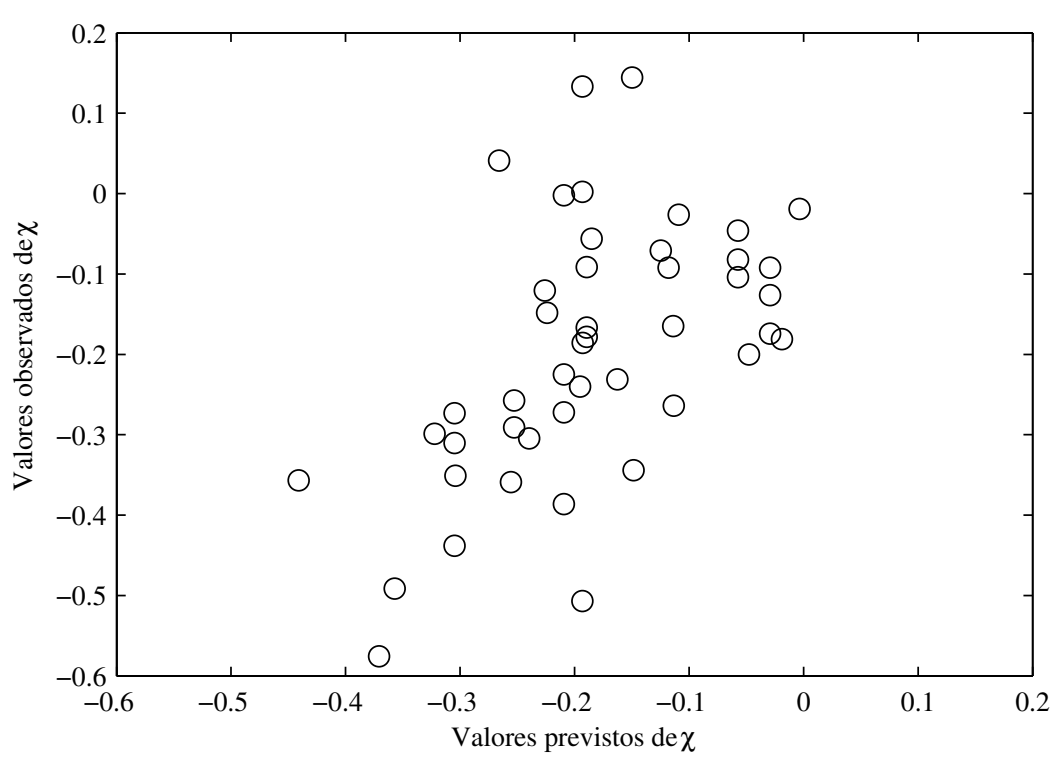

Figura 37 - Comparação entre valores calculados e estimados de $\chi \cdot \mathrm{R}^{2}=$ 0,3940 . 


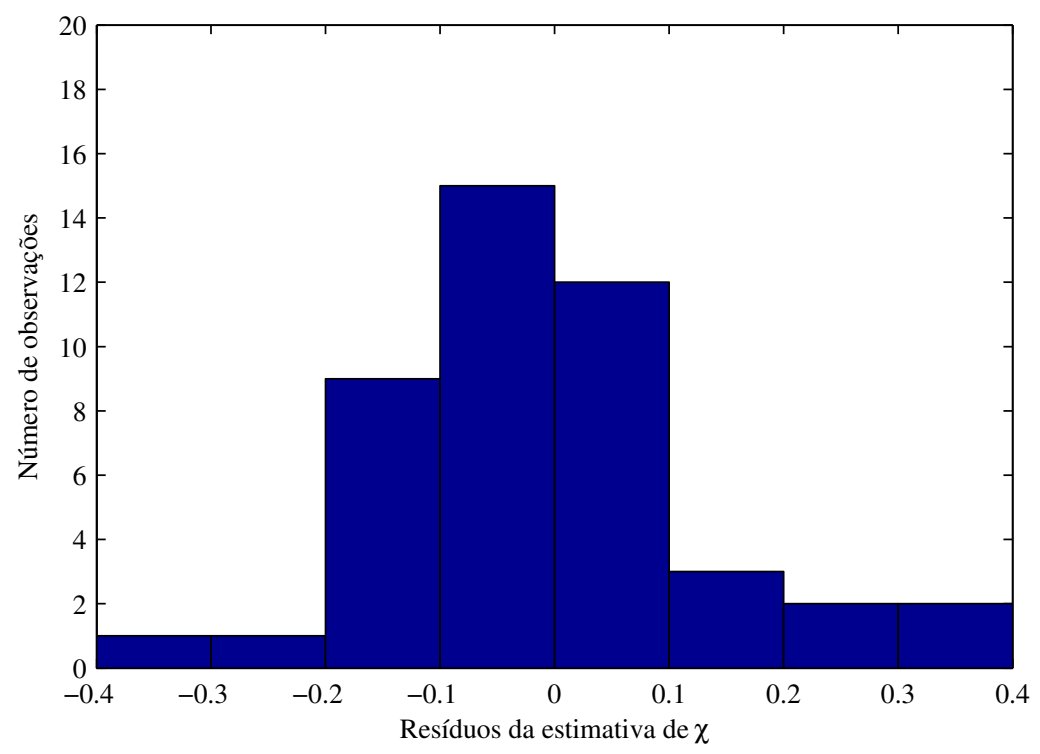

Figura 38 - Histograma dos resíduos da estimativa de $\chi$.

De (4.24), tem-se que a distribuição cumulativa complementar da atenuação por chuvas será dada por:

$$
P(A>a)=\int_{a}^{\infty} f_{A}(a) d A=\frac{1}{2}\left\{1-\operatorname{erf}\left[\ln \left(a /\left(k d b m_{R}^{\alpha+\chi}\right)\right) /\left((\alpha+\chi) \sigma_{R} \sqrt{2}\right)\right]\right\}(
$$

com $b$ e $\chi$ dados por (4.27) e (4.28), respectivamente.

\subsection{4.}

\section{Comparação Modelo Log-normal}

Assim como para os modelos semi-empíricos, foram calculados a média $\left(\mu_{v}\right)$, desvio padrão $\left(\sigma_{v}\right)$ e valor r.m.s. $\left(\rho_{v}\right)$ da variável de teste $V_{i}$ conforme Recomendação ITU-R 311-13 [18]. Os resultados são apresentados nas tabelas e figuras a seguir. Pode-se observar que a primeira aproximação obtida para o modelo Log-normal apresenta desempenho comparável ao modelo da Recomendação ITU-R P.530-13. Melhores ajustes deverão ser obtidos para os valores de $b$ e $\chi$, e consequentemente para o modelo, a partir da avaliação de outros parâmetros meteorológicos. 
4 Desenvolvimento de Modelos para Previsão da Atenuação por Chuvas para Radioenlaces Terrestres

Tabela 13 - Média da variável ITU-R P.311-13 comparação modelo Log-normal para atenuação por chuvas em enlaces terrestres.

\begin{tabular}{|c|c|c|c|c|}
\hline $\mathbf{p}$ & Ap_530-13 & Ap_530-14 & Ap_3M/208-E & Ap_Log-normal \\
\hline 0,001 & $-0,1498$ & 0,0034 & $-0,0298$ & $-0,4503$ \\
\hline 0,002 & $-0,2431$ & $-0,0130$ & $-0,0413$ & $-0,4104$ \\
\hline 0,003 & $-0,2886$ & $-0,0671$ & $-0,0800$ & $-0,3100$ \\
\hline 0,006 & $-0,3328$ & $-0,1054$ & $-0,0894$ & $-0,1781$ \\
\hline 0,01 & $-0,3513$ & $-0,1392$ & $-0,1313$ & $-0,1506$ \\
\hline 0,02 & $-0,3832$ & $-0,1716$ & $-0,1538$ & $-0,0586$ \\
\hline 0,03 & $-0,4031$ & $-0,1992$ & $-0,1694$ & $-0,0144$ \\
\hline 0,06 & $-0,4527$ & $-0,2429$ & $-0,2004$ & 0,1111 \\
\hline 0,1 & $-0,4893$ & $-0,2796$ & $-0,2336$ & 0,2121 \\
\hline
\end{tabular}

Tabela 14 - Desvio padrão da variável ITU-R P.311-13 comparação modelo Log-normal para atenuação por chuvas em enlaces terrestres.

\begin{tabular}{|c|c|c|c|c|}
\hline $\mathbf{p}$ & Ap_530-13 & Ap_530-14 & Ap_3M/208-E & Ap_Log-normal \\
\hline 0,001 & 0,3775 & 0,2623 & 0,2198 & 0,3004 \\
\hline 0,002 & 0,3593 & 0,2119 & 0,2159 & 0,4783 \\
\hline 0,003 & 0,3471 & 0,1869 & 0,1897 & 0,4855 \\
\hline 0,006 & 0,3441 & 0,1997 & 0,2276 & 0,4835 \\
\hline 0,01 & 0,3547 & 0,2349 & 0,2596 & 0,4534 \\
\hline 0,02 & 0,3682 & 0,2464 & 0,2827 & 0,4638 \\
\hline 0,03 & 0,3676 & 0,2559 & 0,2894 & 0,4595 \\
\hline 0,06 & 0,3903 & 0,2813 & 0,2947 & 0,4427 \\
\hline 0,1 & 0,3988 & 0,2888 & 0,3014 & 0,4211 \\
\hline
\end{tabular}

Tabela 15 - Valor RMS da variável ITU-R P.311-13 comparação modelo Log-normal para atenuação por chuvas em enlaces terrestres.

\begin{tabular}{|c|c|c|c|c|}
\hline $\mathbf{p}$ & Ap_530-13 & Ap_530-14 & Ap_3M/208-E & Ap_Log-normal \\
\hline 0,001 & 0,4061 & 0,2623 & 0,2218 & 0,5413 \\
\hline 0,002 & 0,4338 & 0,2123 & 0,2198 & 0,6302 \\
\hline 0,003 & 0,4514 & 0,1986 & 0,2059 & 0,5760 \\
\hline 0,006 & 0,4788 & 0,2259 & 0,2445 & 0,5153 \\
\hline 0,01 & 0,4992 & 0,2730 & 0,2909 & 0,4777 \\
\hline 0,02 & 0,5314 & 0,3003 & 0,3219 & 0,4674 \\
\hline 0,03 & 0,5455 & 0,3243 & 0,3353 & 0,4598 \\
\hline 0,06 & 0,5978 & 0,3717 & 0,3564 & 0,4565 \\
\hline 0,1 & 0,6312 & 0,4020 & 0,3813 & 0,4714 \\
\hline
\end{tabular}




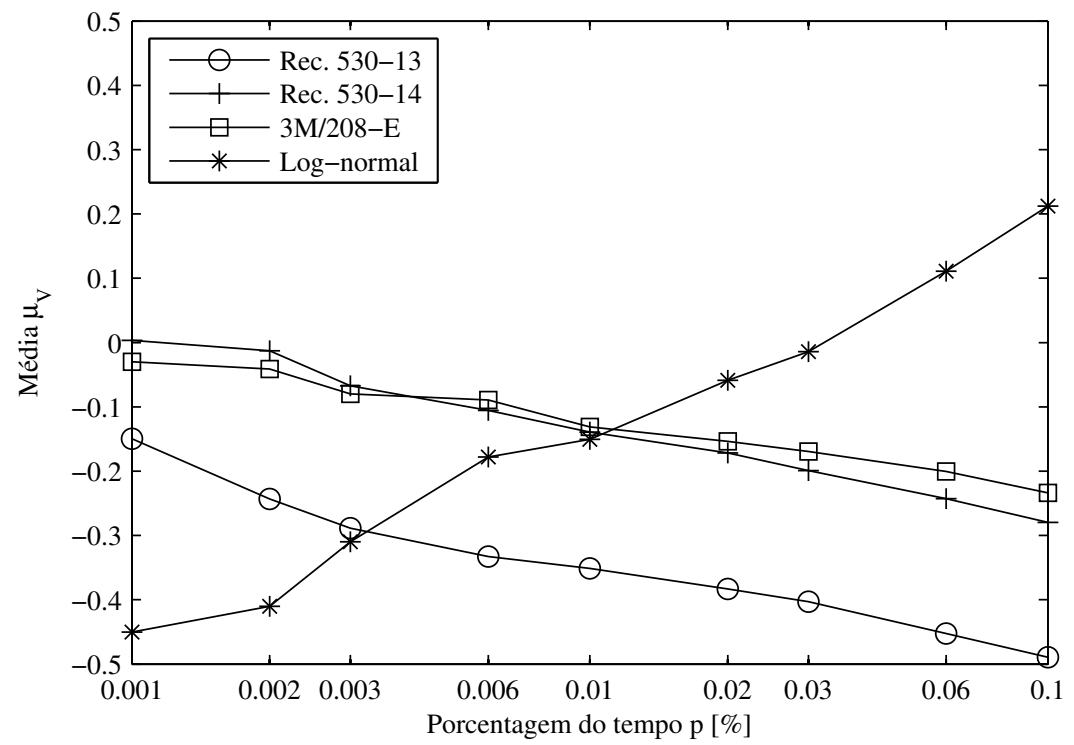

Figura 39 - Valor médio da variável de teste ITU-R P.311-13 comparação Modelo Lognormal.

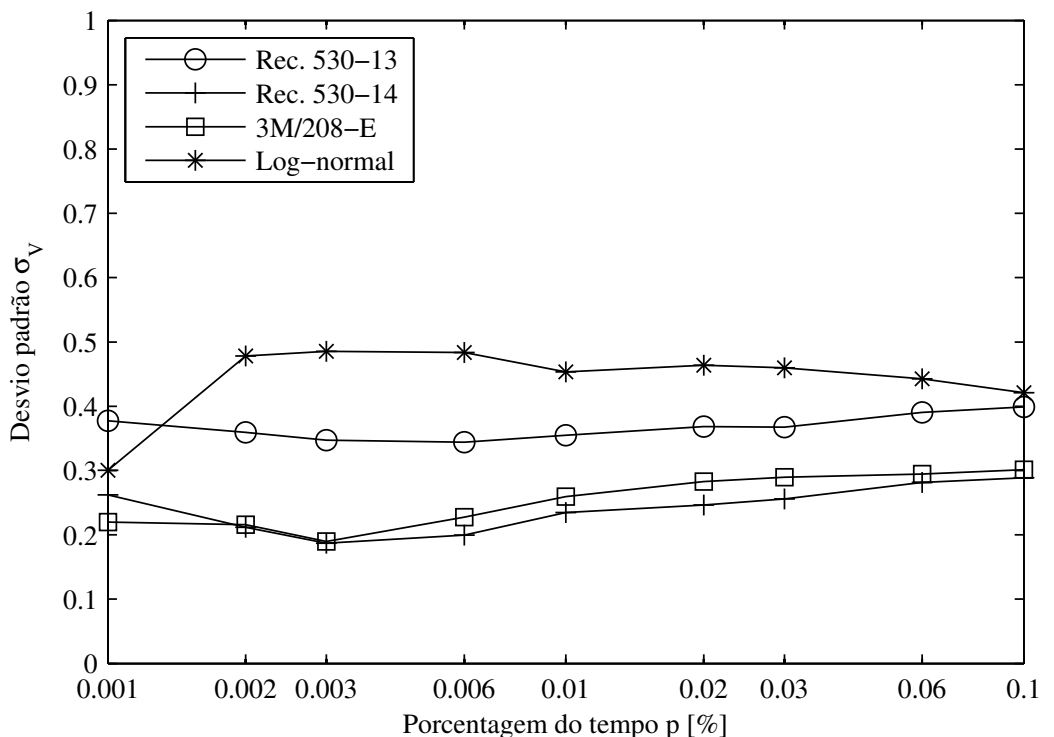

Figura 40 - Desvio padrão da variável de teste ITU-R P.311-13 comparação Modelo Lognormal. 


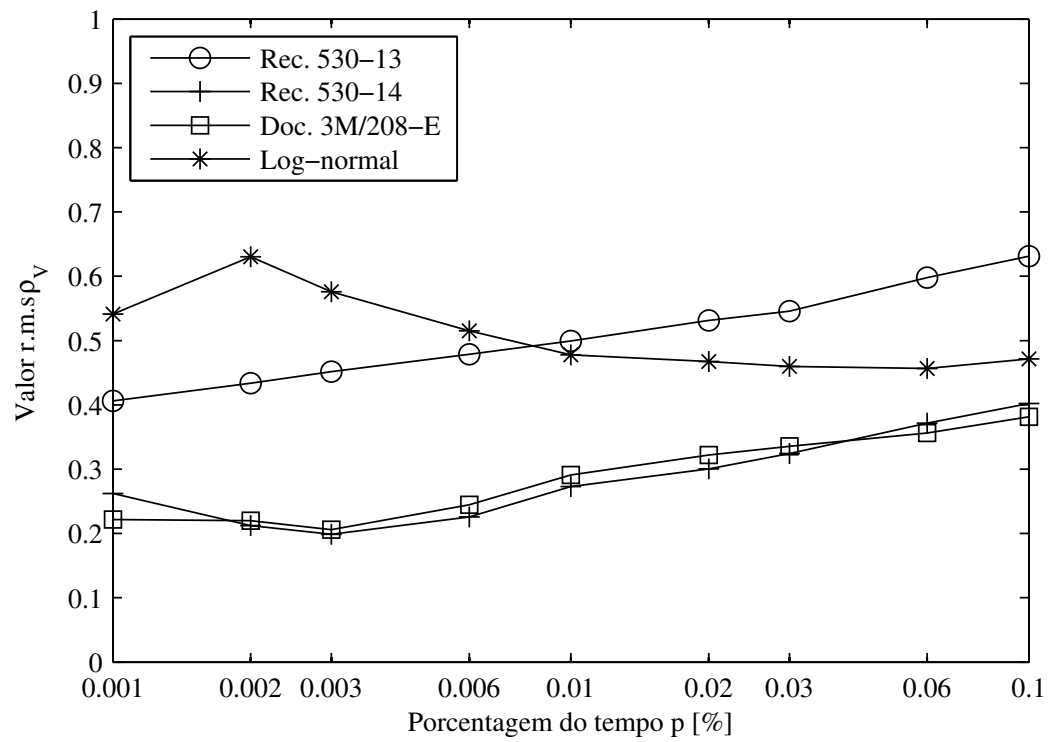

Figura 41 - Valor r.m.s. da variável de teste ITU-R P.311-13 comparação Modelo Log-normal. 


\section{5 \\ Conclusões}

O trabalho apresentou uma descrição das recomendações do UIT-R que permitem estimar a atenuação por chuvas em enlaces terrestres e as últimas modificações dos modelos. A proposta de alteração do modelo submetida pelo Brasil em 2007 foi utilizada para comparação de desempenho dos modelos desenvolvidos.

O banco de dados DBSG3 do UIT-R de atenuação por chuvas, com distribuições cumulativas de atenuação e taxa de precipitação foi empregado para obter modelos semi-empíricos de aplicação global. Dados de 36 estatísticas com informações de latitude e longitude das estações transmissora e receptora foram selecionados, e os azimutes dos enlaces calculados.

Rotinas para o processamento de arquivos de parâmetros meteorológicos globais foram desenvolvidas e aperfeiçoadas. Os arquivos em grade binária foram obtidos diretamente do servidor do banco de dados da ECMWF com resolução de $1,125^{\circ} \times 1,125^{\circ}$, mesma resolução dos dados da Recomendação ITU-R P 837-6.

Dois modelos semi-empíricos de atenuação por chuvas para enlaces terrestres foram desenvolvidos utilizando parâmetros meteorológicos globais e dados experimentais do banco de dados do UIT-R. A direção do vento é um parâmetro promissor para a modelagem da atenuação por chuvas, apesar de apresentar grande variabilidade para os intervalos de registro elevados disponíveis no banco de dados da ECMWF.

Os testes demonstram que os modelos das recomendações ITU-R P.530-13, ITU-R P.530-14 e Doc. 3M/208-E na média subestimam as atenuações por chuva, enquanto os Modelos 1 e 2 superestimam as atenuações. Apesar de apresentar menor erro médio, o Modelo 2 apresenta maior desvio em relação à média se comparado ao Modelo 1. De maneira geral os modelos apresentam desempenho semelhante, sendo que os modelos desenvolvidos apresentam desempenho superior aos modelos atualmente recomendados. 
Além disso, os modelos semi-empíricos desenvolvidos utilizam o conceito da chuva efetiva equivalente para modelar variação espaço temporal da chuva. A influência da frequência na atenuação por chuvas esta representada através dos parâmetros $k$ e $\alpha$, diferentemente da recomendação atual, que considera estes parâmetros no cálculo do fator de redução.

Por fim, os modelos semi-empíricos apresentam equações mais simples, e utilizam a distribuição cumulativa da taxa de precipitação completa, evitando o emprego de extrapolação para o cálculo da atenuação para porcentagens de tempo diferentes de $0,01 \%$.

Em outra linha de investigação, foi desenvolvido um terceiro modelo, estatisticamente consistente, para a previsão da distribuição da atenuação a partir da representação da distribuição cumulativa complementar da taxa de precipitação. Este modelo foi desenvolvido a partir da suposição de um relacionamento com significado físico entre a taxa de precipitação e atenuação, e do cálculo analítico da distribuição cumulativa complementar da atenuação. $\mathrm{O}$ desempenho do modelos foi comparável ao modelo da Recomendação ITU-R P.530-13, porém inferior ao modelo da Recomendação atual.

Como trabalho futuro sugere-se a realização de medições experimentais de atenuação por chuvas em conjunto com os registros dos parâmetros direção e velocidade do vento. Estas medições permitirão confirmar os indícios da influência da direção do vento observados no trabalho, além de permitir a obtenção de modelos mais precisos. Outra linha de investigação a ser explorada é a utilização de outras distribuições, além da Log-normal, e outros parâmetros meteorológicos para o desenvolvimento de modelos estatisticamente consistentes. 


\section{Referências Bibliográficas}

[1] Seybold, J.S. “Introduction to RF Propagation". John Wiley \& Sons, Inc. 2005.

[2] Mello, L. da S.; Pontes, M. S. "Unified Method for the Prediction of Rain Attenuation in Satellite and Terrestrial Links". Journal of Microwaves, Optoelectronics and Electromagnetic Applications, Vol. 11, $\mathrm{n}^{\circ} 1$. Junho, 2012.

[3] Recommendation ITU-R P.530-13. "Propagation data and prediction methods required for the design of terrestrial line of sigth systems". International Telecommunications Union, 2009.

[4] Recommendation ITU-R P.530-14. "Propagation data and prediction methods required for the design of terrestrial line of sigth systems". International Telecommunications Union, 2012.

[5] Mello, L. da S. ET AL. "Apostila do Curso de Sistemas de Comunicação via Rádio”. CETUC, 2013.

[6] Gibbins, C. J.; Walden, C. J. "A study into the derivation of improved rain attenuation regression coefficients". Radiocomunications Agency Report $\mathrm{N}^{\circ}$ AY4359, 2003.

[7] de Souza, R. M. 'Previsão da Atenuação por Chuvas Através de uma Modelagem Semi-Empírica Consistente para Enlaces Rádio Terrestre e Via Satélite". Tese de Doutorado na Pontifícia Universidade Católica do Rio de Janeiro (PUC-Rio), Agosto 2006. Rio de Janeiro, Brasil.

[8] Recommendation ITU-R P.838-3. "Specific attenuation model for rain for use in prediction methods". International Telecommunications Union, 2005.

[9] Recommendation ITU-R P. 837-6. “Characteristics of precipitation for propagation modelling”. International Telecommunications Union, 2005.

[10] Document ITU-R 3M/27-E. "Proposed Amendment to Recommendation ITU-R P.530-9 - Rain Attenuation Effective Path Length”, Australia. 2001.

[11] Document ITU-R 3M/28-E. "Proposed Modification to Recommendation ITU-R P.530-10 - Propagation data and prediction methods required for the design of terrestrial line of sight systems". United Kingdom, 2003.

[12] Document ITU-R 3M/107-E. "Proposed modification to Recommendation ITU-R P.530-10 - An Improved prediction method of rain attenuation for terrestrial line-of-sight path”. China (People's Replublic of), 2005.

[13] Document ITU-R 3M/208-E. "Proposed Modification to Recommendation ITU-R P.530-11 - Propagation data and prediction methods required for the design of terrestrial line of sight systems". Brazil, 2007. 
[14] Mello, L. da S.; Pontes, M. S.; de Souza, R. L. S.; Miranda, E. C. "Modeling of Effective Rainfall Rate Based on Attenuation Measurements in Converging Terrestrial Links". First European Conference on Antennas and Propagation (EuCAP), 2006.

[15] Mello, L. da S.; Almeida, M. P. C.; Andrades, F. J. A.; Pontes, M. S.; "Influence of Wind Direction on Rain Attenuation in Terrestrial Line-ofSight Links". International Microwave \& Optoelectronics Conference (IMOC), 2013.

[16] Siqueira, G. L. "Medida de Taxa de Precipitação e Atenuação por Chuva em Enlaces Terrestres de 15 e 23 GHz (EMBRATEL)". Relatório CETUC. 1993.

[17] Guide to GRIB. “A Guide to the Code form FM 92-IX Ext. GRIB”. World Meteorological Organization (WMO). Disponível em: http://www.wmo.int/pages/prog/www/WDM/Guides/Guide-binary-2.html.

[18] Recommendation ITU-R P.311-13. "Acquisition, presentation and analysis of data in studies of tropospheric propagation". International Telecommunications Union, 2009.

[19] UIT-R Study Group 3 Data Banks. “DBSG3”. Janeiro, 2012. Disponível eletronicamente em: http://www.itu.int/ITU-R/index.asp?category=studygroups\&rlink=sg3-dtbank-dbsg3\&lang=en.

[20] ECMWF. "Banco de dados ERA-40”. Janeiro, 2013. Disponível em: http://www.ecmwf.int/products/data/archive/descriptions/e4/.

[21] ECMWF. “Banco de dados ERA-Interim”. Janeiro, 2013. Disponível em: http://www.ecmwf.int/products/data/archive/descriptions/ei/.

[22] ITU-R SG 3. "Fascicle concerning the rainfall rate model given in Recommendation ITU-R P.837-5”. Fevereiro, 2013. Disponível em: https://www.itu.int/oth/R0A04000005/en.

[23] STATISTICA. Software STATISTICA. Janeiro, 2013. Disponível em: http://www.statsoft.com.br/. 